\title{
Um Modelo para Interoperabilidade entre Instituições Heterogêneas
}

\author{
Cláudia Josimar Abrão de Araújo
}

TESE APRESENTADA

$\mathrm{AO}$

Instituto DE MatemáticA E EstatísticA

DA

UNIVERSIDADE DE SÃO PAULO

PARA

OBTENÇÃO DO TÍTULO

$\mathrm{DE}$

DOUTOR EM CIÊNCIAS

Programa: Ciência da Computação

Orientador: Prof. Dr. Flávio Soares Corrêa da Silva

Durante o desenvolvimento deste trabalho o autor recebeu auxílio financeiro da CAPES

São Paulo, dezembro de 2012 


\section{Um Modelo para Interoperabilidade entre Instituições Heterogêneas}

Esta versão definitiva da tese contém as correções e alterações sugeridas pela Comissão Julgadora durante a defesa realizada por Cláudia Josimar Abrão de Araújo em 07/12/2012.

Comissão Julgadora:

- Prof. Dr. Flávio Soares Corrêa da Silva (orientador) - IME-USP

- Profa. Dra. Ana Cristina Vieira de Melo - IME-USP

- Profa. Dra. Débora Abdalla Santos - UFBA

- Profa. Dra. Lúcia Vilela Leite Filgueiras - EP-USP

- Profa. Dra. Ana Gonçalves Magalhães - MAC-USP 


\section{Agradecimentos}

Agradeço ao meu orientador Flávio Soares Corrêa da Silva por sua dedicação, amizade e paciência durante estes anos, sempre pronto para indicar caminhos, ampliar meu conhecimento e com quem também compartilho um ideal maior.

Agradeço à professora Ana Gonçalves Magalhães pela inestimável colaboração, pela disponibilidade, atenção e dedicação durante o desenvolvimento deste trabalho, dando uma nova dimensão à aplicação que aqui apresentamos. Mas acima dos resultados práticos para este trabalho, quero agradecer por me mostrar uma nova visão sobre arte, de forma clara, contagiante e bela.

Agradeço às professoras Ana Cristina Vieira de Melo, Débora Abdalla Santos, Lúcia Vilela Leite Filgueiras e Ana Gonçalves Magalhães pelos comentários e sugestões que auxiliaram a tornar a versão final desta tese mais precisa e didática e também pelas ideias para continuidade de minha pesquisa e trabalhos futuros relacionados.

Agradeço a todos os colegas com quem convivi durante este processo, especialmente a Mirtha Lina Fernández Venero e Diego Mira David que tanto colaboraram no desenvolvimento deste trabalho.

Agradeço ao IME e à USP pela oportunidade de realização do doutorado nesta instituição e à CAPES pelo apoio financeiro durante todo o processo.

Agradeço à minha filha Clara, por todo amor, carinho e paciência durante o desenvolvimento deste trabalho. Agradeço à minha filha Rafaela pela alegria e independência que tanto ajudaram neste processo. Agradeço ao meu marido Elidier, por estar sempre presente e pela enorme paciência e dedicação.

Agradeço aos meus pais pelo amor incondicional, compreensão, dedicação e ajuda constante em todos os momentos da minha vida. Agradeço à minha irmã Flávia, pelo amor e carinho e pela presença em todos os momentos. Agradeço ao meu irmão Ricardo pelo amor e pelas conversas. Agradeço à minha tia Darli, por proporcionar a oportunidade motivadora de todo este processo.

Agradeço àquele que sempre desperta em mim o desejo de ser uma pessoa melhor e que faz a realidade ser muito melhor que o sonho!

Ao meu Mestre, Dr. Celso Charuri, idealizador e criador da Pró-Vida, meu eterno agradecimento. 


\section{Resumo}

A interação entre instituições heterogêneas tem sido cada vez mais necessária para obter e disponibilizar informações e serviços para seus usuários internos e externos. Esta interação tem sido sustentada principalmente pelo uso das novas tecnologias da informação e comunicação.

A interoperabilidade entre instituições heterogêneas garante esta interação e proporciona vários benefícios como, por exemplo, utilizar toda a plataforma legada das instituições e ainda permitir a interação entre os sistemas. Entretanto, para que esta interoperabilidade seja possível é necessária a definição de conceitos comuns que padronizam e orientam as interações entre as instituições. Através destes conceitos comuns, as instituições podem trocar informações entre si e ainda manter sua independência e as particularidades em seus sistemas internos.

Em nosso trabalho, propomos um Modelo para Interoperabilidade entre Instituições Heterogêneas (MIIH). A especificação das regras de interação e, especificamente, os protocolos de interoperabilidade entre as instituições são escritas usando JamSession, que é uma plataforma para a coordenação de serviços de software heterogêneos e distribuídos. O modelo também define uma arquitetura baseada em Artefatos do Conhecimento Institucionais para lidar com as conexões com os sistemas das instituições. Estes Artefatos do Conhecimento Institucionais são baseados no conceito geral de Artefatos do Conhecimento, ou seja, "objetos que contêm e transmitem uma representação utilizável do conhecimento". Os Artefatos do Conhecimento Institucionais são padrões arquitetônicos recorrentes que são observados no projeto de mecanismos de interoperabilidade para conectar instituições heterogêneas e são usados como uma descrição de alto nível da arquitetura para um projeto de sistema. Eles funcionam como padrões arquiteturais pré-concebidos que norteiam e padronizam as interações e, portanto, a interoperabilidade organizacional e semântica entre as instituições. Os Artefatos do Conhecimento Institucionais são fundamentados sobre uma ontologia de conceitos relevantes para os serviços destas instituições, cujo nível de abstração pode variar, dependendo do nível de integração necessário para as instituições - quanto mais sofisticada a interação, mais detalhes devem ser representados explicitamente na ontologia. Os Artefatos do Conhecimento Institucionais implementados também se comunicam com a camada de interação com o usuário, baseada em mundos virtuais, para garantir a comunicação adequada com estes usuários.

Além do modelo conceitual proposto, apresentamos como resultado deste trabalho, um exemplo de uso do MIIH no contexto das instituições relacionadas à herança cultural (museus, galerias, colecionadores, etc.). Tendo reconhecido que este contexto dos museus é importante para toda a sociedade, verificamos mais profundamente o funcionamento dos museus e suas interações entre si e com seus usuários. Identificamos neste cenário a aplicação direta de nosso projeto, uma vez que a interoperabilidade entre os museus é fundamental para o desempenho de suas funções e a interoperabilidade com seus usuários define a razão de sua existência, conforme identificamos na definição de museu apresentada pela UNESCO. 
Este exemplo de uso é construído seguindo a metodologia proposta neste trabalho e serve para mostrar a utilização do nosso modelo no desenvolvimento de uma aplicação concreta para uso em instituições de arte e também por seus usuários.

Palavras-chave: Interoperabilidade, Inteligência Artificial, Mundos Virtuais, Representação da Informação, Artefatos do Conhecimento, Ontologia. 


\section{Abstract}

Heterogeneous institutions interactions have increasingly been required to obtain and provide information and services to their internal and external users. This interaction has been sustained mainly by the use of new information and communication technologies.

Interoperability between heterogeneous institutions ensures this interaction and provides various benefits such as, use the legacy platforms of the institutions and still allow the interaction between their systems. However, to make this interoperability possible it is necessary to define common concepts that standardize and guide the interactions between institutions. Through these common concepts, institutions can exchange information with each other and maintain the independence and particularities in their internal systems.

In our work, we propose a Model for Interoperability between Heterogeneous Institutions (MIHI). The specification of the interaction rules and specifically the protocols for interoperability between institutions are written using JamSession, which is a platform for the coordination of heterogeneous and distributed software services. The model also defines an architecture based on Institutional Knowledge Artifacts to handle the connections to the systems of the institutions. These Institutional Knowledge Artifacts are based on the general concept of Knowledge Artifacts, i.e., "objects that convey and hold usable representation of knowledge". The Institutional Knowledge Artifacts are recurring architectural patterns that are observed in the design of mechanisms for interoperability to connect heterogeneous institutions and are used as a high-level description of the architecture for a system design. They function as pre-designed architectural patterns that guide and standardize the interactions and therefore the organizational and semantic interoperability between institutions. The Institutional Knowledge Artifacts are based on ontology of concepts relevant to these services institutions whose level of abstraction can vary, depending on the level of integration necessary for institutions - the more sophisticated interaction, more details should be represented explicitly in the ontology. The Institutional Knowledge Artifacts implemented also communicate with the use interface layer, based on virtual worlds, to ensure proper communication with these users.

Besides the proposed conceptual model, we present as a result of this work, an example of the use of MIIH in the context of institutions related to cultural heritage (museums, galleries, collectors, etc.). Having recognized that the context of museums is important for the society, we studied more deeply the operation of museums and their interactions with each other and their users. We identified in this scenario the direct application of our project, since interoperability among museums is vital to the performance of its functions and interoperability with its users define the reason for its existence, as we verified in the definition of museum presented by UNESCO.

This example of use is constructed following the methodology proposed in this work and serves to show the use of our model in the development of a practical application for use in art institutions and also by its users. 
Keywords: Interoperability, Artificial Intelligence, Virtual Worlds, Information Representation, Knowledge Artifacts, Ontology. 


\section{Sumário}

$\begin{array}{ll}\text { Lista de Abreviaturas } & \text { ix }\end{array}$

Lista de Figuras

1 Introdução $\quad 1$

1.1 Motivação e Considerações Preliminares . . . . . . . . . . . . . . . . . . . 2

1.2 Formulação do problema . . . . . . . . . . . . . . . . . . . . 3

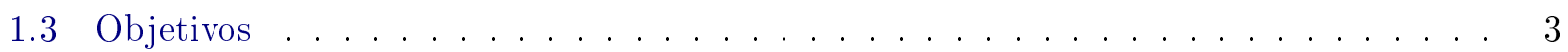

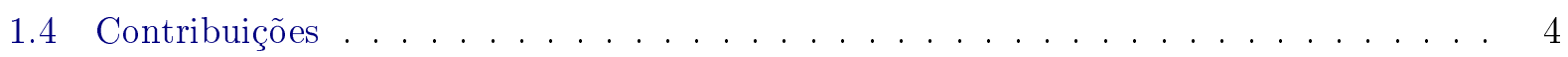

1.5 Organização do Trabalho . . . . . . . . . . . . . . . . . . . . . 4

2 Conceitos 5

2.1 Cross-Organizational Workflows ........................ 5

2.1 .1 Interoperabilidade . . . . . . . . . . . . . . . . . 6

2.2 Protocolos de Interação . . . . . . . . . . . . . . . . . . . 7

2.2.1 Algumas Ferramentas Relacionadas . . . . . . . . . . . . . . . . . . 7

2.2 .2 JamSession . . . . . . . . . . . . . . . . . . . . . . . 7

2.3 Conceitos Relacionados . . . . . . . . . . . . . . . . . . . . . . . . 12

2.3 .1 Artefatos do Conhecimento . . . . . . . . . . . . . . . . 12

2.3 .2 Ontologia para Interoperabilidade Semântica . . . . . . . . . . . . . . . 14

2.3 .3 Mundos Virtuais . . . . . . . . . . . . . . . . . . 16

2.4 Governo Eletrônico . . . . . . . . . . . . . . . . . . . . . . . 16

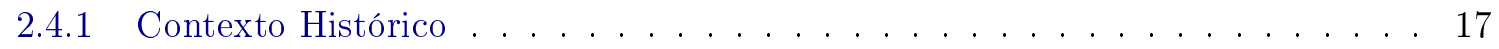

2.4 .2 Conceituação e Diretrizes Brasileiras . . . . . . . . . . . . . . . . . . 18

2.4 .3 Interoperabilidade no contexto do governo . . . . . . . . . . . . 18

2.4 .4 Iniciativas do Governo Brasileiro . . . . . . . . . . . . . . . . . . . . . . 19

2.4.5 Iniciativas de Governo Eletrônico no Mundo . . . . . . . . . . . . . . . . 21

2.4 .6 Interação com os Cidadãos . . . . . . . . . . . . . . . . . . . . . 23

2.5 Trabalhos Relacionados . . . . . . . . . . . . . . . . . . . 24

2.5.1 Instituições Eletrônicas e Instituições Virtuais . . . . . . . . . . . . . . . . 24

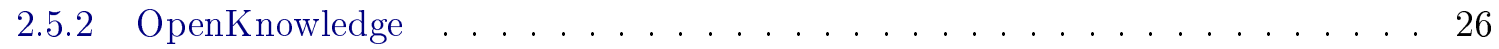

2.5.3 Lightweight Coordination Calculus (LCC) . . . . . . . . . . . . . . 27

2.5.4 Google Art Project . . . . . . . . . . . . . . . . . . . . 27

2.5 .5 Considerações . . . . . . . . . . . . . . . . . . . . . . . 27

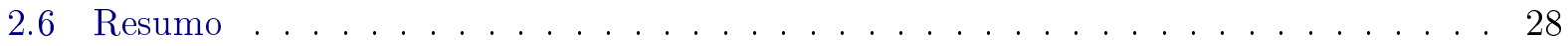


3 Modelo para Interoperabilidade entre Instituições Heterogêneas

3.1 Artefatos do Conhecimento Interoperáveis para o MIIH . . . . . . . . . . . . . . . 30

3.2 Métodos . . . . . . . . . . . . . . . . . . . . 35

3.3 Metodologia do $\mathrm{MIIH} \ldots \ldots \ldots \ldots \ldots$

3.4 Métricas de Avaliação . . . . . . . . . . . . . . . . . . . 38

3.5 Resumo . . . . . . . . . . . . . . . . . . . . 40

4 Exemplo de Uso $\quad 41$

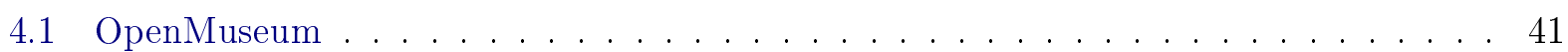

4.1 .1 Contexto do Sistema . . . . . . . . . . . . . . . . . . 41

4.1.2 O Museu de Arte Contemporânea da Universidade de São Paulo (MAC USP) 42

4.1 .3 OpenMuseum Lite . . . . . . . . . . . . . . . . . . . 43

4.1.4 Definição do Sistema OpenMuseum Lite . . . . . . . . . . . . . . . . . . 45

4.2 PoupaVirtual . . . . . . . . . . . . . . . . . . . . 53

4.2 .1 Definição do Sistema PoupaVirtual . . . . . . . . . . . . . . . . . . 53

4.3 Resumo . . . . . . . . . . . . . . . . . . . . . 5 54

5 Conclusões $\quad 55$

5.1 Considerações Finais . . . . . . . . . . . . . . . . . . . . . 55

5.2 Resumo das Contribuições . . . . . . . . . . . . . . . . . . . 55

5.2 .1 Publicações Realizadas . . . . . . . . . . . . . . . . . . . . . 56

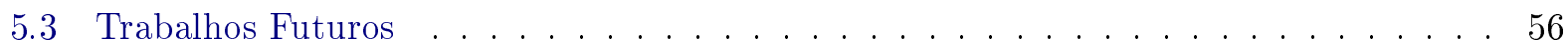

$\begin{array}{ll}\text { Referências Bibliográficas } & 57\end{array}$ 


\section{Lista de Abreviaturas}

$\begin{array}{ll}\text { ASES } & \text { Avaliador e Simulador para a Acessibilidade de Sítios } \\ \text { Cege } & \text { Comitê Executivo de Governo Eletrônico } \\ \text { CETIC.br } & \text { Centro de Estudos sobre as Tecnologias da Informação e da Comunicação } \\ \text { CoP } & \text { Community of Practice } \\ \text { e-MAG } & \text { Modelo de Acessibilidade de Governo Eletrônico } \\ \text { e-Ping } & \text { Padrões de Interoperabilidade em Governo Eletrônico } \\ \text { IV } & \text { Instituição Virtual } \\ \text { LCC } & \text { Lightweight Coordination Calculus } \\ \text { MIIH } & \text { Modelo para Interoperabilidade entre Instituições Heterogêneas } \\ \text { MIHI } & \text { Model for Interoperability between Heterogeneous Institutions } \\ \text { OSCIP } & \text { Organização da Sociedade Civil de Interesse Público } \\ \text { PRODESP } & \text { Companhia de Processamento de Dados do Estado de São Paulo } \\ \text { SISP } & \text { Sistema de Administração dos Recursos de Informação e Informática } \\ \text { SLTI } & \text { Secretaria de Logística e Tecnologia da Informação } \\ \text { SOA } & \text { Arquitetura Orientada a Serviços (Service-Oriented Architecture) } \\ \text { SOAP } & \text { Simple Object Access Protocol } \\ \text { TIC } & \text { Tecnologias de Informação e Comunicação (Information and Communication Technology) }\end{array}$




\section{Lista de Figuras}

2.1 Grafo de localizações. Agentes podem mover, por exemplo, da localização 1 para a localização 2, mas não podem se mover da localização 3 para a localização $1 \ldots$. . 8

2.2 Representações gráficas para as três entidades básicas de um protocolo de interação baseado em conhecimento. . . . . . . . . . . . . . . . . . . . 10

2.3 Representação gráfica de um simples protocolo de interação baseado em conhecimento. 11

2.4 Configuração inicial para um simples protocolo de interação baseado em conhecimento. 11

2.5 Perfil do Cidadão - Dificuldade de uso X Experiência de uso . . . . . . . . . . . . . . 24

2.6 Arquitetura de Execução $[$ Bog07] . . . . . . . . . . . . . . . . . . . . . 26

3.1 Esquema do Artefato do Conhecimento Interoperável . . . . . . . . . . . . . . . 31

3.2 Artefato do Conhecimento Interoperável e Community of Practice . . . . . . . . . . . 35

3.3 Esquema de interoperabilidade do $\mathrm{MIIH} \ldots \ldots \ldots \ldots$

3.4 Esquema da metodologia para uso do MIIH . . . . . . . . . . . . . . . . . 38

4.1 Esquema do OpenMuseum Lite - Busca e Criação de Exposição Na Página de Busca, o usuário solicita uma busca por autor ou obra. A plataforma JamSession dispara os respectivos protocolos para efetivamente realizar as buscas automaticamente em toda a CoP. Se necessário, é realizado também o mapeamento de ontologias, de forma transparente para o usuário. Ao final de cada busca, a Página de Resposta é criada/atualizada, apresentando as imagens das obras encontradas. Quando o usuário finaliza sua pesquisa, ele pode selecionar, ainda nesta página, quais obras ele deseja ver "expostas". O usuário seleciona, então, a opção de criar Exposição e a respectiva página é gerada . . . . . . . . . . . . . . . . . . 46

4.2 Esquema do OpenMuseum Lite - Detalhes de uma Obra e Interação com Redes Sociais Ao visualizar uma Exposição, o usuário pode selecionar uma obra e ter acesso às informações e detalhes sobre esta obra. O usuário pode selecionar dentro destes detalhes, ver comentários em redes sociais. Neste caso, a plataforma JamSession dispara os protocolos para verificar estes comentários e retorná-los para o usuário. . . . . . . . . . . . . . . 46

4.3 Esquema do OpenMuseum Lite - Cruzamento de Informações entre Web Sites Um exemplo de interoperabilidade de informações entre instituições da CoP, é utilizar os protocolos de interação para disparar uma busca por obra no site do Museu de Arte Moderna de São Paulo (MAM) e, retornado o nome do autor da obra, pesquisar no site da Bienal das Artes de SP quais obras deste autor estiveram presentes nesta mostra. . . . . . . . . . . . 47

4.4 Ontologia Compartilhada do OpenMuseum Lite . . . . . . . . . . . . . . . . . . . 47

4.5 Workflow de Interoperabilidade do OpenMuseum Lite . . . . . . . . . . . . . . 48

4.6 Grafo de Localizações do OpenMuseum Lite . . . . . . . . . . . . . . . . . . . . . . 50 
4.7 Esquema do Artefato do Conhecimento Interoperável . . . . . . . . . . . . . . . . 51

4.8 Esquema do OpenMuseum . . . . . . . . . . . . . . . . . . . . . 51

4.9 Esquema do Artefato do Conhecimento Interoperável . . . . . . . . . . . . . . . . 54 


\section{Capítulo 1}

\section{Introdução}

A interação entre instituições heterogêneas tem sido cada vez mais necessária para obter e disponibilizar informações e serviços para seus usuários internos e externos. Esta interação tem sido sustentada principalmente pelo uso das novas tecnologias da informação e comunicação.

A interoperabilidade entre instituições heterogêneas garante esta interação e proporciona vários benefícios como, por exemplo, utilizar toda a plataforma legada das instituições e ainda permitir a interação entre os sistemas. Entretanto, para que esta interoperabilidade seja possível é necessária a definição de conceitos comuns que padronizam e orientam as interações entre as instituições. Através destes conceitos comuns, as instituições podem trocar informações entre si e ainda manter sua independência e as particularidades em seus sistemas internos.

Além disso, para que a interoperabilidade possa existir, é fundamental definir os fluxos de trabalho (workflows) dentro de cada organização (ou setor da instituição) e integrar estes workflows, de forma a garantir a colaboração entre as instituições. Para tanto, devemos considerar o fato de que as instituições possuem workflows muito diferentes e, portanto, é fundamental o uso de tecnologias que possibilitam a interação entre estes workflows (cross-organizational workflows), garantindo assim a realização conjunta de tarefas entre estas instituições. Estas interações devem ser realizadas de forma flexível e confiável e devem ainda garantir que cada organização tenha controle sobre seus processos.

Em nosso trabalho, propomos um Modelo para Interoperabilidade entre Instituições Heterogêneas (MIIH). A especificação das regras de interação e, especificamente, os protocolos de interoperabilidade entre as instituições são escritos usando JamSession [CdS11], que é uma plataforma para a coordenação de serviços de software heterogêneos e distribuídos. JamSession é utilizada também como uma ferramenta para integração de cross-organisational workflows [dSVD ${ }^{+} 12$ ], com a característica de ser formalmente verificável, fácil de usar e suficientemente flexível para prover um ambiente para a especificação e execução de padrões de integração que garantem a correta separação de interesses e responsabilidades entre as instituições envolvidas. Na seção 2.2.2 apresentamos uma descrição da plataforma JamSession.

O modelo também define uma arquitetura baseada em Artefatos do Conhecimento Institucionais para lidar com as conexões com os sistemas das instituições. Estes Artefatos do Conhecimento Institucionais são baseados no conceito geral de Artefatos do Conhecimento, ou seja, "objetos que contêm e transmitem uma representação utilizável do conhecimento". Os Artefatos do Conhecimento Institucionais são padrões arquitetônicos recorrentes que são observados no projeto de mecanismos de interoperabilidade para conectar instituições heterogêneas e são usados como uma descrição de alto nível da arquitetura para um projeto de sistema. Eles funcionam como padrões arquiteturais pré-concebidos que norteiam e padronizam as interações e, portanto, a interoperabilidade organizacional e semântica entre as instituições. Os Artefatos do Conhecimento Institucionais são fundamentados sobre uma ontologia de conceitos relevantes para serviços destas instituições, cujo nível de abstração pode variar, dependendo do nível de integração necessário para as instituições quanto mais sofisticada a interação, mais detalhes devem ser representados explicitamente na ontologia. Os Artefatos do Conhecimento Institucionais implementados também se comunicam com 
a camada de interação com o usuário, baseada em mundos virtuais, para garantir a comunicação adequada com estes usuários.

O modelo MIIH satisfaz questões relevantes como:

- adaptabilidade a diferentes níveis de conhecimento dos usuário;

- adaptabilidade à heterogeneidade dos sistemas e workflows das instituições envolvidas;

- alinhamento com os requisitos relacionados à segurança, privacidade, confiabilidade e escalabilidade;

- satisfação dos requisitos de interoperabilidade das instituições envolvidas.

Acreditamos que, independentemente do nível de conhecimento dos usuários, os mundos virtuais proporcionam uma interface simples para interação e facilitam o processo de aprendizado para a utilização dos sistemas oferecidos pelas instituições através do MIIH.

Do lado das instituições virtuais, os requisitos organizacionais, bem como os requisitos de sistema, são questões importantes a serem abordadas antes de efetivamente prover qualquer serviço/interação. Para satisfazer estes requisitos, propomos a adoção da plataforma JamSession, atuando como um coordenador expressivo de recursos heterogêneos.

Para garantir a correta execução do sistema, os serviços oferecidos, o fluxo da informação e os requisitos de interoperabilidade das instituições também são descritos utilizando a plataforma JamSession.

\subsection{Motivação e Considerações Preliminares}

A motivação inicial para este projeto foi uma análise conceitual da rede de serviços Poupatempo, uma iniciativa do governo do estado de São Paulo.

A ideia do Poupatempo surgiu em 1994, quando o então candidato a governador, Mário Covas, propôs a implementação de uma espécie de shopping de serviços públicos [Pau03]. O início de sua primeira gestão em 1995 foi marcado por inúmeras dificuldades administrativas, principalmente porque herdou uma administração estatal, sem os controles básicos e um grande rombo nos cofres públicos. A orientação geral definida pelo governador foi a de otimizar todos os recursos existentes. Nesta época, a administração pública implantou várias iniciativas de melhoria de qualidade nos serviços públicos e iniciou um projeto de qualidade total na administração, dentre outras iniciativas.

Iniciou-se, então, o projeto Poupatempo, encabeçado pela empresa de tecnologia do estado (PRODESP), em parceria com todas as secretarias de estado e os órgãos e empresas que prestavam algum serviço direto ao cidadão. Em 1997 a primeira unidade do Poupatempo iniciou suas atividades, já com um conceito de qualidade total. O grande diferencial do Poupatempo estava em oferecer um rápido atendimento, centralizar a oferta de todos os serviços públicos (na esfera estadual) em um único local e prover um serviço humanizado e eficiente. Ainda sem a aplicação dos conceitos de integração e interoperabilidade, os órgãos participantes do projeto tiveram que realizar ajustes mínimos em seus sistemas, de modo a oferecer algumas informações centralizadas de atendimento, caracterizando os primeiros passos para uma integração de dados e informações. Também avançouse muito nos procedimentos operacionais destes órgãos, por força de sua interação e da inevitável troca de experiências resultantes, levando a algo inédito no serviço público até então.

A experiência do Poupatempo mostrou diversas possibilidades sistêmicas e conceituais e inovou pela ousadia em agir como um fornecedor em busca da satisfação de seu cliente: o cidadão.

Atualmente, o Poupatempo conta com a integração e interoperabilidade entre os sistemas de todos os órgãos envolvidos na prestação dos serviços oferecidos e o cidadão continua sendo o ponto central na prestação de seus serviços.

Uma nova motivação para nosso trabalho surgiu a partir de conversas com a professora Ana Magalhães, curadora do Museu de Arte Contemporânea da USP, graças às quais pudemos observar 
a necessidade de uma interoperabilidade entre os museus, os profissionais relacionados à arte e os usuários destas organizações. A interação mais comum entre estas partes acontece nas exposições, onde as obras de arte são apresentadas em espaços físicos (normalmente museus e galerias) e, devido à limitação destes espaços, somente as informações básicas são fornecidas.

Com a disseminação da Web, a mídia virtual se tornou um espaço muito interessante para os museus, que podem se utilizar desta tecnologia para apresentar muitas outras informações. Inicialmente, os museus começaram a apresentar informações institucionais, mapas do espaço físico do museu, informações sobre as exposições em andamento e, em alguns casos, compras online de ingressos para as exposições. Recentemente, alguns museus começaram a disponibilizar na Web o catálogo digital de seu acervo para o usuário final.

Pesquisando mais profundamente o universo dos museus, percebemos que existe uma necessidade de interoperabilidade entre estas organizações para que estas possam obter mais informações para o conhecimento das obras de arte e seus respectivos artistas. Também existe a necessidade de apresentar informações mais amplas e técnicas sobre cada obra de arte para o usuário final, seja ele um especialista ou pesquisador da área ou simplesmente um apreciador de arte.

Neste contexto, assim como no caso do Poupatempo, identificamos a necessidade de interoperabilidade entre as organizações e seus usuários, assim como a necessidade de utilização de uma nova mídia, mais adequada a esta nova realidade, que possibilite a interação com usuários de todos os níveis culturais.

Desta forma, definimos o contexto de nossa tese para tratar de instituições que requerem interoperabilidade entre si e com seus usuários, de forma simples, segura e confiável, além de proporcionar ao usuário (de qualquer nível cultural) uma experiência agradável, intuitiva e imersiva.

Por questões de facilidade de acesso a informações reais e identificação de um problema concreto, escolhemos desenvolver nesta tese um Exemplo de Uso baseado no universo dos museus virtuais. No Capítulo 4, inicialmente apresentamos o cenário dos museus em mais detalhes e, em seguida, descrevemos o Exemplo de Uso que desenvolvemos para esta tese. Por fim, sugerimos uma abordagem para o caso de prestação de serviços públicos, um modelo para um possível Poupatempo virtual.

\subsection{Formulação do problema}

O desafio em nosso projeto está em definir um modelo para interoperabilidade entre instituições e usuários, preservando as seguintes características, que consideramos fundamentais:

1. Integração entre os sistemas das várias instituições envolvidas;

2. Correto funcionamento do sistema, garantindo a interoperabilidade entre as instituições e destas com seus usuários;

3. Workflow bem definido, para cada instituição e para cada interação entre instituições;

4. Facilidade de entendimento e uso do sistema, por parte dos funcionários e usuários;

5. Interface simples e intuitiva.

\subsection{Objetivos}

Os objetivos que definimos para nosso trabalho são:

1. Definir um Modelo para Interoperabilidade entre Instituições Heterogêneas (MIIH);

2. Especificar os fluxos de serviços, incluindo Interoperabilidade entre Instituições Heterogêneas;

3. Definir um modelo de representação das informações que trafegam nos workflows dentro/entre estas instituições. 


\subsection{Contribuições}

O resultado deste projeto é a definição de um Modelo para Interoperabilidade entre Instituições Heterogêneas (MIIH).

As principais contribuições deste trabalho são:

1. Modelo para a especificação das atividades/interações/serviços oferecidos por instituições virtuais, garantindo a interoperabilidade entre as instituições e destas com seus usuários;

2. Modelo para a representação da informação transportada através dos workflows das instituições virtuais;

3. Exemplo de Uso: especificação e implementação de um workflow completo, utilizando o modelo conceitual definido neste trabalho.

\subsection{Organização do Trabalho}

Este trabalho está organizado da seguinte forma:

- No Capítulo 2, apresentamos os principais conceitos relacionados a com nosso trabalho. Apresentamos também conceitos relacionados às tecnologias envolvidas no projeto e alguns trabalhos relacionados.

- No Capítulo 3, apresentamos a proposta de tese propriamente dita.

- No Capítulo 4 apresentamos uma aplicação desenvolvida utilizando o modelo proposto neste trabalho, exemplificando sua aplicabilidade em um exemplo prático.

- Finalmente, no Capítulo 5 discutimos algumas conclusões provenientes deste trabalho e fazemos algumas considerações para possíveis trabalhos futuros. 


\section{Capítulo 2}

\section{Conceitos}

Nesse capítulo apresentamos os principais conceitos relacionados ao nosso trabalho, com o objetivo de contextualizá-lo e apresentar as definições necessárias para elaboração de nossa pesquisa.

$\mathrm{Na}$ seção 2.1 apresentamos o conceito de cross-organizational workflow, que é essencial para o enfoque de interoperabilidade de nosso trabalho. Na seção 2.1.1 apresentamos a definição de interoperabilidade de forma a identificar mais diretamente o contexto em que nosso trabalho está inserido.

Na seção 2.2 apresentamos a ideia geral dos protocolos de interação e sistemas multiagentes que podem servir de base para os sistemas que iremos considerar.

Na seção 2.3 apresentamos alguns conceitos relacionados ao nosso trabalho.

Na seção 2.4 apresentamos a definição de Governo Eletrônico e um breve histórico políticosocial brasileiro, que elucida as diretrizes estabelecidas pelo Governo Federal sobre a questão da interação entre Governo e Sociedade. Nesta seção, apresentamos também como estamos alinhados com a proposta do governo, suas diretrizes e padrões e qual será a contribuição deste trabalho para a sociedade. Nas seções 2.4.4 e 2.4.5 apresentamos algumas iniciativas de Governo Eletrônico no Brasil e no mundo, respectivamente, que são referência para nosso trabalho. Na seção 2.4.6 apresentamos a questão da interação com os cidadãos nos sistemas de Governo Eletrônico, identificando os principais problemas e soluções existentes, principalmente no Brasil.

$\mathrm{Na}$ seção 2.5 apresentamos alguns trabalhos relacionados à nossa proposta.

\subsection{Cross-Organizational Workflows}

Em nosso trabalho tratamos da interoperabilidade entre instituições para que estas possam prestar serviços para seus usuários, assim como colaborar entre si para que cada uma delas possa atingir seus objetivos. Neste contexto, para que estas atividades tenham sucesso, elas precisam estar bem definidas e ordenadas de forma a garantir que o objetivo final seja satisfeito.

Tecnologias para workflow são amplamente utilizadas para auxiliar na especificação, execução e realização de processos dentro das organizações ([Hol95]). Com estas tecnologias podemos especificar como as atividades dentro das organizações estão ordenadas e quem é responsável por cada uma delas.

Entretanto, com a evolução das relações entre as instituições, definir os workflows dentro de cada instituição (ou setor da instituição) não é suficiente. É necessário integrar estes workflows, de forma a garantir a colaboração entre as instituições. Considerando o fato de que as organizações possuem workflows muito diferentes, é fundamental o uso de tecnologias que possibilitem a interação entre estes workflows (cross-organizational workflows), garantindo assim a realização conjunta de tarefas entre as organizações.

Estas interações devem ser realizadas de forma flexível e confiável e devem ainda garantir que cada organização tenha controle sobre seus processos.

Muitas iniciativas de sistemas para cross-organisational workflows podem ser encontradas na literatura e, recentemente, Corrêa da Silva propôs a plataforma JamSession para a integração e co- 
ordenação de recursos computacionais heterogêneos [CdS11]. Em [dSVD $\left.{ }^{+} 12\right]$, JamSession é apresentada como uma ferramenta para integração de cross-organisational workflows, com a característica de ser formalmente verificável, fácil de usar e suficientemente flexível para prover um ambiente para a especificação e execução de padrões de integração que garantem a correta separação de interesses e responsabilidades entre as organizações envolvidas. Neste último artigo, os autores apresentam um conjunto de protocolos baseados em conhecimento para ilustrar a aplicabilidade da plataforma para a integração de cross-organisational workflows. JamSession requer que a separação de interesses e responsabilidades sejam construídas nos protocolos, de tal forma que cada organização constrói os protocolos de interação capazes de trocar informação diretamente com seu workflow interno, garantindo os níveis de segurança e confiabilidade.

Em nosso trabalho, usaremos a plataforma JamSession também com este enfoque.

\subsubsection{Interoperabilidade}

Nesta seção apresentamos o conceito amplo de interoperabilidade.

"Interoperabilidade é a habilidade dos sistemas de Tecnologia de Informação e Comunicação (TIC), bem como dos processos de negócio que eles suportam, trocarem dados e habilitarem o compartilhamento de informações e conhecimento". [Com04b]

Considerando um ponto de vista mais técnico, interoperabilidade pode ser classificada em quatro categorias [PLGT08] [Muc11] [Bur04]:

- Técnica: refere-se à incompatibilidade da infraestrutura técnica, implica o processamento automático e a reutilização da informação entre diferentes sistemas e plataformas.

- Sintática: lida com a heterogeneidade dos formatos de dados.

- Semântica: engloba o processamento e a interpretação do significado dos dados compartilhados. Trata da capacidade de sistemas heterogêneos e distribuídos trabalharem em conjunto, compartilhando informações entre eles, com entendimento comum de seu significado.

- Organizacional: lida com a incompatibilidade dos diferentes processos de negócio e seus objetivos. Diz respeito à colaboração entre organizações que desejam trocar informações, mantendo diferentes estruturas internas e processos de negócio variados.

Interoperabilidade organizacional é, provavelmente a categoria mais desafiadora, uma vez que ainda não existe uma clareza conceitual para definir os conceitos básicos, os participantes e os objetivos gerais desta categoria [CH09].

Uma das definições mais aceitas para a interoperabilidade organizacional é fornecida pela IDABC EIF [Com04a]:

Interoperabilidade organizacional envolve um grande conjunto de elementos de interação, incluindo processos de negócio, interfaces de negócio (e-mail, portais Web, ...), eventos de negócio dentro e entre administrações, e eventos da vida, envolvendo partes externas (negócios e cidadãos). ... Interoperabilidade Organizacional visa endereçar os requisitos da comunidade de usuários, tornando os serviços disponíveis, fáceis de identificar, acessíveis e orientados ao usuário.

Nosso trabalho está focado na Interoperabilidade Organizacional quando tratamos de prestação de serviços e na Interoperabilidade Semântica quando tratamos da representação do conhecimento, como será apresentado no Capítulo 3. 


\subsection{Protocolos de Interação}

Um Sistema Multiagentes é composto por um grupo de agentes autônomos que interagem para alcançar seus objetivos[Les95]. Normalmente, cada agente possui um conjunto de capacidades comportamentais que definem sua competência, um conjunto de objetivos e a autonomia necessária para utilizar suas capacidades comportamentais a fim de alcançar seus objetivos. Um agente é uma entidade computacional com um comportamento autônomo que lhe permite decidir suas próprias ações [AS97], considerando as mudanças no ambiente em que atua e tendo como meta, alcançar seu objetivo.

Os agentes interagem entre si, de acordo com alguns padrões, denominados protocolos de interação. Em cada protocolo de interação são definidos, por exemplo, os papéis que podem ser desempenhados pelos agentes, os tipos de mensagens que podem ser enviadas e recebidas em cada papel, além da sequência em que essas mensagens são trocadas.

\subsubsection{Algumas Ferramentas Relacionadas}

Em nosso trabalho, adotamos JamSession, uma plataforma para especificar e executar workflows, monitorar e controlar recursos heterogêneos, e que pode ser especialmente útil para especificar e implementar a coordenação de atividades multimídia, multimodal e de tempo real. JamSession é utilizada para especificar e executar protocolos de interação baseados em conhecimento, que são formalmente fundamentados e podem ser formalmente analisados e verificados utilizando uma linguagem gráfica amigável. Um protocolo de interação baseado em conhecimento determina como disparar recursos pode trabalhar cooperativamente para construir comportamentos complexos em ambientes interativos inteligentes.

JamSession possui várias similaridades com Instituições Eletrônicas [Est03] (descrita na seção 2.5). Entretanto, o conceito de papéis em Instituições Eletrônicas é substituído pela noção de localização em JamSession. Os agentes precisam se mover para localizações específicas para poder participar de ações colaborativas, uma vez que suas capacidades tornam-se disponíveis apenas nestas localizações.

Várias iniciativas (por exemplo, [dSV10], [VKN09]) de interações mediadas por normas foram desenvolvidas. Nestes casos, os protocolos de interação são fundamentados em regras normativas que especificam permissões e proibições, às quais os agentes devem estar em conformidade. Em JamSession, este conceito é simulado como regras condicionais anexadas a localizações específicas.

Lightweight Coordination Calculus (LCC) [Rob04] é uma linguagem para construir especificações executáveis, semelhante a linguagens de especificação algébrica, como o Ambient Calculus. A principal diferença entre LCC e JamSession é que a primeira não trata explícita e diretamente das noções de mobilidade e contextualização.

Em uma linha diferente, a arquitetura de Sistemas Multicamadas Multiagentes Situados (Multilayered Multiagent Situated Systems architecture (MMASS)) [Viz04] considera a mobilidade como a noção central para contextualização e interações em sistemas multi-agentes. Em MMASS encontramos a noção dos locais, que são estruturados pelos caminhos formando um gráfico de sites através dos quais os agentes podem se mover para procurar recursos específicos para realizar seus objetivos. JamSession tomou emprestado e incorporou esses conceitos.

Em nosso trabalho, utilizamos JamSession como ferramenta de especificação dos sistemas que abordaremos, onde a interoperabilidade organizacional é enfatizada, especialmente no que se refere à facilidade de utilização e publicação de fluxos de trabalho.

\subsubsection{JamSession}

JamSession é uma plataforma conceitual para especificar, projetar e implementar ambientes interativos inteligentes. JamSession é um coordenador expressivo de recursos heterogêneos, que pode ser usado em vários cenários, incluindo a coreografia de workflows e a coordenação de recursos 
multimídia em aplicações como inteligência ambiental, realidade aumentada, jogos de computadores, artes digitais interativas e entretenimento digital.

JamSession foi desenvolvido com a visão de que um ambiente interativo amigável para o usuário pode ser útil para melhorar a qualidade dos serviços providos pelos sistemas computacionais para um largo espectro de usuários.

Uma noção fundamental em JamSession é o conceito de localização. Intuitivamente, nós temos agentes nos ambientes, cujas capacidades são bloqueadas ou liberadas para o uso, dependendo da localização destes agentes. Quando um usuário precisa de um serviço específico, ele deve ter certeza de que o agente que possui a capacidade de fornecer este serviço em uma localização específica, tenha efetivamente se movido para esta localização.

Localizações são, portanto, abstrações de grupos de serviços, cuja acessibilidade é controlada pela forma em que os usuários transportam agentes nomeados para as localizações específicas

Temos um grafo direcionado para especificar localizações e suas conexões. Os nós do grafo são as localizações e as arestas caracterizam as transições admitidas, que os agentes podem utilizar para mover para as localizações (Figura 2.1).

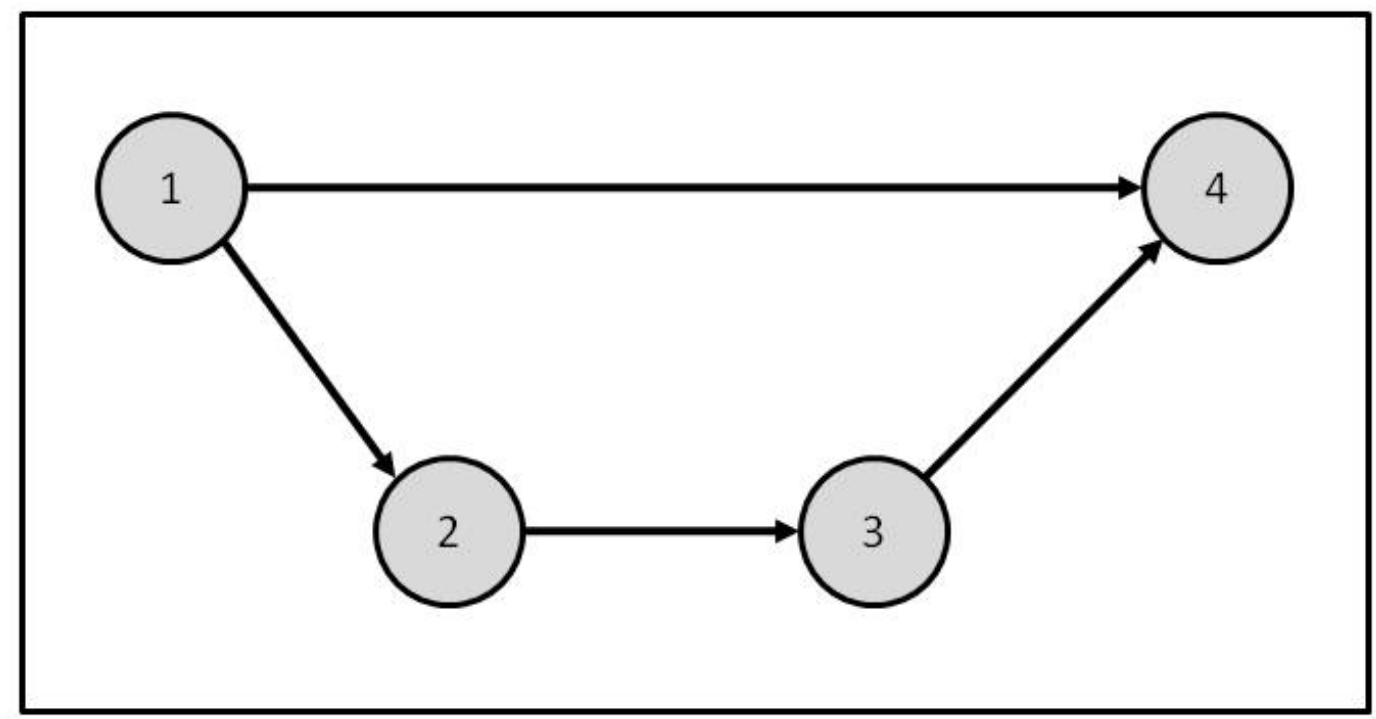

Figura 2.1: Grafo de localizações. Agentes podem mover, por exemplo, da localização 1 para a localização 2, mas não podem se mover da localização 3 para a localização 1

JamSession é um coordenador de recursos, os quais são representados como capacidade de agentes situados. Um agente permanece em uma localização até que receba uma ordem para mover para uma localização diferente.

Uma ordem para um agente mover é uma tripla da forma ${ }^{1}$

$$
\text { move (Agent, } \left.\text { Location }_{1}, \text { Location }_{2}\right) \text {. }
$$

$\mathrm{Na}$ ordem acima, assume-se que o agente Agent está na localização Location $_{1}$ e está sendo requisitado a se mover para Location $_{2}$. Uma ordem para mover pode ser avaliada, neste caso, uma tentativa de executá-la pode se realizada e um valor verdadeiro correspondente pode ser atribuído a isso, dependendo do sucesso da execução. Se o agente Agent está realmente na localização Location $_{1}$, e existe um caminho de Location $_{1}$ para Location $_{2}$, então o Agent é movido de Location 1 para Location $_{2}$, e a ordem é avaliada para T. Caso contrário, Agent permanece onde ele estiver e a ordem é avaliada para $\perp$.

\footnotetext{
${ }^{1}$ empregamos na apresentação de JamSession, a convenção de PROLOG para termos e variáveis. Assim, termos começando com caixa alta são variáveis livres.
} 
Em JamSession, as capacidade dos agentes situados são representadas como predicados de primeira ordem. Cada predicado é associado a um par [Agent, Location]. Os predicados também possuem parâmetros de entrada e saída, os quais são formados respectivamente por termos de primeira ordem e variáveis. Assim, um predicado tem a seguinte forma

$$
[\text { Ag, Loc }] \text { predicate }\left(\left(\operatorname{ITerm}_{1}, \ldots, \text { ITerm }_{n}\right),\left(\operatorname{OVar}_{1}, \ldots, \text { OVar }_{n}\right)\right)
$$

onde $A g$ é um agente, $L o c$ é uma localização, $\operatorname{ITerm}_{i}$ são termos de entrada e $O V a r_{j}$ são variáveis de saída.

Os predicados são definidos durante o projeto do sistema, especificando quais recursos podem ser disparados por quais agentes em quais localizações. Durante a execução do sistema, os predicados são usados para efetivamente disparar recursos.

Um predicado pode ser disparado, isto é, pode existir uma tentativa de avaliá-lo, a qualquer momento. Tipicamente, os predicados são usados como tentativas de ativar recursos do sistema. Os termos de entrada do predicado são verificados sintática e semanticamente, e também é checado se o agente $A g$ está localizado em Loc. Se todas as verificações tiverem sucesso, o recurso correspondente é ativado, possivelmente instanciando as variáveis de saída, e o predicado é avaliado para $T$ ou para $\perp$, dependendo de seu comportamento programado. Se $A g$ não estiver em $L o c$, então o predicado é bloqueado e o recurso correspondente não pode ser ativado. Neste caso, o predicado é avaliado para $\perp$ e as variáveis de saída são retornadas sem serem instanciadas.

Predicados e movimentos são combinados em JamSession através de protocolos de interação baseados em conhecimento. Um protocolo de interação baseado em conhecimento é uma estrutura de entidades que especificam suas ordens de avaliação. As entidades podem ser de três tipos:

1. Ordens para os agentes se moverem.

2. Predicados.

3. Recursivamente, protocolos de interação baseados em conhecimento.

Entidades também podem ser combinadas através de conectivos, conforme explicado abaixo.

Protocolos de interação baseados em conhecimento são ligados à localizações. Um requisito para disparar um protocolo de interação baseado em conhecimento pode resultar em uma das seguintes situações:

1. O protocolo de interação baseado em conhecimento não está definido para a localização específica. Neste caso, o valor verdade obtido é $\perp$.

2. O protocolo de interação baseado em conhecimento é definido para a localização específica. Neste caso, a especificação do protocolo de interação baseado em conhecimento é recuperado e avaliado, baseado nas regras algébricas que governam o comportamento dos conectivos que são usados na especificação do protocolo de interação baseado em conhecimento. O resultado da avaliação determina o valor verdade que deve ser atribuído ao protocolo de interação baseado em conhecimento, o qual pode ser $T$ ou $\perp$.

Um protocolo de interação baseado em conhecimento é denotado como:

$$
\left[\operatorname{Loc}_{k} \operatorname{kbip}\left(\left(\operatorname{ITerm}_{1}, \ldots, \text { Term }_{m}\right),\left(\operatorname{OVar}_{1}, \ldots, O \operatorname{Var}_{n}\right)\right)\right.
$$

Aqui, Loc diz respeito à localização à qual o protocolo de interação baseado em conhecimento está conectado, $I_{\text {Term }}$ são termos de entrada de primeira ordem e $O V a r_{j}$ são variáveis de saída como antes. A utilização esperada dos termos e variáveis na especificação do protocolo de interação baseado em conhecimento é para passagem de parâmetro entre predicados e protocolos de interação baseados em conhecimento auxiliares.

Um protocolo de interação baseado em conhecimento assume a forma de uma fórmula na forma normal disjuntiva, na qual os átomos são as três entidades na lista acima. A especificação de um protocolo de interação baseado em conhecimento assume a seguinte forma: 
- $\left[\operatorname{Loc}_{k} k b i p\left(\left(\operatorname{ITerm}_{1}, \ldots\right.\right.\right.$, ITerm $\left.\left._{m}\right),\left(\operatorname{OVar}_{1}, \ldots, O \operatorname{Var}_{n}\right)\right)::=\bigvee_{1}^{k} F_{i}$.

- $F_{i}=\bigwedge_{1}^{r_{i}} e_{j}$.

- $e_{j}=$ Move $\mid$ Predicate $\mid$ Kbip .

- Move ::= move (Agent, Location $_{1}$, Location $\left._{2}\right)$

- Predicate $::=[$ Ag, Loc $]$ predicate $\left(\left(\right.\right.$ ITerm $_{1}, \ldots$, ITerm $\left._{n}\right),\left(\right.$ OVar $_{1}, \ldots$, OVar $\left.\left._{n}\right)\right)$

- Kbip $::=[\operatorname{Loc}] k b i p\left(\left(I T e r m_{1}^{\prime}, \ldots, I T e r m_{m^{\prime}}^{\prime}\right),\left(O \operatorname{Var}_{1}^{\prime}, \ldots, O V a r_{n^{\prime}}^{\prime}\right)\right)$

Assume-se que ambos, disjunção e conjunção são não-comutativos, como uma forma de simplificar a tarefa computacional de avaliar o valor verdade de um protocolo de interação baseado em conhecimento. Uma avaliação do tipo poda $\alpha-\beta$ é adotada, da seguinte forma:

- Cada conjunto $F_{1}, F_{2}, \ldots, F_{k}$ é avaliado sequencialmente, até que um conjunto é avaliado como $T$. Quando isso ocorre, a avaliação é suspensa e todo o protocolo de interação baseado em conhecimento é avaliado como $T$. Se todos os conjuntos são avaliados e nenhum deles é avaliado como $T$, então o protocolo de interação baseado em conhecimento é avaliado como $\perp$.

- dentro de cada conjunto $F_{i}=\bigwedge_{1}^{r_{i}} e_{j}$, cada entidade $e_{1}, e_{2}, \ldots, e_{r_{i}}$ é avaliado sequencialmente, até que uma entidade seja avaliada para $\perp$. Quando isso ocorre, a avaliação é finalizada e o conjunto é avaliado como $\perp$. Se todas as entidades são avaliadas como $T$, então o conjunto é avaliado como $\top$.

Para simplificar a especificação dos protocolos de interação baseados em conhecimento, uma linguagem gráfica foi elaborada. As três entidades básicas que compreendem um protocolo de interação baseado em conhecimento são caracterizados conforme destacado na Figura 2.2.

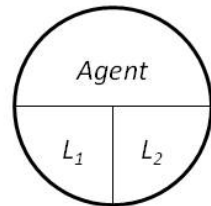

Order to move

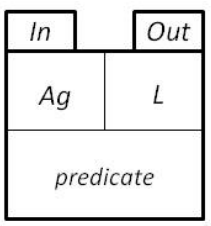

$\underline{\text { Predicate }}$

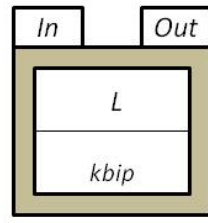

$\underline{K B I P}$

Figura 2.2: Representações gráficas para as três entidades básicas de um protocolo de interação baseado em conhecimento.

Conjunção é desenhada como uma linha conectando duas entidades, e disjunção é desenhada como um círculo preto. Por exemplo, o seguinte protocolo de interação baseada em conhecimento

$\left[\right.$ loc $\left._{1}\right]$ kbip $_{1}(($ inp $),(X))::=\left[a\right.$, loc $\left._{1}\right] \operatorname{pred}_{1}(($ inp $),(X)) \vee\left(\right.$ move $\left(a, \operatorname{loc}_{1}, \operatorname{loc}_{2}\right) \wedge\left[a, \operatorname{loc}_{2}\right] \operatorname{pred}_{2}(($ inp $),(X))$

pode ser representada diagramaticamente como apresentado na Figura 2.3. 


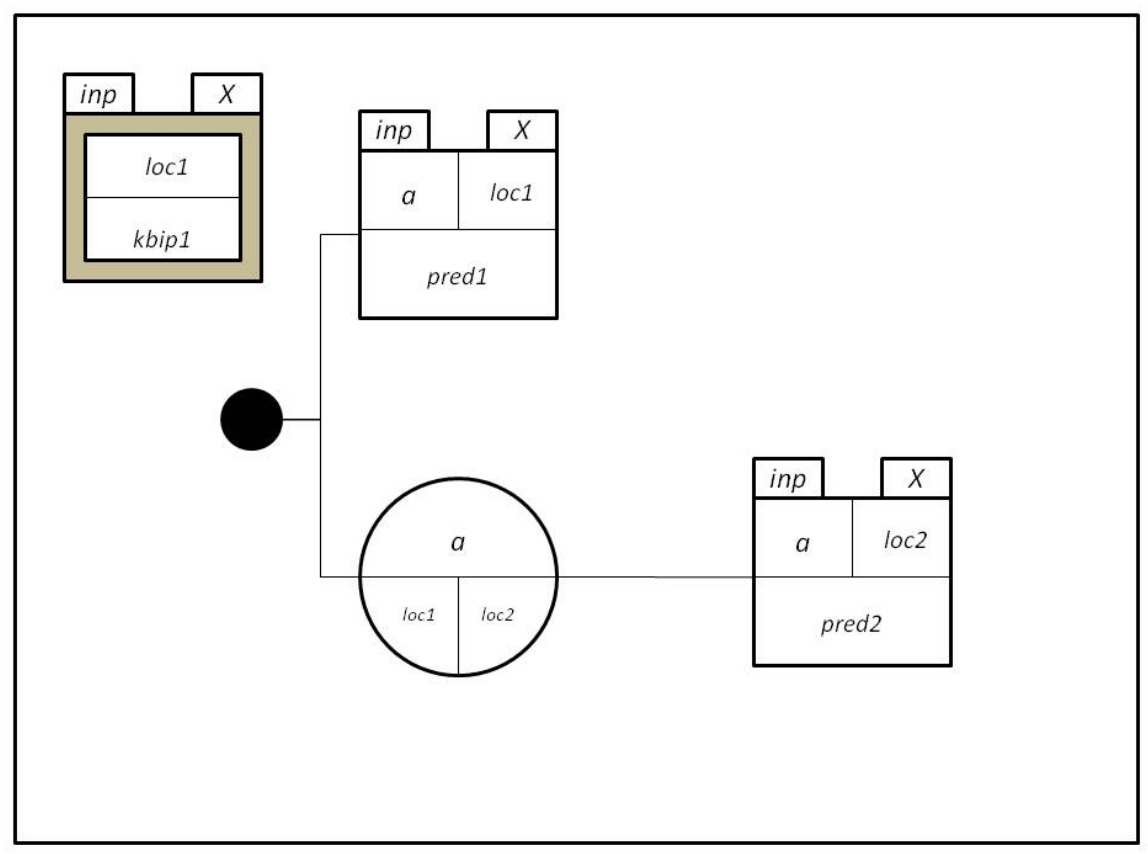

Figura 2.3: Representação gráfica de um simples protocolo de interação baseado em conhecimento.

Esta especificação deve ser complementada pela informação sobre quais recursos pertencem a quais localizações e agentes, sobre a estrutura das localizações e sobre a configuração inicial dos agentes. Por exemplo, podemos ter:

- $\left[a, l o c_{1}\right] \operatorname{pred}_{1}\left((\right.$ inp $\left.),\left(l o c_{1}\right)\right)::=$ (especificação do comportamento associado ao $\left.\operatorname{pred}_{1}\right)$.

- $\left[a, l o c_{2}\right] \operatorname{pred}_{2}\left((\right.$ inp $\left.),\left(l o c_{1}\right)\right)::=\left(\right.$ especificação do comportamento associado ao pred $\left._{2}\right)$.

- Estrutura da localizações e localização inicial do agente a como mostrado na Figura 2.4.

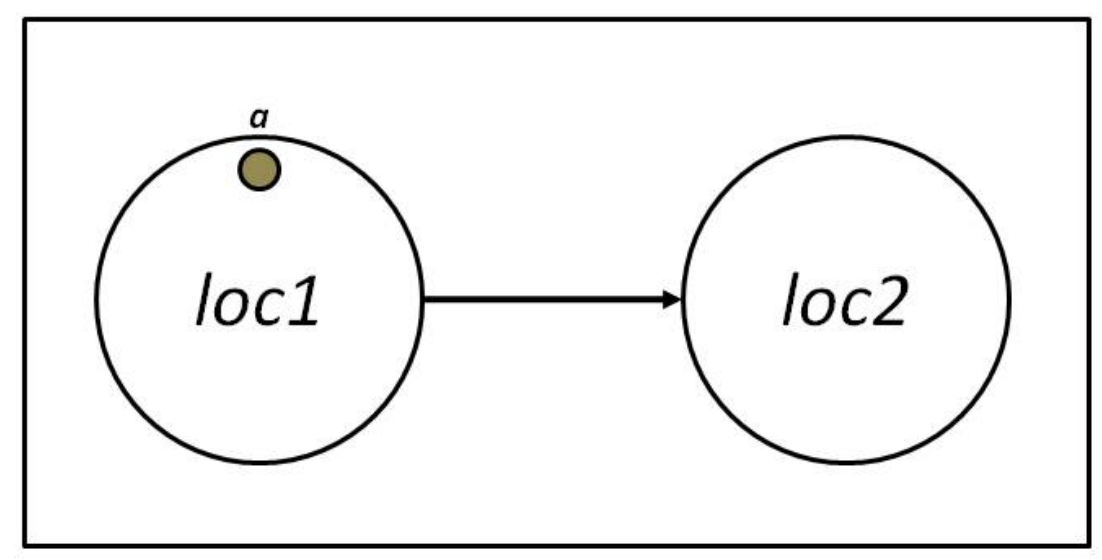

Figura 2.4: Configuração inicial para um simples protocolo de interação baseado em conhecimento.

Os protocolos de interação baseados em conhecimento são usados para especificar, implementar e executar interações entre usuários de um ambiente inteligente interativo, e entre usuários e o ambiente propriamente dito. Agentes, localizações e todas as entidades que incluem os protocolos de interação baseados em conhecimento são os recursos conceituais usados para caracterizar as interações desejadas. 


\section{Provas Formais em JamSession}

A semântica declarativa dos protocolos baseados em conhecimento (KBIPs) em JamSession fornece os meios para a análise e verificação formais destes protocolos.

Por exemplo, a tradução destes protocolos para redes de Petri coloridas pode ser utilizada para simular o comportamento de uma interação e analisar os possíveis estados de conflitos, falhas e exceção. Estas análises podem servir para otimizar a construção de KBIPs, onde os agentes podem ser tratados de forma mais eficaz e os resultados finais correspondem ao comportamento esperado na colaboração.

Em [VdS12a], os autores apresentam uma proposta de semântica para JamSession, que pode ser utilizada na análise, simulação e verificação de protocolos de interação. Inicialmente eles apresentam a sintaxe da linguagem e as regras semânticas de seu processo computacional. Em seguida é mostrado como o comportamento dinâmico de seu mecanismo de coordenação pode ser modelados com redes de Petri aninhadas [LS00]. Em JamSession, os agentes são entidades passivas que executam serviços específicos e gerenciam recursos locais, e os protocolos são os componentes ativos que coordenam a interação dos agentes. Os protocolos de interação podem ser compostos, aninhados e recursivamente definidos. Desta forma, o ambiente (agentes, locais e movimentos) foi representado usando um conjunto de cores e as transições da rede representam a execução dos predicados e chamadas a protocolos, assim como os operadores de conjunção e disjunção. Neste trabalho, o comportamento do sistema foi modelado como um Workflow Net [vdA99] e foi definida uma propriedade para sua corretude, que pode ser utilizada para a detecção precoce de interações conflitantes. Também foi mostrado que esta propriedade é decidível.

Ainda não existem ferramentas para lidar com redes aninhadas e, por isso, em [VdS12b], os autores propõem uma tradução dessas redes para SPIN [Hol03], que é uma das ferramentas mais bem sucedidas para simulação e verificação de sistemas de softwares concorrentes e distribuídos. Dessa forma, algumas propriedades de lógica temporal linear (LTL) também podem ser verificadas.

Outra forma de verificação dos protocolos em JamSession é realizar um análise de configuração. Pode-se verificar se um conjunto de protocolos em JamSession sempre termina com sucesso, analisando-se todas as possíveis saídas destes protocolos e checando se elas sempre completam com o valor-verdade $T$. Desta mesma forma, também pode-se verificar se uma determinada configuração é alcançada ou se uma mensagem de erro é gerada, dado um determinado conjunto de valores de entrada.

\subsection{Conceitos Relacionados}

Para que os conceitos utilizados em nosso trabalho estejam claros, nesta seção apresentamos as definições destes conceitos que adotamos da literatura.

\subsubsection{Artefatos do Conhecimento}

Em nosso modelo, usamos o conceito de Artefatos do Conhecimento Interoperáveis, os quais são baseados no conceito de Artefatos do Conhecimento [STCDS ${ }^{+}$08], como descrevemos a seguir.

Inicialmente apresentamos uma definição para um artefato genérico, como encontrado em [Hil11]: "um artefato é um objeto que foi intencionalmente produzido para um propósito específico.". De acordo com [Mic98], também podemos definir um artefato como o resultado de uma atividade humana disciplinada, seguindo regras e baseado em treinamento e experiência, significando que todo artefato tem um autor e um propósito. Os artefatos podem ser avaliados em termos de como suas características reais estão de acordo com as características pretendidas por seus autores e com os propósitos para os quais foram construídos. Um artefato é caracterizado por uma tripla $(I ; R ; P)$, onde:

- I é uma invenção ou ideia que descreve o artefato em um nível abstrato;

- $R$ é o artefato real usado para o propósito $P$; 
- $P$ é o propósito que gerou o projeto de $I$ e a implementação de $R$, que pode ser diferente do propósito do usuário do artefato.

Entretanto, neste trabalho, estamos particularmente interessados em Artefatos do Conhecimento. Na literatura, encontramos várias definições para Artefatos do Conhecimento, que podem ser classificadas em quatro grupos:

1. um Artefato do Conhecimento é um artefato que representa um conhecimento;

2. um Artefato do Conhecimento é um artefato que representa a codificação de um conhecimento;

3. um Artefato do Conhecimento é um artefato cuja criação requer um conhecimento especializado;

4. um Artefato do Conhecimento é um artefato "feito de" conhecimento;

Uma das definições mais frequentemente utilizadas pode ser encontrada em [HJ01]. Os autores descrevem Artefatos do Conhecimento como "objetos que transmitem e contém uma representação utilizável do conhecimento". Combinando isso com a definição 2) acima, temos codificações utilizáveis (executáveis) do conhecimento, que podem ser adequadamente incorporados como programas de computador, escritos em linguagens de programação como C, Java, ou linguagens de modelagem declarativas como XML, OWL ou SQL. A utilidade de um Artefato do Conhecimento resulta do ponto de vista a partir da qual ele é abordado. Neste trabalho, seguimos a perspectiva da inteligência artificial e consideramos um Artefato do Conhecimento como um artefato cujo principal componente é o conhecimento. A perspectiva da inteligência artificial visa separar o conhecimento da sua utilização. Um Artefato do Conhecimento persiste mesmo sem um sistema para a sua gestão. Além disso, a sua identificação em uma organização poderia ser um guia útil para o desenvolvimento de sistemas baseados em conhecimento, seguindo uma metodologia baseada em Artefatos do Conhecimento. Com o conceito de Artefatos do Conhecimento, temos a oportunidade de reutilizar componentes do tipo $P, I$ e $R$ para construir diferentes artefatos. Quando um Artefato do Conhecimento é reutilizado, caracteriza-se o fluxo de práticas abstratas de alto nível entre diferentes grupos cuja coesão interna é dada por algum tipo de semelhança em suas atividades. Na próxima seção, apresentamos o conceito de Artefatos do Conhecimento Interoperáveis, que se baseiam no conceito de Artefatos do Conhecimento.

\section{Artefatos do Conhecimento Interoperáveis}

Em nosso Modelo para Interoperabilidade entre Instituições Heterogêneas, usamos o conceito de Artefatos do Conhecimento Interoperáveis para garantir sua reusabilidade. Um Artefato do Conhecimento Interoperável é um padrão de arquitetura recorrente que é observado no projeto de mecanismos de interoperabilidade para conectar organizações heterogêneas, o qual é usado como uma descrição arquitetural de alto nível de um projeto de sistema. Neste modelo, Artefatos de Conhecimento Interoperáveis funcionam como padrões de arquitetura pré-concebidos que orientam e padronizam as interações - e, portanto, a interoperabilidade organizacional e semântica - entre as organizações envolvidas. Artefatos de Conhecimento Interoperáveis baseiam-se em uma ontologia de conceitos relevantes para os serviços organizacionais, cujo nível de abstração pode variar dependendo do nível de integração necessário para as organizações - quanto mais sofisticada a integração, mais detalhes devem ser explicitamente representados na ontologia. O leitor interessado pode consultar [AS11] para obter mais detalhes sobre o uso de ontologias no contexto de uma Instituição Virtual. Neste trabalho, Artefatos de Conhecimento Interoperáveis se comunicam através de protocolos de interação baseados em conhecimento implementados usando JamSession. 


\subsubsection{Ontologia para Interoperabilidade Semântica}

Nesta seção, apresentamos o conceito de ontologia, como definido na literatura. Em seguida, descrevemos como as ontologias estão relacionadas ao nosso Modelo para Interoperabilidade entre Instituições Heterogêneas, para que possamos atingir a interoperabilidade semântica. Nós usamos a definição de ontologia dada por [Gru93] e modificada por Borst in [Bor97]:

"Uma ontologia é um especificação explícita de uma conceitualização. O termo foi emprestado da filosofia, onde uma ontologia é uma exposição sistemática da Existência. Para sistemas de Inteligência Artificial, o que existe é aquilo que pode ser representado." [Gru93]

Borst [Bor97] modificou esta definição para:

"Uma ontologia é uma especificação formal de uma conceitualização compartilhada."

De acordo com [SBF98], esta definição pode ser explicada da seguinte forma:

- conceituação refere-se a um modelo abstrato de algum fenômeno no mundo por ter identificado os conceitos relevantes desse fenômeno.

- especificação refere-se aos conceitos, propriedades, relações, funções, restrições, axiomas, etc, explicitamente definidas.

- formal significa que a ontologia deve ser legível por máquina.

- compartilhada significa que uma ontologia captura o conhecimento consensual isto é, o conhecimento aceito por um grupo. O modelo é compartilhado a partir de um entendimento comum.

A definição fornecida pela ontologia serve apenas para especificar um conjunto de conceitos. A real importância das ontologias é sua aplicação. O objetivo das ontologias é permitir o compartilhamento de informações e sua reutilização. Um conceito relevante para o nosso trabalho é a classificação das ontologias, de acordo com seu nível de generalidade [Gua98]:

- Ontologias de alto nível descrevem conceitos gerais como espaço, tempo, matéria objeto, evento, ação, etc, os quai são independentes de um problema ou domínio específico.

- Ontologias de domínio descrevem o vocabulário relacionado a um domínio genérico, através da especialização dos termos introduzidos na ontologia de alto nível.

- Ontologias de tarefas descrevem uma tarefa ou atividade genérica, através da especialização dos termos introduzidos na ontologia de alto nível.

- Ontologias de aplicação descrevem conceitos que são dependentes tanto de um determinado domínio, quanto de uma determinada tarefa, que muitas vezes são especializações de ambas as ontologias relacionadas.

Outro aspecto importante para o nosso trabalho é a linguagem usada para construir ontologias. Em [GPC02] e [PRH $\left.{ }^{+} 06\right]$ existem alguns exemplos dessas linguagens, tais como Knowledge Interchange Format (KIF), Ontolingua, Ontology Language Exchange (XOL), Resource Description Framework (RDF), DARPA Agent Markup Language + OIL (DAML+OIL) e Web Ontology Language (OWL). A linguagem mais adequada para o nosso trabalho é OWL, na versão OWL Lite. OWL é uma linguagem de ontologia padronizada para a Web semântica, desenvolvida pelo World Wide Web Consortium (W3C) Web Ontology Working Group. É compatível com as linguagens de ontologia anteriores e oferece aos engenheiros de sistema mais poder para expressar semântica, incluindo conjunção, disjunção, existencialidade, e variáveis universalmente quantificadas. Sistemas de raciocínio automatizado podem fazer uso desses conceitos para realizar inferências lógicas e derivar conhecimento.

A linguagem OWL foi desenvolvida para descrever classes e relações, permitindo que essas classes sejam reutilizadas ou herdadas em documentos e aplicações web. Uma ontologia OWL pode incluir 
a descrição de classes, propriedades e suas instâncias e a semântica formal de OWL especifica como derivar suas consequências lógicas - por exemplo, fatos não literalmente presentes na ontologia, os quais podem ser derivados a partir de sua semântica.

A linguagem OWL está disponível em três versões [HPSH03]:

- OWL Full: uma extensão sintática e semântica de RDFS.

- OWL DL: uma versão de OWL com inferência decidível, que pode ser escrito como lógica descritível ou de frames. Isto permite raciocínio e inferência mais eficientes, mas perde a compatibilidade com OWL Full.

- OWL Lite: um subconjunto sintático de OWL DL, com uma sintaxe ainda mais simples e inferência mais tratável.

Existem muitos exemplos do uso de ontologias na literatura. Em [UG96] estas aplicações são sub-divididas em três categorias: 1) Comunicação, 2) Interoperabilidade e 3) Engenharia de Sistemas (especificação, confiabilidade e reusabilidade), conforme detalhado a seguir:

- Comunicação: ontologias permitem o entendimento compartilhado e a comunicação entre as pessoas. Alguns aspectos do uso de ontologias para facilitar a comunicação entre as pessoas dentro de uma organização são:

- Modelos normativos: no contexto de sistemas integrados as pessoas precisam ter uma compreensão compartilhada do sistema e dos seus objetivos. Através do uso de ontologia podemos construir um modelo normativo do sistema, criando uma semântica para o mesmo e um modelo extensível que poderá ser refinado posteriormente, permitindo transformações semânticas entre diferentes contextos.

- Redes de Relacionamentos: as ontologias podem ser usadas para criar uma rede de relacionamentos e para exploração e navegação através desta rede. Entretanto, como neste tipo de rede as pessoas têm diferentes perspectivas e pressupostos, as ontologias servem também para tornar todas as suposições explícitas através da identificação das conexões lógicas entre os elementos dos modelos do sistema. Isto é particularmente importante em aplicações que requerem a utilização de múltiplas ontologias a partir de diferentes domínios. Além disso, a ontologia pode ser usada para apoiar a capacidade de raciocinar sobre o impacto de eventuais mudanças do sistema.

- Consistência e ausência de ambiguidade: um papel importante que uma ontologia desempenha na comunicação é a de estabelecer definições inequívocas para os termos usados em um sistema de software. Quando a ontologia do usuário é diferente da ontologia da ferramenta, é necessário prover uma ambiente que possa representar os diferentes significados para os termos usados pelas pessoas.

- Integrar diferentes perspectivas de usuários: em um sistema com múltiplos agentes de comunicação, a integração através do entendimento compartilhado é fundamental. Neste caso, a ontologia pode ser utilizada para prover um modelo normativo do sistema, auxiliando os participantes da comunicação a chegarem a um acordo ou para desenvolver padrões dentro de uma comunidade, onde todos os participantes usam uma ontologia padronizada (ontologia compartilhada) para todos os objetos e relações em seus domínios.

- Interoperabilidade: Para dar suporte à interoperabilidade, as ontologias podem ser usadas para traduzir entre diferentes linguagens e representações. É vital que as ontologias e ferramentas usadas pelos diferentes agentes e organizações dentro de uma mesma empresa possam ser compartilháveis e reutilizáveis entre essas várias organizações.

- Engenharia de Sistemas: aqui consideramos o uso de ontologias que apoiam o projeto e o desenvolvimento de sistemas de software. Por exemplo: 
- Especificação: as ontologias podem auxiliar na especificação de sistemas de software de várias formas, dependendo da formalidade e automação dentro da metodologia de projeto de sistemas. Numa abordagem informal, as ontologias facilitam o processo de identificação dos requisitos do sistema e o entendimento das relações entre seus componentes. Em uma abordagem formal, uma ontologia fornece uma especificação declarativa do sistema de software.

- Confiabilidade: as ontologias podem melhorar a confiabilidade dos sistemas de software provendo a base para a verificação do projeto e do sistema de software com relação à sua especificação. Além disso, estas ontologias podem ser usadas para tornar explícitas as várias suposições feitas por diferentes componentes de um sistema de software, facilitando a sua integração.

- Reutilização: as ontologias também devem dar suporte à reutilização. As ontologias fornecem uma biblioteca de objetos de classes para modelagem de problemas e de domínios e, para serem úteis, estas ontologias devem ser personalizáveis, tanto para a classe de problemas quanto para a classe dos usuários, além de serem extensíveis.

Em nosso trabalho, estamos interessados no uso da interoperabilidade de ontologias, quando se trata de prestação de serviços; e no uso da comunicação, quando se trata da troca de informações entre as instituições e pessoas.

\subsubsection{Mundos Virtuais}

Algumas das definições sobre mundos virtuais que encontramos na literatura são:

- "Virtual Environments are imaginary spaces often manifested through a medium. Such spaces may exist solely in the mind of its originator or be broadcasted so that it is shared with others" [SC02].

- "Immersive Normative Virtual Environments are Virtual Environments, which provide participants with immersive experience and employ a set of rules to control the validity of their interactions" [Bog07].

- "Virtual Worlds are immersive imaginary spaces supporting sensory feedback, visualized through computer simulations and designed for their users to inhabit, collaborate and interact" [Bog07].

- "Avatars are one, two or three-dimensional graphical representations of humanoids" [SC02]. Através dos avatares, os habitantes dos mundos virtuais podem ver uns aos outros e colaborar entre si.

- Um dos tipos mais populares de mundos virtuais disponíveis hoje é a classe de mundos virtuais $3 \mathrm{D}$, onde o mundo que está sendo simulado pelo computador é similar ao mundo real, incluindo suas regras (gravidade, locomoção, ações em tempo-real, comunicação, etc.), mas normalmente são complementados com características não presentes no mundo real.

A imersão em mundos virtuais 3D é realizada através da representação dos usuários como avatares, que normalmente são modelos tridimensionais de humanoides que possuem um conjunto operacional de todas as partes do corpo.

\subsection{Governo Eletrônico}

Nesta seção apresentamos, inicialmente, o contexto histórico no qual está inserida a definição do Governo Eletrônico brasileiro. Em seguida, apresentamos as definições e diretrizes do governo brasileiro para o programa de Governo Eletrônico e introduzimos o conceito de Interoperabilidade, dentro do contexto de Governo Eletrônico. Por fim, apresentamos algumas iniciativas de Governo Eletrônico no Brasil e no mundo. 


\subsubsection{Contexto Histórico}

Em meados da década de 80, o Brasil passava por uma profunda mudança sócio política, onde a chamada Nova República deu aos cidadãos uma pequena amostra de transparência nos negócios públicos. Era o fim de um período de governos fechados e autárquicos. É claro que esta mudança passou ainda por diversas experiências de decisões puramente de gabinete, sem transparência e sem aderência aos interesses dos cidadãos (situação que ainda perdura na administração pública).

Neste período, o inimigo comum era a inflação, que corroía o poder de compra dos cidadãos e tirava a competitividade das empresas, deixando para segundo plano os problemas de relacionamento do Estado com seu cliente: o cidadão. Assim, ficavam mascaradas a ineficiência e a falta de padrões mínimos de relacionamento e intercâmbio de informações entre os órgãos públicos.

Muitas foram as iniciativas para acabar com a inflação, até que no início dos anos 90, o Plano Real, com uma mudança de postura, acabou com o fantasma inflacionário e possibilitou que se avançasse numa agenda mais produtiva. Com o fim da inflação, os níveis de percepção e exigência do cidadão, afloraram. Iniciativas como o Código do Consumidor, puderam se estabelecer e mostrar que o cidadão carecia e merecia um atendimento melhor de seus fornecedores - o que incluía o Governo.

A partir de 95, com o advento do uso comercial da Internet no Brasil, novas possibilidades surgiram. Imediatamente não foi notada pela grande parcela da população mas, já no início do novo milênio, se estabeleceu uma classe de cidadãos que deu um novo parâmetro para as empresas em busca de mercado: o internauta. O Governo demorou a perceber. Contudo, algumas iniciativas, como a implantação do Poupatempo em São Paulo, mostraram que era possível prestar um serviço integrado, prestativo e rápido. Por outro lado, a necessidade de otimizar a utilização dos recursos (humano e material) e a natural competição entre os grupos de poder (partidos políticos, grupos representativos da sociedade, sindicatos, representantes de classe) perceberam a necessidade de uma nova roupagem (os cidadãos estavam cobrando as promessas de campanha) e novos procedimentos na prestação dos serviços públicos.

Como consequência, muitas iniciativas foram criadas a fim de atender esta nova demanda. $\mathrm{O}$ Plano Diretor de Reforma do Aparelho do Estado foi criado em 95 ([d $\left.\mathrm{AOL}^{+} 10\right]$ ), orientou um novo modelo de gestão, descentralizado, flexível e com redução das estruturas do Estado. Diversos Decretos e normativas (entre 1994 e 2000) empreenderam esforços no sentido de regulamentar o uso de recursos de TICs. A criação de um grupo interministerial de TIC (Tecnologias de Informação e Comunicação) foi uma iniciativa pioneira de desenvolver estudos e diagnósticos, vislumbrando uma interação sistêmica e semeando o conceito de interoperabilidade. Criou-se então, o Cege (Comitê Executivo de Governo Eletrônico) lançando assim em 2000 uma proposta de Política de Governo Eletrônico. Assim, pode-se minimamente normatizar, por exemplo, o uso de assinatura eletrônica e certificação digital.

Em 2003, criou-se a arquitetura e-Ping (Padrões de Interoperabilidade em Governo Eletrônico), como consequência de um grupo de trabalho vinculado ao Cege. Este, possibilitou uma arquitetura de interoperabilidade com os padrões mínimos, premissas e especificações técnicas para a interação dos recursos sistêmicos em pauta no governo.

Assim, em 2004, é criado o Departamento de Governo Eletrônico, pelo Decreto n ${ }^{\circ}$ 5.134, de 07 de julho, encarregado de coordenar e articular a implantação de ações unificadas e integradas de governo eletrônico, as atividades relacionadas à prestação de serviços públicos por meios eletrônicos, além de normatizar e disseminar o desenvolvimento de ações e informações de governo eletrônico na administração federal.

Em 2005, foi lançado o Modelo de Acessibilidade de Governo Eletrônico (e-MAG), que reco- 
menda a acessibilidade nos portais e sítios eletrônicos da administração pública para o uso das pessoas com necessidades especiais, garantindo-lhes o pleno acesso aos conteúdos disponíveis. Em 2007, o e-MAG passa a ser institucionalizado e obrigatório no âmbito do Sistema de Administração dos Recursos de Informação e Informática (SISP), pela Portaria $\mathrm{n}^{0}$ 03, de 07 maio.

Em julho, foi publicado o Decreto $\mathrm{n}^{\circ} 5.450$ que regulou as compras governamentais, tornando obrigatório o uso do pregão nas compras de bens e serviços comuns na Administração Pública Federal e determinando que a forma eletrônica deve ser adotada preferencialmente.

Em 2006, surge o Portal de Inclusão Digital, com ações voltadas para as comunidades mais carentes, incluindo iniciativas governamentais.

Ainda neste ano, é realizada a primeira pesquisa de avaliação dos serviços de e-Gov considerando os parâmetros da Metodologia de Indicadores e Métricas de Serviços de Governo Eletrônico, buscando avaliar a qualidade dos serviços eletrônicos prestados pelos governos de todas as esferas.

Em dezembro, a Secretaria de Logística e Tecnologia da Informação (SLTI) disponibilizou o Avaliador e Simulador para a Acessibilidade de Sítios (ASES) - software de código livre para avaliar, simular e corrigir a acessibilidade de páginas, sítios e portais, resultado de uma parceria entre a SLTI e a OSCIP Acessibilidade Brasil.

No ano de 2008, os Padrões Brasil e-GOV surgem como recomendações de boas práticas agrupadas em formato de cartilhas, com o objetivo de aprimorar a comunicação e o fornecimento de informações e serviços prestados por meios eletrônicos pelos órgãos do Governo Federal.

Em 2010, a SLTI passa a recomendar que os órgãos públicos comprem computadores menos poluentes ao meio ambiente por meio da Instrução Normativa $n^{0} 01$ de 2010, seguindo os princípios da sustentabilidade.

\subsubsection{Conceituação e Diretrizes Brasileiras}

O desenvolvimento de programas de Governo Eletrônico tem como princípio a utilização das modernas tecnologias de informação e comunicação (TICs) para democratizar o acesso à informação, ampliar discussões e dinamizar a prestação de serviços públicos com foco na eficiência e efetividade das funções governamentais.

A política de Governo Eletrônico do Estado brasileiro segue um conjunto de diretrizes baseado em três ideias fundamentais: participação cidadã; melhoria do gerenciamento interno do Estado; e integração com parceiros e fornecedores. ([EB07])

O Programa de Governo Eletrônico brasileiro visa a transformação das relações do Governo com os cidadãos, empresas e também entre os órgãos do próprio governo de forma a aprimorar a qualidade dos serviços prestados; promover a interação com empresas e indústrias; e fortalecer a participação cidadã por meio do acesso a informação e a uma administração mais eficiente.

\subsubsection{Interoperabilidade no contexto do governo}

Nesta seção apresentamos a definição de Interoperabilidade, segundo alguns governos, que fundamentam o entendimento do governo brasileiro e identificam os conceitos que adotamos em nosso trabalho. Apresentamos também uma breve descrição do e-Ping (Padrões de Interoperabilidade de Governo Eletrônico) [dGE10].

Segundo [PB09], Interoperabilidade é um importante recurso que pode ser utilizado para melhorar a qualidade dos serviços governamentais. Entretanto, Pardo e Burke, defendem que: 
"Interoperabilidade, assim como tecnologia, não é um fim, mas sim um meio para atingir um fim. Os cidadãos não demandam interoperabilidade; entretanto, os sistemas precisam interoperar, na maioria dos casos, para que o governo entregue o que o cidadão demanda."' [PB09].

A Interoperabilidade, no contexto do governo eletrônico, pode ser realizada a partir da adoção de padrões e por meio de uma arquitetura, seja por um modelo de rede corporativa ou orientada a serviços (SOA), de forma que responda rápida e efetivamente às novas situações e requisitos de informações e serviços de governo [UND07].

A questão de Interoperabilidade dentro do contexto do governo, diz respeito a um conjunto de aspectos como a integração de sistemas, integração de redes, troca de dados entre sistemas, definição de tecnologias e padrões, levando em conta a existência de um legado de sistemas e plataformas de hardware e software instalados.

Segundo [EB07], os quatro conceitos que fundamentaram o entendimento do governo brasileiro a respeito de Interoperabilidade são:

- Governo do Reino Unido:

Intercâmbio coerente de informações e serviços entre sistemas. Deve possibilitar a substituição de qualquer componente ou produto usado nos pontos de interligação por outro de especificação similar, sem comprometimento das funcionalidades do sistema.

- Governo da Austrália:

Habilidade de transferir e utilizar informações de maneira uniforme e eficiente entre várias organizações e sistemas de informação.

- ISO:

Habilidade de dois ou mais sistemas (computadores, meios de comunicação, redes, software e outros componentes de tecnologia da informação) de interagir e de intercambiar dados de acordo com um método definido, de forma a obter os resultados esperados.

- Lichun Wang, Instituto Europeu de Informática - CORBA Workshops:

Interoperabilidade define se dois componentes de um sistema, desenvolvidos com ferramentas diferentes, de fornecedores diferentes, podem ou não atuar em conjunto.

Como iniciativa de interoperabilidade, o governo brasileiro vem consolidando a arquitetura ePING - Padrões de Interoperabilidade de Governo Eletrônico, que tem como propósito ser o paradigma para o estabelecimento de políticas e especificações técnicas que permitam a prestação de serviços eletrônicos de qualidade à sociedade." [dGE10]

Em nosso trabalho, consideramos a arquitetura e-Ping na aplicação do Modelo para Interoperabilidade entre Instituições Heterogêneas direcionados ao governo.

\subsubsection{Iniciativas do Governo Brasileiro}

Nesta seção, citamos quatro iniciativas do Governo Brasileiro que são relevantes para nosso trabalho:

\section{- e-Ping(Padrões de Interoperabilidade de Governo Eletrônico)}

"A arquitetura e-PING - Padrões de Interoperabilidade de Governo Eletrônico - define um conjunto mínimo de premissas, políticas e especificações técnicas que regulamentam a utilização da Tecnologia de Informação e Comunicação (TIC) no governo federal, estabelecendo 
as condições de interação com os demais Poderes e esferas de governo e com a sociedade em geral." [dInB],

As áreas cobertas pela e-PING, estão segmentadas em Interconexão, Segurança, Meios de Acesso, Organização e Intercâmbio de Informações e áreas de Integração para Governo Eletrônico.

A arquitetura e-PING cobre o intercâmbio de informações entre os sistemas do governo federal - Poder Executivo e as interações com cidadãos, as esferas de governo estadual e municipal, os poderes Legislativo, Judiciário e Ministério Público Federal, governos de outros países, Empresas (no Brasil e no mundo) e com o Terceiro Setor.

A e-PING possui foco na Interoperabilidade e trata apenas especificações que são relevantes para garantir a interconectividade de sistemas, integração de dados, acesso a serviço de governo eletrônico e gerenciamento de conteúdo.

A arquitetura e-PING preconiza a adoção do XML e o desenvolvimento de XML Schema como fundamentos para a integração e interoperabilidade eletrônica do governo. Um elemento chave no desenvolvimento de XML Schema é um conjunto de padrões de dados que será usado nos esquemas e em outros processos de intercâmbio de dados.

Os protocolos FTP e/ou HTTP devem ser utilizados para transferência de arquivos, observando suas funcionalidades para recuperação de interrupções e segurança, quando necessário. O protocolo HTTP deve ser priorizado para transferências de arquivos originários de páginas de sítios da Internet. A e-PING enfatiza o uso da tecnologia de Web Services para propiciar a interoperabilidade entre sistemas heterogêneos o que implica também na busca por uma arquitetura de software mais alinhada aos conceitos de serviços em ambientes distribuídos. Nesse contexto, a Arquitetura Orientada a Serviços (SOA - Service-Oriented Architecture) oferece diversas vantagens à aderência aos padrões tecnológicos propostos pela e-PING. [MdP10]. A utilização do protocolo Simple Object Access Protocol (SOAP) é recomendada para interconexão em arquiteturas descentralizadas e/ou distribuídas para implementação de serviços em sistemas de qualquer porte.

\section{- Carta de Serviços ao Cidadão}

A Carta de Serviços é um documento elaborado por uma organização pública que visa informar aos cidadãos quais os serviços prestados por ela, como acessar e obter esses serviços e quais são os compromissos com o atendimento e os padrões de atendimento estabelecidos. [MdP08]

A sua prática implica para a organização um processo de transformação sustentada em princípios fundamentais - participação e comprometimento, informação e transparência, aprendizagem e participação do cidadão. Esses princípios têm como premissas o foco no cidadão e a indução do controle social.

A Carta de Serviços tem por finalidade melhorar a relação da Administração Pública com os cidadãos, divulgar os serviços prestados pelas organizações públicas com os seus compromissos de atendimento para que sejam amplamente conhecidos pela sociedade, fortalecer a confiança e a credibilidade da sociedade na administração pública quando esta percebe uma melhora contínua em sua eficiência e eficácia e garantir o direito do cidadão para receber serviços em conformidade com as suas necessidades.

\section{- e-poupatempo}

O e-poupatempo é uma iniciativa da Superintendência do Poupatempo para levar o Padrão de Atendimento dos serviços presenciais ao meio eletrônico. [e-p]

O e-poupatempo desenvolve vários trabalhos a fim de conhecer o perfil dos usuários dos serviços públicos na Internet e, ainda, atua como um observatório da execução destes serviços, através das salas de atendimento ao cidadão. Estas observações fornecem subsídios aos diversos órgãos e entidades do Governo do Estado de São Paulo, para que o atendimento eletrônico prestado ao cidadão seja constantemente aprimorado. 


\section{- Cidadão.SP}

O Cidadão.SP é um portal que dá acesso a inúmeros serviços e informações do Governo do Estado de São Paulo disponíveis na Internet. [cid] O Portal Cidadão.SP integra todos os sites de órgão do governo que oferecem serviços e informações através da Internet, evitando que o cidadão precise decorar as siglas e nomes de órgãos para encontrar os serviços que procura. O portal Cidadão.SP foi feito para facilitar a vida do usuário e para isso organiza as informações de maneira simples e intuitiva oferecendo alternativas para que o cidadão encontre o que procura.

"Para que o usuário encontre o que procura de maneira fácil o conteúdo do Cidadão.SP é classificado conforme a ideia da "linha da vida", isto é, os assuntos relacionados a certos eventos da vida do cidadão estão todos juntos independente do órgão que presta aquele serviço ou aquela informação. Assim, se o usuário quiser informações sobre emprego ele encontrará todas as informações e serviços do Governo do Estado sobre o assunto disponíveis na Internet reunidos no mesmo tópico, no caso "Trabalho e Desemprego"." [cid]

\subsubsection{Iniciativas de Governo Eletrônico no Mundo}

Nesta seção apresentamos as iniciativas de Governo Eletrônico em alguns países do mundo.

\section{- Chile}

Um dos principais exemplos em governo eletrônico na América Latina é o do Chile. O site oficial do governo chileno [chib] disponibiliza uma série de serviços ao cidadão, como emissão de documentos, fornecimento de mapas e cartografia, acompanhamento de processos, entre outros serviços. Segundo a Controladoria-Geral da União, em sua página de notícias [not], o Chile é o primeiro país da América Latina em governo eletrônico no que tange ao uso de ferramentas sistêmicas para o combate à corrupção. Situa-se entre os principais países no mundo pelo critério de transparência administrativa, oferecendo uma grande quantidade de informações acerca de atos e programas de governo. Durante o Foro Ibero-americano de Governo Eletrônico, Ernesto Evans, Secretário Executivo do Programa Estratégia Digital do Chile, anunciou novo portal do governo chileno (Chile Clic) [chia], que consiste de uma página de entrada que organiza de uma maneira simples, na forma de um guia, mais de 1.500 serviços prestados por 138 órgãos públicos. Desses, quase 400 serviços estão disponíveis online.

\section{- Argentina}

O governo argentino disponibiliza poucos serviços ao cidadão. Em seu site oficial, somente algumas páginas são destinadas à informação de procedimentos (pré requisitos, documentação necessária, endereços e legislação básica) para a obtenção de documentos (passaporte, identidade, carteira de trabalho e outros). Contudo, os processos ainda são realizados fisicamente, em balcões públicos.

Alguns serviços referenciados on-line são:

- Emissão de passaporte: possui uma página inicial de esclarecimento ao cidadão dos prérequisitos, documentos, trâmites, valores e prazos para a obtenção de um passaporte;

- Emissão, atualização e duplicação de documento de identidade;

- Emissão de carteira de trabalho (Código Único de Identificación Laboral - CUIL.

\section{- Canadá}

Segundo a empresa Accenture, em pesquisa realizada entre 8 e 19 de Janeiro de 2001, que avaliou a oferta de 165 serviços governamentais online em 22 países, o Canadá é o primeiro da lista, seguido de Cingapura e USA. O Brasil ficou em $18,{ }^{\circ}$ lugar. Nesta pesquisa, destacam-se alguns portais: Província de BritishColombia [bri], considerado o melhor site de província; 
Província de PrinceEdward Island [pri], que integra municípios, província e governo federal e Ministério da Saúde [min], que integra informações de cerca de 500 organizações. O documento intitulado "Construindo a Sociedade da Informação: Movendo o Canadá em Direção ao Século XXI" [oSC96], apresenta as políticas e iniciativas a serem adotadas para facilitar a transição rumo a uma sociedade da informação e a uma economia do conhecimento. Desta forma, são definidas as quatro bases das ações implementadas a partir de então:

1. Desenvolvimento de uma super via da informação.

2. Promoção e incremento do conteúdo canadense.

3. Obtenção de benefícios econômicos e sociais para todos os canadenses.

4. Governo acessível, responsivo e com melhor qualidade nos serviços públicos.

\section{- Reino Unido}

Os vinte mais altos rankings em desenvolvimento de e-Gov no mundo pertencem aos países com alta renda per capita, e este ano quem recebeu as melhores pontuações na pesquisa foram respectivamente, a Coreia do Sul (em primeiro lugar), seguida dos governos eletrônicos dos EUA, Canadá, Reino Unido e Holanda. Segundo mesmo ranking, o Brasil está em 61o. lugar no mundo.

Segundo o portal do Instituto de Governo Eletrônico [ins]:

"Entrega de e-Serviços mais avançados aos cidadãos, melhor acesso à informação e o aperfeiçoamento da interação entre sociedade e governos estão entre as tendências apontadas no United Nations E-Government Survey 2010 como os maiores investimentos dos governos eletrônicos no mundo atualmente."

"...Como em anos anteriores, os vinte mais altos rankings em desenvolvimento de e-Gov no mundo pertencem aos países com alta renda per capita, e este ano quem recebeu as melhores pontuações na pesquisa foram respectivamente, a Coreia do Sul (em primeiro lugar), seguida dos governos eletrônicos dos EUA, Canadá, Reino Unido e Holanda." Segundo mesmo ranking, o Brasil está em 61o. lugar no mundo.

O Livro Branco da Modernização do Governo britânico foi publicado em março de 1999 e ressalta as características de uma nova realidade em que o governo deve ser capaz de adaptarse continuamente a reestruturações sociais, políticas e econômicas, aos impactos das TIC, a buscar novas formas de inter-relação com os cidadãos e com o mercado e a promover a aprendizagem contínua de seus servidores. Assim, este documento apresenta um programa de mudanças em que a modernização do serviço público, orientada para o atendimento ao cidadão e a resultados, é peça fundamental na melhoria na forma como o governo:

a) elabora as suas políticas;

b) provê serviços de interesse da sociedade;

c) avalia a qualidade dos serviços prestados;

d) utiliza as novas tecnologias e

e) valoriza o serviço público.

Destes cinco pressupostos surgiu a recomendação de que fosse desenvolvida uma estratégia de utilização das TIC que resultou em documento intitulado "Governo Eletrônico - Uma estrutura estratégica para os serviços públicos na era da informação", publicado em abril de 2000.

\section{- Cingapura}

Conforme relatório da consultoria Accenture, intitulado Liderança em Governo Eletrônico, 14 entre 22 governos que buscam o aperfeiçoamento das suas soluções de governo eletrônico, 
Cingapura ocupa o segundo lugar (logo abaixo do Canadá) em uma categoria que é classificada como "maturidade em e-gov" - um conceito que engloba definições como tipo, nível e modo com que os serviços de divulgação de informações, de interação e de transações eletrônicas são prestados por estes mesmos governos.

Após pesados investimentos em TIC nas esferas governamentais, o Governo de Cingapura criou o Infocomm Development Authority of Singapore - IDA. Como principais ações do primeiro grupo de trabalho criado pela IDA, o grupo de planejamento de sistemas governamentais (GSG) temos:

a) a criação do portal do governo de Cingapura (em 1995);

b) o desenvolvimento de um centro virtual de prestação de serviços aos cidadãos (o e-Citizen Centre), sendo que este último está organizado, não pelas estruturas de governo, mas por eventos da vida; e

c) a criação de um portal de vendas eletrônico (Government Shopfront) para todas as publicações e vídeos do Ministério do Desenvolvimento da Comunidade, além de todas as publicações do Ministério de Estatísticas. Diversos serviços voltados para o desenvolvimento humanos (servidores públicos, cidadãos, profissionais de educação, etc) foram implementados, além de vários outros portais de serviços públicos.

\subsubsection{Interação com os Cidadãos}

O conceito de governo focado no cidadão foi o tema central de programas de governo eletrônico de vários países, como Canadá, Estados Unidos, Inglaterra e Austrália [PG04], em que o cidadão torna-se o centro da dinâmica dos processos do governo.

Nesses casos, o uso das TICs promoveram impactos significativos na eficiência do setor público e no relacionamento do governo com a sociedade [dInB10].

Segundo [dInB10], "Primeiramente, as aplicações do e-Gov têm que ser simples, intuitivas, e até mesmo lúdicas, a fim de favorecerem aqueles com pouca familiaridade do uso da Internet. Nesse sentido, um parâmetro de aplicação amplamente disseminado e que cresce ano após ano são as aplicações voltadas às redes sociais, especialmente os sites de relacionamento, pois proporcionam um uso amplamente inclusivo, tanto para as camadas desfavorecidas da população, quanto para pessoas com níveis de escolaridade inferiores, além de incluírem indivíduos nos extremos do espectro etário (crianças e idosos)."

Alguns dados interessantes sobre uso da Internet e de Governo Eletrônico no Brasil podem ser extraídos de pesquisas realizadas por órgãos ligados à área. A seguir, apresentamos alguns destes dados, segundo a pesquisa [dEsaTdIedCC09] realizada pelo Centro de Estudos sobre as Tecnologias da Informação e da Comunicação (CETIC.br), que é o departamento do NIC.br responsável pela coordenação e publicação de pesquisas sobre a disponibilidade e uso da Internet no Brasil. Esses estudos são referência para a elaboração de políticas públicas que garantam o acesso da população às Tecnologias da Informação e da Comunicação (TICs), assim como para monitorar e avaliar o impacto socioeconômico das TICs.

- "O estudo apontou crescimento significativo no percentual de acessos à Internet nos domicílios em comparação aos centros públicos pagos, conhecidos popularmente como lanhouses. Pela primeira vez desde 2007 o acesso residencial, com $48 \%$ das menções, ficou à frente das lanhouses, citadas por 45\%dos respondentes. Apesar do menor número no total Brasil, o papel desempenhado pelos centros de acesso, tanto pagos como gratuitos, continua sendo de extrema importância para a inclusão digital, principalmente na área rural", diz Alexandre Barbosa, gerente do CETIC.br."

- "Quanto ao uso do Governo Eletrônico, considerando a área urbana, 30\% dos indivíduos que acessam a Internet fizeram uso das ferramentas de e-Gov, comparado com $25 \%$ no ano anterior. Entre 2005 e 2009, o uso do governo eletrônico mais que dobrou nessas áreas. Entretanto, em 


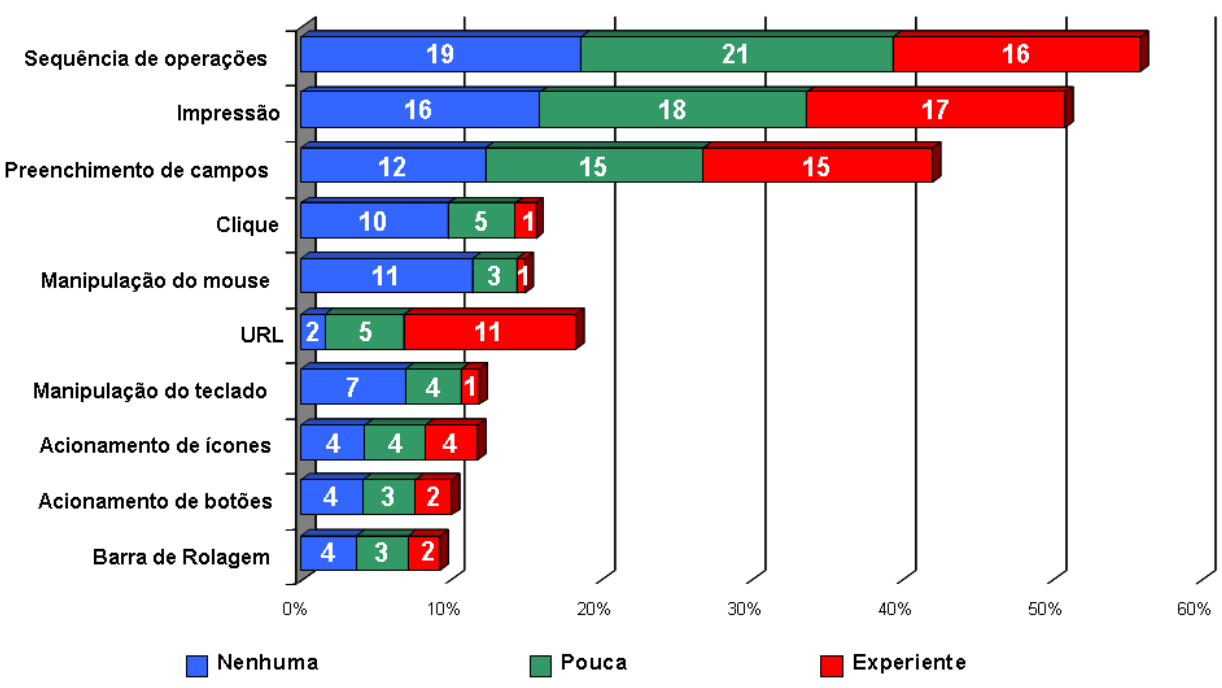

Figura 2.5: Perfil do Cidadão - Dificuldade de uso X Experiência de uso

comparação com a zona rural, onde somente $10 \%$ da população usuária de Internet fez uso dos serviços de governo eletrônico nos últimos 12 meses, a diferença é expressiva. A proporção de uso mostra que para cada usuário de e-Gov no campo existem três na cidade."

- Quanto às barreiras encontradas pelos internautas, com relação ao Governo Eletrônico, "mais da metade (56\%) dos internautas não-usuários de governo eletrônico afirma preferir fazer as consultas/contato pessoalmente; dado que pode estar associado à dificuldade para navegação nos sites do governo e à própria complexidade inerente de alguns processos disponibilizados para a população: $12 \%$ afirmam ser uma barreira a complicação na hora de usar a Internet para entrar em contato com a administração pública, outros $9 \%$ declararam que os serviços dos quais necessitavam não estavam disponíveis na Internet; por fim, $8 \%$ afirmam que os serviços desejados eram difíceis de serem encontrados nos sites de governo."

O e-poupatempo também gera relatórios sobre perfil dos cidadãos observados em suas salas de atendimento. O gráfico da Figura 2.5 foi obtido pelo e-poupatempo, identificando as dificuldades no uso dos serviços públicos, considerando também a experiência do cidadão no uso da Internet:

Um dos objetivos do nosso trabalho é facilitar o uso dos serviços governamentais pelos cidadãos, provendo uma forma de acesso a estes serviços, que seja simples, direta e envolvente. No Capítulo 3 , apresentamos nossa proposta de solução para esta questão.

\subsection{Trabalhos Relacionados}

Nesta seção, citamos alguns trabalhos relacionados ao nosso projeto, apresentando uma breve descrição de cada trabalho.

\subsubsection{Instituições Eletrônicas e Instituições Virtuais}

Instituições Virtuais são mundos virtuais 3D com regulação normativa das interações [Bog07]. Este conceito surgiu como uma combinação de Instituições Eletrônicas [Est03] e mundos virtuais 3D. Neste contexto, as Instituições Eletrônicos são usadas para especificar as regras que regulam os comportamentos dos participantes, enquanto que os mundos virtuais 3D são utilizados para facilitar a participação humana na instituição. 
O projeto de Instituições Virtuais é dividido em duas tarefas: 1) especificação das regras da instituição e 2) geração do mundo virtual.

As regras da Instituição Virtual são definidas utilizando o modelo de Instituição Eletrônica, que é composto pelos seguintes componentes:

- Framework Dialógico: Define uma ontologia e uma linguagem comum, para permitir que humanos, com diferentes níveis culturais, possam interagir. O mesmo se aplica aos agentes. Tanto esta ontologia, quanto a linguagem para os humanos, serão transformadas em possíveis ações que podem ser executadas no mundo virtual. Estas ações estão conectadas a modelos 3D do ambiente, o que irá auxiliar a eliminar a barreira cultural. Esta conversão da linguagem de comunicação em ações e vice-versa, permitirá que os agentes possam interagir com os humanos e entender suas ações. Este framework também define quais papéis os participantes podem assumir e quais são os relacionamentos entre eles.

- Cena: As interações entre agentes são articuladas através de encontros de grupos de agentes (cenas), com um protocolo de comunicação bem definido. O protocolo de uma cena é a especificação dos possíveis diálogos que os agentes podem ter. O protocolo de comunicação que define as possíveis interações dentro de uma cena é baseado em papéis e não em agentes.

- Estrutura Performativa: As cenas podem ser conectadas, compondo uma rede de cenas chamada estrutura performativa. A especificação de uma estrutura performativa contém a descrição de como os agentes podem mover de cena para cena, de acordo com os papéis que cada agente pode desempenhar. Os agentes podem participar de diferentes cenas, com diferentes papéis e ao mesmo tempo.

- Normas: As normas determinam as consequências das ações dos usuários. Estas consequências são modeladas como compromissos que cada participante assume, como consequência de suas ações e devem ser satisfeitos futuramente. Estes compromissos podem restringir futuras atividades dos usuários.

O mundo virtual é gerado no momento em que as regras institucionais estão especificadas. Isso é feito automaticamente de acordo com as atividades que podem ser realizadas, definidas na especificação. Especificamente, uma sala 3D é representada para cada atividade (cena). Como resultado, um mapeamento é criado entre as atividades definidas na especificação e onde estas atividades ocorrem dentro do mundo virtual. Adicionalmente, as mensagens especificadas nos protocolos da cena são mapeados em ações suportadas pelo mundo virtual. A especificação das regras institucionais pode ser considerada como sequências válidas de ações. Os atributos associados aos diferentes papéis e atividades ajudam a manter o estado dos participantes ou atividades. Eles mantém informação das ações anteriores que são relevantes para determinar a validade das ações futuras.

As Instituições Virtuais são implantadas por uma infraestrutura de 3 camadas, conforme apresentado na Figura 2.6, encontrada em [Bog07].

A primeira camada é a camada de Instituição Eletrônica. Esta camada utiliza o sistema AMELI $\left[\mathrm{AEN}^{+} 05\right]$ para executar as regras institucionais estabelecidas no passo de especificação. AMELI mantém o estado de execução da instituição e o utiliza juntamente com a especificação, para garantir que as ações dos participantes não violem nenhuma restrição institucional.

A segunda camada é a camada de comunicação, cuja tarefa é conectar causalmente [MN88] a infraestrutura institucional com o sistema de visualização, transformando as ações do sistema de visualização em mensagens, que podem ser compreendidas pela infraestrutura institucional e vice-versa. Esta conexão causal é realizada através do servidor de conexão causal utilizando o mapeamento entre as mensagens institucionais e as ações do mundo virtual. A conexão causal acontece da seguinte forma: uma ação executada no mundo virtual 3D (e verificada pela instituição) resulta em uma mudança no estado da instituição na camada AMELI. De forma similar, toda mudança no estado institucional reflete no mundo virtual 3D e altera seu estado. A camada de 


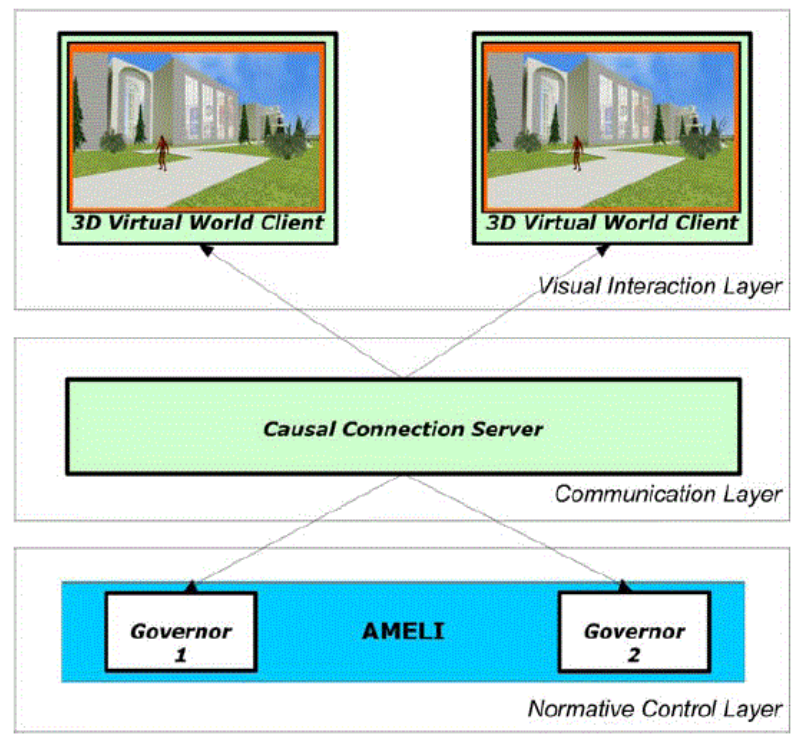

Figura 2.6: Arquitetura de Execução [Bog07]

comunicação conecta conceitualmente e tecnologicamente duas metáforas: Instituições Eletrônicas e Mundos Virtuais. E esta é a grande contribuição das Instituições Virtuais.

A terceira camada é a camada de visualização, utilizada para visualizar mundos virtuais 3D para os usuários.

\subsubsection{OpenKnowledge}

OpenKnowledge é um sistema que permite pares, em uma grande rede ponto-a-ponto arbitrária, a interagirem produtivamente entre si, sem nenhum acordo global ou conhecimento, anterior à execução, sobre com quem interagir ou como as interações irão proceder. Qualquer tipo de serviço pode se tornar um par ou prover facilidades para que os usuários possam facilmente criar seu próprio par, compartilhando código ou escrevendo seu próprio código. [Pro]

Os serviços que já existem podem ser traduzidos dentro dos pares OpenKnowledge e podem utiliza-se de toda a funcionalidade do sistema. O processo de tradução de serviços WSDL já existe no sistema e novos processos podem ser criados para outros tipos de serviços. Isso é possível através do uso de protocolos de interação que são compartilhados e podem ser escritos por qualquer usuário do sistema e, depois, reutilizados por qualquer par na rede. Estes protocolos descrevem interações entre dois ou mais pares, e detalham as mensagens que serão enviadas como parte desta interação, bem como as restrições destas mensagens, que fornecem informações sobre a semântica das mensagens e sobre quais circunstâncias as mensagens podem ser enviadas. Um par pode desempenhar um papel em qualquer um destes protocolos, desde que ele possa satisfazer todas as restrições.

Neste modelo de interação, o acordo semântico pode ser realizado localmente. A não existência de uma ontologia global, significa que os pares podem utilizar diferentes termos que não combinam, mas a interpretação destes termos precisa ser feita somente na interação e apenas para os termos que afetam diretamente esta interação. Assim, o problema da heterogeneidade semântica fica restrito ao contexto da interação, o que ajuda no processo de interpretação.

Os protocolos compartilhados que descrevem as interações são chamados Modelos de Interação e são escritos em Lightweight Coordination Calculus (LCC) [Rob04]. Os Modelos de Interação em LCC são especificações declarativas e executáveis, que podem ser entendidas independentemente por qualquer par ou modelo de execução Entretanto, podem existir detalhes à interação que não podem ser escritos em LCC. Nestes casos, arquivos de anotação são escritos para os Modelos de Interação. Desta forma, OpenKnowledge permite que as pessoas compartilhem interações e, através destas, compartilhem conhecimento. 


\subsubsection{Lightweight Coordination Calculus (LCC)}

Lightweight Coordination Calculus (LCC) [Rob04] é um process calculus para especificar normas sociais e foi projetado para expressar interações ponto-a-ponto em sistemas multiagentes [WR02]. LCC também permite poderosos mecanismos de análise, simulação e implantação de sistema interativos e pode ser utilizado para especificar, verificar e executar protocolos de interação.

A especificação de protocolos de interação utiliza-se da sintaxe formal do LCC para construir modelos de interação, os quais podem ser vistos como templates que, uma vez "preenchidos" pelos agentes, processos e valores de parâmetros apropriados, podem ser executados como scripts de ações. Os modelos de interação podem ser formalmente verificados, garantindo a satisfação de propriedades desejadas.

\subsubsection{Google Art Project}

O Google Art Project [goo] é um site mantido pelo Google em colaboração com museus espalhados por diversos países que disponibiliza visitas virtuais ao interior dos maiores museus e galerias de arte, proporcionando ao visitante, uma nova experiência na forma de observar uma obra de arte online.

O Google Art Project também disponibiliza imagens em alta resolução de obras selecionadas de cada museu, utilizando a tecnologia Gigapixel. Assim, ao passear pelas galerias, o visitante pode selecionar estas obras e visualizá-la mais detalhadamente.

O serviço entrou no ar em 1 de fevereiro de 2011, com os acervos do Alte Nationalgalerie e Gemäldegalerie, em Berlim; Freer Gallery of Art, em Washington; The Frick Collection, The Metropolitan Museum of Art e MoMA, em Nova York; Uffizi, em Florença; National Gallery e Tate Britain, em Londres; Museu Reina Sofia e Museu Thyssen, em Madri; Palácio de Versalhes, na França; Museu Kampa, em Praga; Museu Van Gogh e Rijksmuseum, em Amsterdã; Museu Estatal Hermitage, em São Petersburgo; e a Galeria Estatal Tretyakov, em Moscou [Reu].

Em 3 de abril de 2012 foi lançada a segunda fase do projeto, com o número de acervos digitalizados passando de 17 para 151. No Brasil, a Pinacoteca do Estado de São Paulo e o MAM-SP (Museu de Arte Moderna de São Paulo) fazem parte do projeto [dSP].

Para fotografar o interior dos museus, utiliza-se um veículo pequeno (trolley) com câmeras que captam as imagens em $360^{\circ}$. Esta sequencia de imagens criam a visita virtual. Os usuários podem navegar pelos ambientes onde estão expostas as obras como se estivessem fisicamente presentes naquele ambiente.

\subsubsection{Considerações}

Os três primeiros trabalhos anteriormente citados estão bem centrados na questão da interoperabilidade entre as partes envolvidas.

A Instituição Virtual considera ainda a questão da interface na interação com o usuário e o OpenKnowledge considera também uma interação entre diferentes ontologias, mas não define uma ontologia global e sim uma interpretação dos termos que afetam a interação entre as partes. O LCC, por sua vez, possui mecanismos para verificação formal dos modelos de interação.

Entretanto, estas propostas não abordam as questões iniciais que garantem a interoperabilidade como, por exemplo, o propósito da interação e o entendimento comum das informações trocadas durante esta interação. Neste sentido, nosso modelo trata a interoperabilidade de forma mais ampla, identificando as etapas que devem ser verificadas antes da realização da interoperabilidade, como será apresentado no Capítulo 3

Por outro lado, a relação do Google Art Project com nosso projeto está na funcionalidade de visualização de museus e exposições. O Google Art Project proporciona uma experiência agradável para o usuário que pode "visitar" os museus de qualquer lugar do mundo. Entretanto, a questão de interoperabilidade não é considerada neste projeto. 


\subsection{Resumo}

Neste capítulo apresentamos os principais conceitos relacionados à nossa proposta e alguns trabalhos relacionados à nossa pesquisa. No próximo capítulo apresentamos o Modelo para Interoperabilidade entre Instituições Heterogêneas (MIIH), que definimos neste trabalho; uma metodologia para auxiliar na sua utilização e algumas métricas de avaliação para este modelo. Durante a descrição do MIIH apresentamos como os conceitos acima citados são aplicados em nosso modelo. 


\section{Capítulo 3}

\section{Modelo para Interoperabilidade entre Instituições Heterogêneas}

A necessidade de interação entre instituições heterogêneas tem sido cada vez mais necessária para obter e disponibilizar informações e serviços para seus usuários internos e externos. Esta interação tem sido sustentada principalmente pelo uso das novas tecnologias da informação e comunicação.

A interoperabilidade entre instituições heterogêneas garante esta interação e proporciona vários benefícios como, por exemplo, utilizar toda a plataforma legada das instituições e ainda permitir a interação entre os sistemas. Entretanto, para que esta interoperabilidade seja possível é necessária a definição de conceitos comuns que padronizam e orientam as interações entre as instituições. Através destes conceitos comuns, as instituições podem trocar informações entre si e ainda manter sua independência e as particularidades em seus sistemas internos.

É fundamental também definir os fluxos de trabalho (workflows) dentro de cada instituição (ou setor da instituição) e integrar estes workflows, de forma a garantir a colaboração entre as instituições. Para tanto, devemos considerar o fato de que as instituições possuem workflows muito diferentes e, portanto, é fundamental o uso de tecnologias que possibilitem a interação entre estes workflows (cross-organizational workflows), garantindo assim a realização conjunta de tarefas entre estas instituições. Estas interações devem ser realizadas de forma flexível e confiável e devem garantir que cada organização tenha controle sobre seus processos.

Em nosso trabalho, propomos um Modelo para Interoperabilidade entre Instituições Heterogêneas (MIIH), para que estas instituições possam interagir satisfazendo as considerações acima citadas. A especificação das regras de interação e, especificamente, os protocolos de interoperabilidade entre as instituições são escritas usando JamSession que, como descrito no capítulo anterior, é uma plataforma para a coordenação de serviços de software heterogêneos e distribuídos. Utilizamos JamSession também como uma ferramenta para integração de cross-organisational workflows, com a característica de ser formalmente verificável, fácil de usar e suficientemente flexível para prover um ambiente para a especificação e execução de padrões de integração que garantem a correta separação de interesses e responsabilidades entre as instituições envolvidas.

O MIIH também define uma arquitetura baseada em Artefatos do Conhecimento Interoperáveis para lidar com as conexões com os sistemas das instituições. Estes Artefatos do Conhecimento Interoperáveis são baseados no conceito geral de Artefatos do Conhecimento, ou seja, "objetos que contêm e transmitem uma representação utilizável do conhecimento". Os Artefatos do Conhecimento Interoperáveis são padrões arquitetônicos recorrentes que são observados no projeto de mecanismos de interoperabilidade para conectar instituições heterogêneas e são usados como uma descrição de alto nível da arquitetura para um projeto de sistema. Eles funcionam como padrões arquiteturais pré-concebidos que norteiam e padronizam as interações e, portanto, a interoperabilidade organizacional e semântica entre as instituições. Os Artefatos do Conhecimento Interoperáveis são fundamentados sobre uma ontologia de conceitos relevantes para serviços destas instituições, cujo nível de abstração pode variar, dependendo do nível de integração necessário para as instituições quanto mais sofisticada a interação, mais detalhes devem ser representados explicitamente na on- 
tologia. Os Artefatos do Conhecimento Interoperáveis implementados também se comunicam com a camada de interação com o usuário, baseada em mundos virtuais, para garantir a comunicação adequada com estes usuários. Na seção 3.1 os Artefatos do Conhecimento Interoperáveis são definidos no contexto do MIIH.

Acreditamos que, independentemente do nível de conhecimento dos usuários, os mundos virtuais proporcionam uma interface simples para interação e facilitam o processo de aprendizado para a utilização dos sistemas oferecidos pelas instituições através do MIIH.

Do lado das instituições virtuais, os requisitos institucionais, bem como os requisitos de sistema, são questões importantes a serem abordadas antes de efetivamente prover qualquer serviço/interação. Para satisfazer a estes requisitos, propomos também a adoção da plataforma JamSession, atuando como um coordenador expressivo de recursos heterogêneos.

Para garantir a correta execução do sistema, os serviços oferecidos, o fluxo da informação e os requisitos de interoperabilidade das instituições são formalmente descritos utilizando a plataforma JamSession.

Conforme citado anteriormente, as instituições aqui consideradas interagem através do uso de TICs, seguindo o modelo que definimos. Então, podemos definir que estas instituições possuem uma presença virtual. Em nosso trabalho, usamos o conceito de Instituição Virtual, conforme definido em [Bog07] e apresentado na seção 2.3. Assumimos também a separação proposta em [Bog07], para o desenvolvimento dos mundos virtuais baseados neste conceito, em duas fases independentes: especificação das regras de interação e projeto do ambiente de interação. Entretanto, relaxamos a exigência do mundo virtual $3 \mathrm{D}$ e permitimos mundos virtuais $2 \mathrm{D}$, quando necessário. Isso permite uma rápida portabilidade para novas plataformas de visualização e diferentes tipos de renderização. A especificação das regras de interação e, especificamente os protocolos de interoperabilidade são escritos na plataforma JamSession.

O Modelo para Interoperabilidade entre Instituições Heterogêneas assume uma arquitetura distribuída, consistindo de uma rede interconectada de mundos virtuais, onde cada nó é um representante de uma instituição virtual (IV) ou um departamento da mesma. Os usuários interagem com as instituições através de mundos virtuais e as instituições virtuais trocam informações baseadas nos protocolos de interação implementados utilizando a plataforma JamSession.

\subsection{Artefatos do Conhecimento Interoperáveis para o MIIH}

Retomamos o conceito de que um artefato é caracterizado por uma tripla $(I ; R ; P)$, onde:

- I é uma invenção ou ideia que descreve o artefato em um nível abstrato;

- $R$ é o artefato real usado para o propósito $P$;

- $P$ é o propósito que gerou o projeto de $I$ e a implementação de $R$, que pode ser diferente do propósito do usuário do artefato.

No contexto do Modelo para Interoperabilidade entre Instituições Heterogêneas definimos esta tupla da seguinte forma:

- I é um conceito compartilhado, a respeito do qual as instituições têm o mesmo entendimento e podem interoperar;

- $R$ é um conjunto definido por:

- Sistema Baseado em Conhecimento,

- Semântica Compartilhada,

- Ontologia Compartilhada, 
- Ontologias Particulares,

- Workflows Particulares,

- Workflow de Interoperabilidade,

- Mediador para que a interoperabilidade aconteça (definido fazendo uso da plataforma JamSession).

- $P$ é a própria interoperabilidade entre as instituições.

A Figura 3.1 abaixo ilustra esta definição de Artefato do Conhecimento Interoperável.

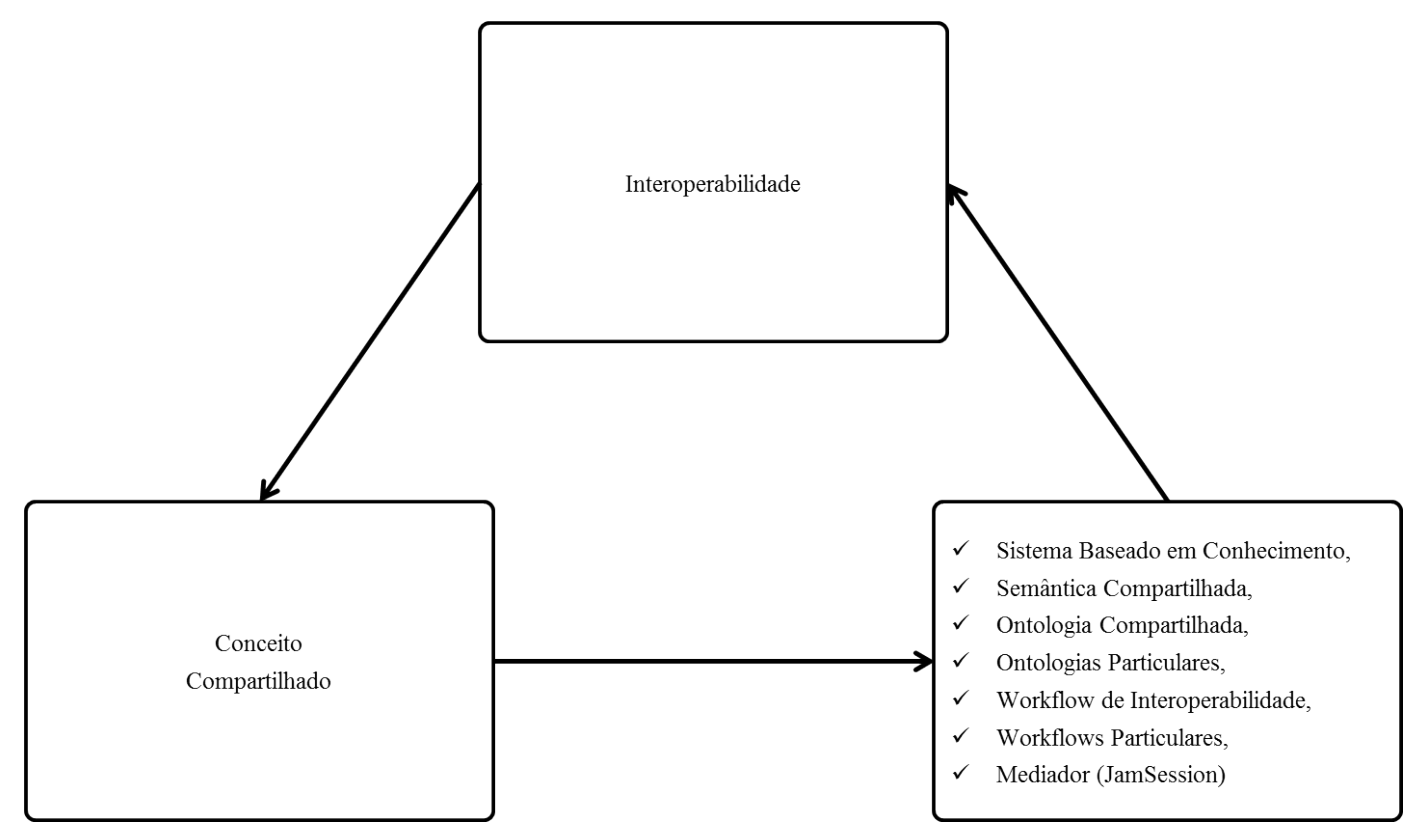

Figura 3.1: Esquema do Artefato do Conhecimento Interoperável

Os componentes do Artefato do Conhecimento Interoperável são detalhados nos itens a seguir:

\section{- P: Interoperabilidade entre as instituições.}

O propósito existente no Artefato de Conhecimento Interoperável, por definição é a interoperabilidade entre as instituições. O motivo pelo qual as instituições precisam interoperar varia de acordo com suas necessidades. Nosso modelo está focado na Interoperabilidade Organizacional quando tratamos de serviços e na Interoperabilidade Semântica quando tratamos da representação do conhecimento.

A interoperabilidade semântica engloba o processamento e a interpretação do significado dos dados compartilhados, enquanto que a interoperabilidade organizacional lida com a incompatibilidade dos diferentes processos de negócio e seus objetivos. De acordo com a definição fornecida pela IDABC EIF [Com04a]:

"Interoperabilidade organizacional envolve um grande conjunto de elementos de interação, incluindo processos de negócio, interfaces de negócio (e-mail, portais Web, ...), eventos de negócio dentro e entre administrações, e eventos da vida, envolvendo partes externas (negócios e cidadãos). ... Interoperabilidade Organizacional visa endereçar os requisitos da comunidade de usuários, tornando os serviços disponíveis, fáceis de identificar, acessíveis e orientados ao usuário." 


\section{- I: Conceito compartilhado.}

Para que possamos trabalhar com a interoperabilidade entre as instituições, é fundamental que estas tenham o mesmo entendimento sobre aquilo que desejam compartilhar. É necessário, portanto, a definição de um conceito compartilhado.

Recorremos ao conceito de Community of Practice (CoP), onde um grupo de pessoas informalmente ligadas umas às outras por compartilharem interesses, problemas, soluções etc. e que aprofundam seus conhecimentos e experiências através da interação contínua, possui um conjunto de métodos, ferramentas, símbolos etc. que é produzido e compartilhado por esta comunidade e que define seu jargão formal, com base em regras e convenções sintáticas e semânticas bem precisas. Dentro deste cenário, precisamos extrair o conceito compartilhado por esta CoP, que é o ponto de interoperabilidade entre seus membros.

\section{- R: A implementação de I, representada pelo conjunto definido por:}

\section{- Sistema Baseado em Conhecimento}

Sistemas Baseados em Conhecimento são programas de computador que usam conhecimento representado explicitamente para resolver problemas que, normalmente, requerem uma quantidade razoável de conhecimento humano e especialização [Rez03]. A representação simbólica do conhecimento é chamada base de conhecimento [BL04] Os fatoreschave dos sistemas baseado em conhecimento são a aquisição e representação do conhecimento e a aplicação de uma grande quantidade de conhecimento a um domínio específico do problema no qual o sistema baseado em conhecimento opera [Smi85]. Sistemas Baseados em Conhecimento (SBC) tornam o conhecimento explícito, além de separá-lo do sistema que o manipula e interpreta. O processo de desenvolvimento de um sistema baseado em conhecimento é iterativo porque continuamente novos conhecimentos são adquiridos e incorporados à base de conhecimento. Esse processo pode ser desenvolvido em 4 fases:

1. Planejamento do SBC

Esta fase descreve o domínio do conhecimento, termos chave e referências. Além disso, identifica alguns dos conceitos relacionados ao domínio do conhecimento.

2. Aquisição do conhecimento

Esta é a fase de identificação, conceitualização e formalização do conhecimento.

3. Implementação do SBC

Esta é a fase em que o conhecimento adquirido é representado formalmente utilizandose a estrutura de Representação do Conhecimento selecionada na fase 1.

4. Validação e refinação

Esta fase engloba a validação e verificação do sistema, assegurando que o sistema funcione corretamente, fornecendo resultados verdadeiros e satisfazendo os requisitos do usuário do SBC.

Em nosso modelo, o Sistema Baseado em Conhecimento é um Artefato do Conhecimento Interoperável incorporado sob a forma de sistemas de software.

\section{- Semântica Compartilhada.}

A definição do conceito compartilhado é expressa pela semântica deste conceito.

\section{- Ontologia Compartilhada.}

Conforme apresentado no Capítulo 2, "Uma ontologia é uma especificação formal de uma conceitualização compartilhada." ([Bor97]), onde, de acordo com [SBF98], conceituação refere-se a um modelo abstrato de algum fenômeno no mundo por ter identificado os conceitos relevantes desse fenômeno; especificação refere-se aos conceitos, propriedades, relações, funções, restrições, axiomas, etc, explicitamente definidas; formal significa que 
a ontologia deve ser legível por máquina e compartilhada significa que uma ontologia captura o conhecimento consensual isto é, o conhecimento aceito por um grupo. O modelo é compartilhado a partir de um entendimento comum.

No MIIH, estamos interessados no objetivo das ontologias de permitir o compartilhamento de informações e sua reutilização. Desta forma, dentro da classificação das ontologias, segundo seu nível de generalidade [Gua98], trabalhamos com as Ontologias de Domínio que descrevem o vocabulário relacionado a um domínio genérico, através da especialização dos termos introduzidos na ontologia de alto nível. O domínio em questão é aquele em que o Sistema Baseado em Conhecimento está contextualizado.

Ainda no sentido de alinhar nosso modelo com as definições existentes na literatura, podemos identificar a categoria da nossa aplicação com relação ao uso da ontologia. Seguindo a classificação de [UG96], nosso modelo está nas categorias

* Comunicação: as ontologias permitem o entendimento compartilhado e a comunicação entre as pessoas, principalmente no que diz respeito a modelos normativos, uma vez que, dentro de sistemas integrados as pessoas devem ter uma compreensão compartilhada do sistema e dos seus objetivos. Usando uma ontologia podemos construir um modelo normativo do sistema, criando uma semântica para o sistema e um modelo extensível. Posteriormente, este modelo poderá ser refinado, permitindo transformações semânticas entre diferentes contextos.

* Interoperabilidade: nosso modelo compreende diferentes instituições e usuários que precisam trocar informações e, portanto, as ontologias podem ser usadas para traduzir entre diferentes linguagens e representações. É fundamental que as ontologias e ferramentas usadas pelos diferentes agentes e organizações possam ser compartilháveis e reutilizáveis entre si.

Outro aspecto importante para o nosso trabalho é a linguagem usada para construir ontologias. Em [GPC02] e [ $\left.\mathrm{PRH}^{+} 06\right]$ existem alguns exemplos dessas linguagens. Consideramos que a linguagem mais adequada para o nosso trabalho é OWL, e sugerimos a utilização da versão OWL Lite [HPSH03]. As demais versões podem ser utilizadas quanto for preciso maior expressividade. OWL é uma linguagem de ontologia padronizada para a Web semântica, desenvolvida pelo World Wide Web Consortium (W3C) Web Ontology Working Group. É compatível com as linguagens de ontologia anteriores e oferece aos engenheiros de sistema mais poder para expressar semântica, incluindo conjunção, disjunção, existencialidade, e variáveis universalmente quantificadas.

A linguagem OWL foi desenvolvida para descrever classes e relações, permitindo que essas classes sejam reutilizados ou herdadas em documentos e aplicações web. Uma ontologia OWL pode incluir a descrição de classes, propriedades e suas instâncias e a semântica formal de OWL especifica como derivar suas consequências lógicas - por exemplo, fatos não literalmente presentes na ontologia, os quais podem ser derivados a partir de sua semântica. Sugerimos, quando possível, a utilização da linguagem OWL na versão Lite pois esta possui uma sintaxe mais simples e um mecanismo de inferência mais tratável. É importante citar que o MIIH permite substituir OWL por qualquer outra linguagem adequada, sem comprometer a definição do modelo.

\section{- Workflows Particulares.}

Tecnologias para workflow são amplamente utilizadas para auxiliar na especificação, execução e realização de processos dentro das organizações ([Hol95]). Com estas tecnologias é possível especificar como as atividades dentro das organizações estão ordenadas e quem é responsável por cada uma delas. A definição destes workflows é necessária também para que a interação entre estes workflows (cross-organizational workflows) seja realizada de forma correta, garantindo assim a interoperabilidade entre as organizações. 


\section{- Workflow Compartilhado.}

Para que possamos garantir a correta interoperabilidade entre as instituições, garantindo a colaboração entre elas, precisamos integrar seus workflows, mantendo suas particularidades e estabelecendo uma coordenação dos mesmos, que proporcione a correta execução do conjunto. Estas interações devem ser realizadas de forma flexível e confiável e devem ainda garantir que cada organização tenha controle sobre seus processos.

Em nosso modelo, utilizamos JamSession também como a ferramenta para integração de cross-organisational workflows, com a característica de ser formalmente verificável, fácil de usar e suficientemente flexível para prover um ambiente para a especificação e execução de padrões de integração que garantem a correta separação de interesses e responsabilidades entre as instituições envolvidas.

Em [dSVD $\left.{ }^{+} 12\right]$, JamSession é apresentada como uma ferramenta para integração de cross-organisational workflows. Neste artigo, os autores apresentam um conjunto de protocolos baseados em conhecimento para ilustrar a aplicabilidade da plataforma para a integração de cross-organisational workflows. JamSession requer que a separação de interesses e responsabilidades seja construída nos protocolos, de tal forma que cada organização constrói os protocolos de interação capazes de trocar informação diretamente com seu workflow interno, garantindo os níveis desejados de segurança e confiabilidade.

\section{- Mediador para a Interoperabilidade - JamSession.}

Em nosso modelo, o sistema mediador para a interoperabilidade entre instituições heterogêneas deve satisfazer algumas funcionalidades como, por exemplo, a coordenação de recursos heterogêneos e a coordenação de cross-organizational workflows.

JamSession atende estes requisitos pois é uma plataforma para a integração e coordenação de recursos computacionais, concebido inicialmente para sistemas altamente interativos e estendido para gerenciar recursos computacionais genéricos. As principais características de JamSession são:

* Alto desempenho computacional para fornecer os meios para a coordenação e integração de componentes de software em sistemas de tempo real.

* Usabilidade para garantir que os usuários sejam capazes de integrar e coordenar recursos heterogêneos facilmente.

* Bases formal e declarativa para fornecer os meios para o projeto, a análise e a verificação formal dos protocolos de coordenação.

* Integração desacoplada de recursos computacionais heterogêneos para garantir a sua independência, provendo suporte à separação de interesses e responsabilidades no projeto e na implementação da integração de workflows.

A plataforma JamSession avança na coordenação e integração de workflows, apresentando todos os recursos em uma única plataforma.

Neste trabalho propomos utilizar JamSession como mediador, mas nosso modelo permite que este componente possa ser substituído por qualquer outro sistema que possua os atributos mínimos citados acima.

Com o uso de Artefatos do Conhecimento Interoperáveis, abrimos a possibilidade de reutilização dos componentes $P, I$ e $R$ para a construção de diferentes artefatos.

Dentro de cada instituição, as pessoas possuem um conhecimento e uma interpretação dos conceitos que a cercam e para que seu conhecimento e suas experiências possam ser compartilhados, estes precisam ser formalizados. Neste caso, é interessante identificarmos uma Community of Practice $(\mathrm{CoP})$, isto é, um grupo de pessoas informalmente ligados uns aos outros por compartilharem interesses, problemas, soluções, etc e que aprofundam seus conhecimentos e experiências através 
da interação contínua. Entre estas pessoas existe um conjunto de métodos, ferramentas, símbolos, etc que é produzido e compartilhado por esta comunidade. Quando estas estruturas estão suficientemente identificadas e elaboradas elas são transformadas em artefatos que incorporam uma linguagem que é entendida por todos e provê informação suficiente para ser útil; este é o jargão formal da comunidade, que compreende regras e convenções sintáticas e semânticas bem precisas.

Quando um Artefato do Conhecimento é reutilizado, caracteriza-se o fluxo de conhecimento dentro de uma CoP. Quando um artefato é utilizado entre CoPs, atribuindo-se a mesma semântica ou uma semântica diferente a seus componentes, este artefato é chamado de artefato de fronteira, uma vez que ele se torna o ponto de contato entre estas CoPs.

A Figura 3.2 ilustra esta relação entre Artefatos do Conhecimento e Community of Practice.

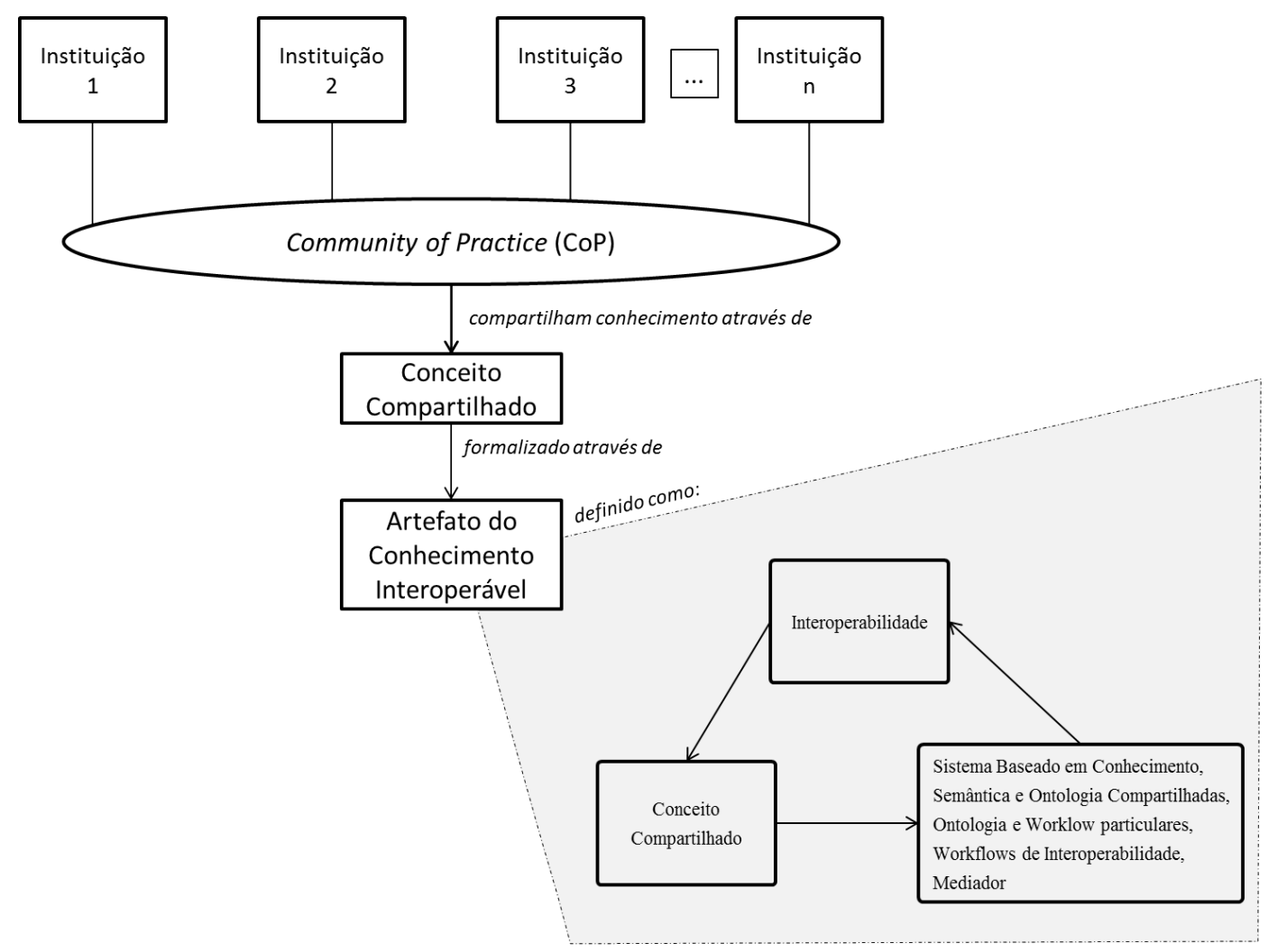

Figura 3.2: Artefato do Conhecimento Interoperável e Community of Practice

\subsection{Métodos}

Neste trabalho definimos um Modelo para Interoperabilidade entre Instituições Heterogêneas que apresenta um modelo de representação da informação, modelagem de serviços e regras de interoperabilidade. Utilizamos a plataforma JamSession para modelar, simular e controlar formalmente as atividades e as regras de interoperabilidade que são relevantes para as organizações envolvidas e utilizamos mundos virtuais para interagir com o usuário final.

A Figura 3.3 mostra um esquema do MIIH. A interoperabilidade entre diferentes níveis de usuários é garantida pela arquitetura do modelo, que fornece os meios para a integração de diferentes organizações com interfaces amigáveis (baseadas em sistemas de simulação de mundos virtuais), através de protocolos de interação escritos e executados pela plataforma JamSession. Como mostrado na Figura 3.3, a nossa abordagem é centrada no usuário. Note que a plataforma JamSession é empregada como um middleware que "gruda" todos os componentes do sistema.

Os Artefatos de Conhecimento Interoperáveis comunicam-se através de protocolos de interação 
baseados em conhecimento que são implementados utilizando JamSession, cuja integridade pode ser formalmente verificada, garantindo assim a confiabilidade das transações inter-organizacionais. Finalmente, os Artefatos de Conhecimento Interoperáveis implementados, comunicam-se com a camada de interação com o usuário (baseada em mundos virtuais), garantindo a comunicação apropriada com os usuários finais.

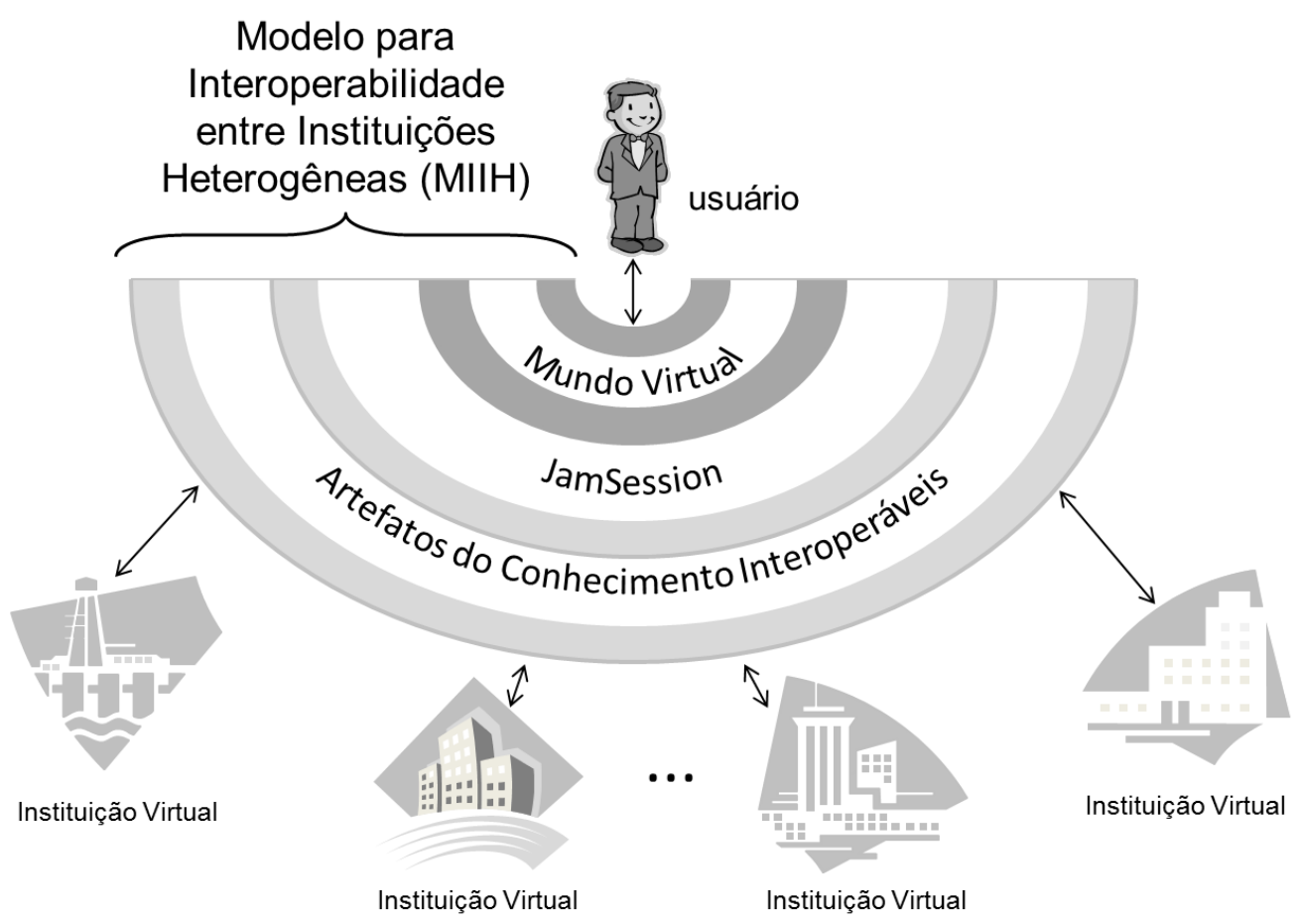

Figura 3.3: Esquema de interoperabilidade do $M I I H$

No MIIH, as organizações (instituições virtuais) são abstraídas na forma de workflows. Cada organização coordena seu workflow particular e a plataforma JamSession é responsável por coordenar a integração entre estes workflows. Os Artefatos do Conhecimento Interoperáveis caracterizam o ponto comum que possibilita a comunicação entre as instituições e eles são implementados como protocolos do JamSession que caracterizam interfaces entre o Conceito Compartilhado e cada uma das instituições.

No Modelo para Interoperabilidade entre Instituições Heterogêneas, garantimos a reusabilidade através de Artefatos do Conhecimento Interoperáveis, que funcionam como padrões de arquitetura pré-concebidos que orientam e padronizam as interações - e, portanto, a interoperabilidade organizacional e semântica - entre as organizações envolvidas.

\subsection{Metodologia do MIIH}

Para que o MIIH possa ser facilmente utilizado, propomos uma metodologia para a construção do Artefato do Conhecimento Interoperável, conforme descrita a seguir:

\section{Identificação do Domínio}

Identificar e definir o domínio da aplicação que será desenvolvida.

\section{Identificação da Community of Practice (CoP)}

Identificar qual é o grupo de pessoas/instituições que irão interoperar através desta aplicação 
para compartilhar interesses, problemas, soluções etc. e aprofundar seus conhecimentos e experiências através da interação contínua.

\section{Identificação do "jargão" da CoP}

Identificar o conjunto de métodos, ferramentas, símbolos etc. que é produzido e compartilhado por esta comunidade e que define seu jargão formal, com base em regras e convenções sintáticas e semânticas bem precisas.

\section{Definição do objetivo da CoP}

Identificar qual é o propósito da interação entre os membros da CoP.

5. Definição do Conceito Compartilhado por esta CoP e sua respectiva semântica Identificar e definir o conceito compartilhado e seu significado, a respeito do qual os membros da CoP têm o mesmo entendimento e podem interoperar.

\section{Definição da Ontologia Compartilhada e eventual mapeamento para as Ontologias} particulares, caso as instituições envolvidas possuam particularidades

Definir a ontologia que permite o entendimento compartilhado e a comunicação entre os membros da CoP. Usando uma ontologia devemos construir um modelo normativo do sistema, criando uma semântica para o mesmo. Nosso modelo compreende diferentes instituições e usuários que precisam trocar informações e, no caso destes utilizarem diferentes ontologias, será necessário fazer o mapeamento entre estas ontologias e a ontologia compartilhada.

\section{Definição do Workflow Compartilhado}

Para que possamos garantir a correta interoperabilidade entre as instituições e a colaboração entre elas, precisamos integrar seus workflows, mantendo suas particularidades e estabelecendo uma coordenação dos mesmos, que proporcione a correta execução do conjunto. Estas interações devem ser realizadas de forma flexível e confiável e devem ainda garantir que cada organização tenha controle sobre seus processos. Aqui deve-se definir o workflow que será responsável pela integração dos demais workflows das instituições envolvidas.

\section{Definição do Sistema Baseado em Conhecimento}

Definição dos componentes da aplicação, incluindo bases de dados, interfaces, etc.

\section{Mapeamento do Mediador}

Implementação do mecanismo de interoperabilidade. Em nosso modelo propomos o uso do JamSession e, portanto, precisamos mapear seus elementos:

- definir grafo de localização

- criar agentes

- definir protocolos e predicados

A Figura 3.4 sintetiza esta metodologia. 


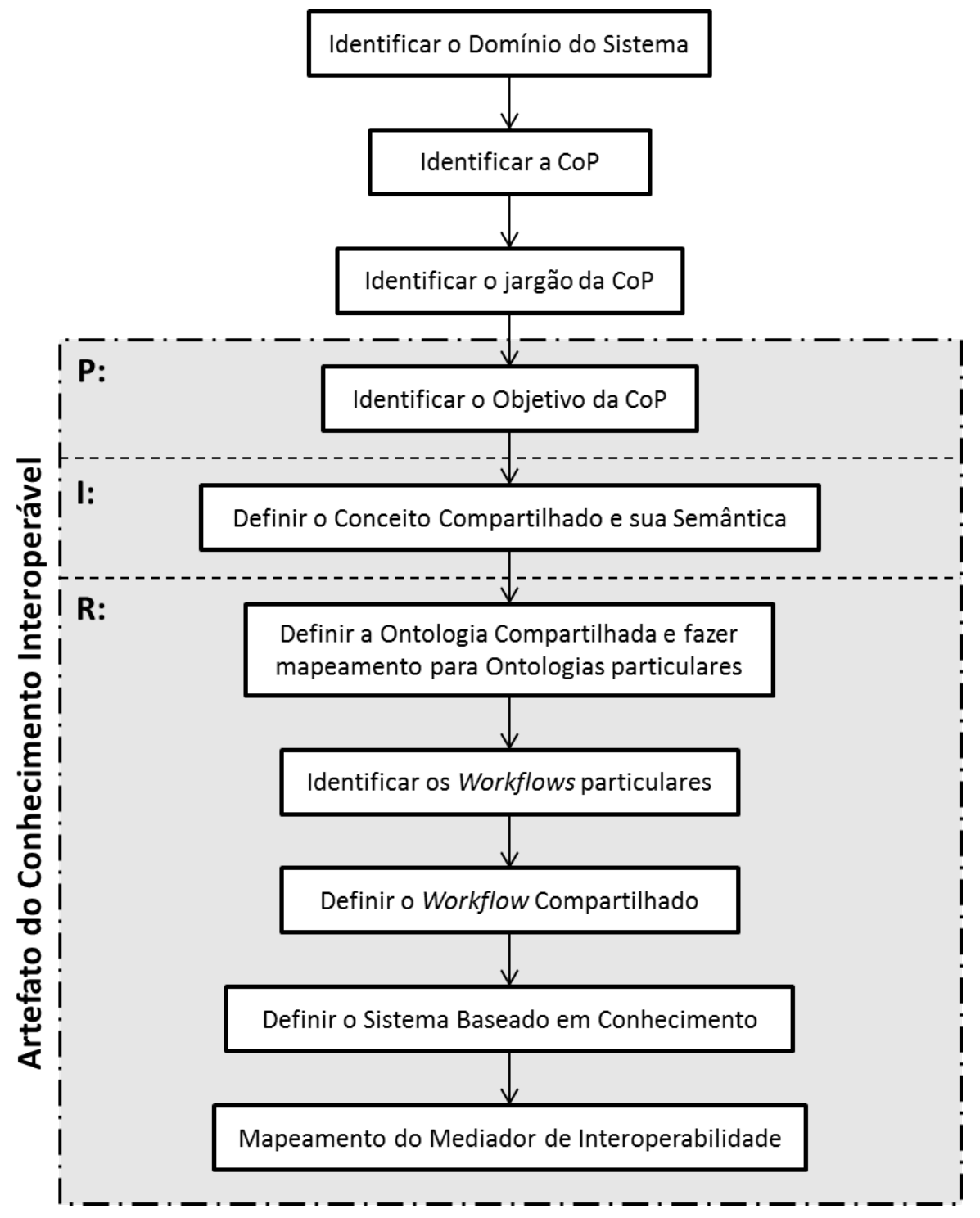

Figura 3.4: Esquema da metodologia para uso do MIIH

\subsection{Métricas de Avaliação}

O objetivo principal deste trabalho é definir um Modelo para Interoperabilidade entre Instituições Heterogêneas. Para validar nosso modelo conceitual, desenvolvemos um Exemplo de Uso, que consiste na especificação e implementação de um sistema completo, utilizando o modelo conceitual definido neste projeto. Este Exemplo de Uso é apresentado em detalhes no Capítulo 4.

Em [SRP07] encontramos um método de avaliação que consideramos apropriado para avaliar nosso Exemplo de Uso: Avaliação Heurística. A seguir descrevemos este método.

A Avaliação Heurística é uma técnica de inspeção de usabilidade, desenvolvida inicialmente por Jakob Nielsen [NM90, Nie95], onde especialistas, guiados por um conjunto de princípios de usabilidade, as heurísticas, avaliam se um elemento de interface com o usuário está de acordo com os princícios estabelecidos. Originalmente, Nielsen desenvolveu um conjunto de heurísticas derivado empiricamente da análise de 249 problemas de usabilidade [Nie94]. Estas heurísticas foram revisadas em 2006 [Nie], são elas:

\section{Visibilidade do status do sistema}

O sistema deve sempre manter os usuários informados sobre o que está acontecendo, através de feedback apropriado em tempo razoável. 


\section{Correspondência entre o sistema e o mundo real}

O sistema deve falar a língua do usuário, com palavras, frases e conceitos familiares ao usuário, ao invés de termos orientados ao sistema. Siga as convenções do mundo real, fazendo com que a informação apareça em uma ordem lógica e natural.

\section{Liberdade e controle do usuário}

Os usuários frequentemente escolhem funções do sistema por engano e vão precisar de uma "saída de emergência"claramente marcada para saírem do estado indesejado, sem ter que passar por um extenso diálogo. Suporte a "desfazer" e "refazer".

\section{Consistência e padrões}

Os usuários não devem ter que adivinhar se diferentes palavras, situações ou ações significam a mesma coisa. Siga as convenções da plataforma.

\section{Prevenção de erros}

Melhor do que boas mensagens de erro, é um projeto cuidadoso que impede que um problema ocorra. Deve-se eliminar as condições de propensão a erro ou verificá-los e apresentar ao usuário uma opção de confirmação, antes de se comprometer com a ação.

\section{Reconhecimento ao invés de recordação}

Minimizar a carga de memória do usuário, tornando os objetos, ações e opções visíveis. $\mathrm{O}$ usuário não deve ter que lembrar informação de uma parte do diálogo para outra. Instruções para utilização do sistema devem estar visíveis e facilmente recuperáveis quando necessário.

\section{Flexibilidade e eficiência do uso}

Aceleradores - despercebidos pelo usuário novato - podem frequentemente acelerar a interação para o usuário avançado, de tal forma que o sistema pode servir tanto para usuários inexperientes quanto para os experientes. Permita que os usuários adaptem ações frequentes.

\section{Estética e design minimalista}

Diálogos não devem conter informação irrelevante ou raramente necessária. Cada unidade extra de informação em um diálogo compete com unidades relevantes de informação e diminui sua visibilidade relativa.

9. Ajudar os usuários a reconhecer, diagnosticar e recuperar de erros Mensagens de erro devem ser expressas em linguagem clara (sem códigos), indique com precisão o problema e construtivamente procure sugerir uma solução.

\section{Ajuda e documentação}

Mesmo que seja melhor utilizar o sistema sem documentação, pode ser necessário fornecer ajuda e documentação. Todas as informações devem ser fáceis de pesquisar, focadas na tarefa do usuário, devem listar os passos concretos a serem realizados, e não devem ser muito grande.

Estas heurísticas são bastante genéricas e, para que possam ser utilizadas na avaliação de alguns produtos, Nielsen sugere o desenvolvimento de heurísticas específicas. Assim, pode-se fazer uma composição destes dois conjuntos de heurísticas e realizar uma avaliação mais direcionada ao produto em questão.

Seguindo esta diretriz, buscamos na literatura algumas heurísticas adequadas para nosso trabalho que, em conjunto as heurísticas acima citadas, formaram o conjunto para avaliar nosso trabalho. O método g-Quality [MNG] apresenta o seguinte conjunto de heurísticas para a qualidade de sítios governamentais, que consideramos bastante apropriadas para nosso modelo:

\section{Usabilidade}

Associado com os atributos de utilização do usuário, engloba as 10 heurísticas de Nielsen acima citadas; 


\section{Acessibilidade}

O sítio deve ser projetado com o objetivo de ser acessível a pessoas com necessidades especiais ou ser acessível em vários tipos de ambientes.

\section{Interoperabilidade}

Considera a habilidade de trocar informações entre sistemas diferentes.

\section{Segurança e privacidade}

As informações confidenciais devem ser trafegadas com segurança, de forma que o usuário se sinta seguro em fornecer as informações solicitadas.

\section{Veracidade da informação}

Informar a data da última atualização de cada página do sítio.

\section{Agilidade de serviço}

O tempo de resposta de uma tarefa em um sítio deve ser rápido e a disponibilidade do serviço deve ser garantida.

\section{Transparência}

As informações devem ser fornecidas de forma completa, provendo uma visão geral de todo o serviço/conteúdo oferecido no sítio.

A avaliação heurística deve ser realizada em 3 passos, conforme sugerido em [SRP07]:

1. Sessão de briefing Preparação de um roteiro para que os especialistas possam se guiar e saber o que avaliar.

2. Período de avaliação Os especialistas inspecionam a aplicação utilizando as heurísticas e o roteiro como guia.

3. Sessão de debriefing Os especialistas se reunem e concluem quais os problemas encontrados, propondo soluções.

Na seção 4.1.4 apresentamos o resultado desta avaliação heurística, aplicada ao Exemplo de Uso desenvolvido.

\subsection{Resumo}

Neste capítulo apresentamos a necessidade de interação entre instituições heterogêneas, como esta necessidade pode ser satisfeita através da interoperabilidade e definimos nosso Modelo para Interoperabilidade entre Instituições Heterogêneas (MIIH). Os conceitos apresentados no Capítulo 2 são utilizados e relacionados na descrição do MIIH. Apresentamos também uma metodologia para a utilização deste modelo e algumas métricas para a avaliação de sistemas desenvolvidos utilizando este modelo.

No próximo capítulo apresentamos dois Exemplos de Uso desenvolvidos utilizando o modelo e a metodologia aqui descritas. 


\section{Capítulo 4}

\section{Exemplo de Uso}

Neste capítulo apresentaremos dois exemplos de utilização do Modelo para Interoperabilidade entre Instituições Heterogêneas definido no capítulo anterior:

1. OpenMuseum: sistema de integração entre instituições, profissionais de arte e seus usuários.

2. PoupaVirtual: sistema inspirado no PoupaTempo que integra agências governamentais para oferecer serviços ao cidadão.

O primeiro exemplo foi definido e implementado, caracterizando nosso Exemplo de Uso. O segundo exemplo foi proposto e publicado em [AadAdS09] e [AS11] e, finalmente modelado neste trabalho com os Artefatos do Conhecimento Interoperáveis.

\subsection{OpenMuseum}

\subsubsection{Contexto do Sistema}

O processo de elaboração deste Exemplo de Uso iniciou-se com uma pesquisa sobre a definição e o propósito de um museu. A definição de museu tem sido modificada durante os dois séculos de existência dessas instituições. Atualmente, de acordo com a definição apresentada pela UNESCO em [une], os museus são "instituições permanentes, sem fins lucrativos, a serviço da sociedade e de seu desenvolvimento, e abertas ao público, que adquirem, conservam, pesquisam, comunicam e exibem, com o propósito de estudo, educação e diversão, evidências materiais de pessoas e seus ambientes.

Lado a lado com o patrimônio monumental, tais coleções agora constituem a maior parte do que é universalmente conhecido como patrimônio cultural. A finalidade principal do museu é a de proteger, salvaguardar e preservar o patrimônio tangível e intangível. Para isso, realiza estudos científicos para compreender e estabelecer tanto o seu significado quanto a sua posse. Museus também têm uma missão educativa, que ajuda na preparação de uma ética global baseada na prática para a conservação, proteção e difusão dos valores do patrimônio cultural. Um museu apresenta as interações entre cultura e natureza: um número crescente de museus estão concentrando seu interesse na ciência e na tecnologia. Finalmente, voltado para o seu público, os museus comunitários estão atentos para a mudança social e cultural e nos ajudam a apresentar nossa identidade e diversidade em um mundo em constante mudança.

De acordo com a UNESCO, algumas questões importantes são:

- O patrimônio cultural reflete a vida da comunidade, sua história e sua identidade. Sua preservação ajuda a reconstruir as comunidades destruídas, restabelecer suas identidades, e vincular o seu passado com seu presente e futuro.

- Objetos culturais móveis e os museus em que são conservados constituem repositórios de diversidade cultural. Como pontos de acesso para o conhecimento sobre as culturas e centros 
de educação, museus também contribuem para a compreensão mútua e coesão social, bem como para o desenvolvimento econômico e humano.

- A estratégia da UNESCO concentra-se nos museus e coleções que melhor contribuem para uma compreensão integrada do patrimônio e da sua contribuição potencial para o desenvolvimento econômico, social e humano das comunidades locais e dos grupos desfavorecidos. Esta estratégia é implementada através de atividades de formação que envolvam técnicas simples e eficientes para salvaguardar objetos, com uma ênfase especial na criação de ferramentas pedagógicas; desenvolvimento de museus através do reforço das redes profissionais e de parcerias; melhoria dos conteúdos educativos e acesso ao conhecimento através de ações de sensibilização e atividades educativas; e promoção do retorno, restituição e melhoria do acesso aos bens culturais por meio de sensibilização e atividades de consultoria e parcerias inovadoras.

Tendo reconhecido que este contexto dos museus é importante para toda a sociedade, verificamos mais profundamente o funcionamento dos museus e suas interações entre si e com seus usuários. Identificamos, neste cenário, a aplicação direta de nosso projeto, uma vez que a interoperabilidade entre os museus é fundamental para o desempenho de suas funções e a interoperabilidade com seus usuários define a razão de sua existência conforme verificamos na conceituação da UNESCO, apresentada anteriormente.

A interoperabilidade entre os museus diz respeito principalmente ao compartilhamento de informações sobre suas obras de arte, eventuais empréstimos de obras e montagem conjunta de exposições de suas obras. Para tanto, é fundamental que estas organizações (os museus) possuam uma definição clara do conceito que compartilham. No caso, o conceito diz respeito às obras de arte dentro de seus acervos e participantes de exposições. Envolvem ainda outras organizações como, por exemplo, as instituições culturais que realizam exposições destas obras e colecionadores de obras de arte que podem ceder suas obras para exposições específicas. Do outro lado, estão os visitantes (usuários) destas organizações que querem conhecer estas obras de arte e, para tanto, visitam exposições que apresentam estas obras. Aqui também se identifica a interoperabilidade entre museu e visitante.

Buscamos, então, um caso real para aplicarmos nossa solução e podermos validar na prática a nossa tese. O museu com o qual realizamos uma parceria nesta pesquisa foi o Museu de Arte Contemporânea da Universidade de São Paulo, conforme será descrito na próxima seção.

\subsubsection{O Museu de Arte Contemporânea da Universidade de São Paulo (MAC USP)}

O Museu de Arte Contemporânea da Universidade de São Paulo tinha interesse em desenvolver um ambiente virtual, no site do MAC USP (www.mac.usp.br), para complementação da exposição das 71 obras adquiridas pelo casal Matarazzo para a criação do antigo Museu de Arte Moderna de São Paulo. O objetivo não é apresentar no mundo virtual aquilo que se pode encontrar no mundo físico. A ideia é inovar em dois sentidos: 1) o desafio de trabalhar com duas linguagens distintas: uma coleção de pinturas modernistas e um suporte virtual que as traduz e 2) explorar um ambiente virtual inovador e não meramente a reprodução do espaço expositivo real.

Portanto, o ambiente virtual da exposição deve ser um espaço onde o visitante do museu possa ter acesso a outras camadas de leitura e de aprofundamento da compreensão das obras que estão sendo exibidas no espaço do museu. A partir desse pressuposto, este ambiente virtual deve organizar os conteúdos complementares da pesquisa sobre as obras em três ferramentas diferentes:

- Documentação sobre as análises físicas feitas com 10 obras em exposição:

- descrever as técnicas de análise utilizadas: infra-vermelho, ultra-violeta, radiografia, Raman e luz razante;

- apresentar textos e verbetes sobre essas diferentes técnicas de análise das características físicas das obras e sua importância no auxílio à conservação e restauração destas obras; 
- apresentar as imagens obtidas através destas análises;

- interagir com o visitante, onde este pode ter acesso à animação gráfica de sobreposição das imagens resultantes das análises realizadas nas obras.

- Uma coleção de coleções:

- apresentar as obras em exposição dentro de seu contexto original de proveniência, de coleções privadas italianas dos anos 1930, com textos e verbetes sobre os diferentes personagens que emergiram a partir da pesquisa sobre as obras;

- reagrupar estas obras em suas coleções originais.

- Galeria virtual dos anos 1930:

- apresentar uma maquete virtual que possa reconstruir um ambiente que simule a disposição dessas obras em contextos domésticos, isto é, nos espaços criados pelo colecionismo privado milanês dos anos 1930 .

- utilizar esta maquete para confrontar outras coleções públicas formadas segundo os mesmos princípios poderiam ser confrontadas com a coleção em exposição no MAC USP.

Os conteúdos abordados a partir dessas três ferramentas formam uma base de interpretação histórica sobre as obras italianas das coleções Matarazzo em exposição, que prepara o visitante para criar seu próprio percurso de visita no conjunto das obras e também criar sua própria galeria com obras selecionadas, acrescentando ainda comentários sobre sua seleção, suas preferências, etc.

Além destas ferramentas, que suprem uma necessidade de projeto do MAC, identificamos outras ferramentas de grande utilidade e contribuição para a sociedade:

- Criação de exposições virtuais: permitir que os usuários (profissionais de arte, educadores, alunos e leigos) possam selecionar obras disponíveis nos acervos de museus (associados ao nosso sistema) e possivelmente em outros Web Sites de arte, e criar suas próprias exposições de arte virtuais.

- Cruzamento de informações sobre obras e artistas: cruzamento de informações sobre obras e artistas, disponíveis em Web Sites de museus, galerias e exposições.

- Recuperação de comentários sobre obras, disponíveis em Redes Sociais: particularmente, após criar sua própria exposição virtual, o usuário pode clicar em uma das obras "em exposição" e recuperar comentários sobre estas obras, que foram apresentados em algumas redes sociais pré-definidas.

Este interesse do MAC está alinhado com nosso trabalho e foi a fonte real de informações que precisávamos para concretizar nosso exemplo. As três primeiras ferramentas apresentadas estão atualmente em desenvolvimento para atender as necessidades do MAC e para enriquecer o conteúdo e a interface com o usuário em um protótipo em desenvolvimento, chamado sistema OpenMuseum. Para este Exemplo de Uso desenvolvemos e analisamos as ferramentas que requerem maior grau de interoperabilidade entre as instituições (museus, galerias, colecionadores e usuários) e, portanto, servem como mecanismo para validar a nossa tese. Este Exemplo de Uso foi denominado OpenMuseum Lite.

\subsubsection{OpenMuseum Lite}

Desenvolvemos um sistema, denominado OpenMuseum Lite, para a criação e manutenção de museus e exposições virtuais. O objetivo é prover os museus/galerias/coleções com uma presença virtual, que possa ser acessada mundialmente e que permita o compartilhamento de informações entre estas instituições, profissionais de arte e interessados em arte. Estes museus virtuais têm as seguintes características: 
- Espaço e armazenamento de exposições de obras de arte;

- Exposições educacionais;

- Catálogo de coleções (acervo);

- Ferramentas de pesquisa.

O sistema OpenMuseum Lite fornece as seguintes funcionalidades:

- O armazenamento de todas as informações sobre o acervo, incluindo imagens de alta resolução e informações detalhadas de cada obra e registro de todas as exposições que incluíram estas obras.

- O espaço virtual do museu conta com uma representação 2D ou 3D do espaço de exposição e a ferramenta proporciona a facilidade de criar uma exposição com todas (ou algumas) as obras de seu acervo. Essa funcionalidade pode ser usada por curadores que podem planejar a exposição antes de sua criação física; por professores que podem planejar uma exposição de acordo com seu tema de aula; e por estudantes que podem planejar uma exposição de acordo com uma atividade de aula.

- A interoperabilidade entre museus, para o intercâmbio de coleções de obras, de informações sobre exposições e outras questões relevantes.

- A navegação através do espaço virtual do museu. Este projeto tem um modelo geral de interoperabilidade entre as instituições e a interação com os usuários. Os problemas de interoperabilidade são orquestrados pela plataforma de integração de serviços JamSession. Como o projeto deve estar disponível para o maior espectro possível de usuários, existe uma adaptação automática do formato e do conteúdo exibido, dependendo dos dispositivos, plataformas e perfis de usuário. A fim de garantir a interação entre os museus, foi definida uma forma de representação de informações que pode garantir a integração e o compartilhamento de informações. Assim, foram utilizadas técnicas avançadas de representação de informações e mapeamento de ontologias. Considerando este último aspecto, é importante ressaltar que os itens do museu existem em uma variedade de formas, tais como pinturas, documentos, manuscritos, esculturas, instrumentos musicais e levam informações significativas que merecem um tratamento particular. Além disso, os metadados correspondentes são frequentemente utilizados por uma variedade de aplicações, como sites, portais, aplicações interativas e dispositivos de computação móvel e, portanto, diferentes visões das mesmas informações são necessárias para aumentar o aspecto técnico da recuperação contextual da informação. Com base nessas características, os requisitos do sistema incluem a gravação completa e precisa dos itens do patrimônio cultural; a segurança e a integridade dos ativos digitais e seus metadados respectivos e o apoio a uma administração e documentação eficaz do material digitalizado. Nosso objetivo é permitir a reutilização e o compartilhamento do conhecimento para atingir a interoperabilidade entre as instituições. Portanto, este trabalho faz uso de abordagens ontológicas e técnicas relacionadas para estabelecer um sistema baseado no conhecimento através do uso de padrões. Um padrão recomendado na literatura é o Modelo de Referência Conceitual CIDOC que fornece uma ontologia extensível para conceitos e informações em documentação do patrimônio cultural e de museus. Este é o padrão internacional (ISO 21127:2006) para o controle e a integração entre fontes heterogêneas de informação do patrimônio cultural. A aplicação OpenMuseum tem uma correspondência com o Modelo de Referência Conceitual CIDOC. No caso do MAC, seu banco de dados está sendo remodelado, seguindo uma estrutura ontológica definida de acordo com a necessidade da curadoria do museu. Para a implementação deste Exemplo de Uso, criamos um banco de dados com parte do acervo, que servirá de piloto para as demais ações planejadas junto ao MAC. No caso deste Exemplo de Uso, não seguimos o Modelo de Referência Conceitual CIDOC. 


\subsubsection{Definição do Sistema OpenMuseum Lite}

O sistema OpenMuseum Lite, desenvolvido de acordo com a descrição apresentada anteriormente neste capítulo é um ambiente virtual para museus, que provê interoperabilidade entre as organizações envolvidas e seus usuários ${ }^{1}$. Seguimos a metodologia apresentada no MIIH para definirmos este sistema.

\section{Domínio do Sistema}

Ambiente de Estudo, Pesquisas e Apreciação de Obras de Artes

\section{Community of Practice ( $\mathrm{CoP})$ do OpenMuseum Lite}

A CoP deste sistema compreende as instituições que tratam de obras de arte - museus, galerias, colecionadores; profissionais de arte - artista, fotógrafos; e pessoas interessadas em artes.

\section{Jargão utilizado pela CoP}

O jargão utilizado pela CoP concentra-se em torno da expressão "obra de arte" e compreende os termos exposição, acervos, coleções, técnicas de produção de obras de arte, restauro, dentre outras.

\section{Artefato do Conhecimento Interoperável instanciado para o OpenMuseum Lite}

Instanciando o Modelo para Interoperabilidade entre Instituições Heterogêneas para o domínio dos museus/galerias/colecionadores, definimos a tupla referente ao Artefato do Conhecimento Interoperável, da seguinte forma:

- $P$ é a interoperabilidade entre as instituições para compartilhar informações sobre a obra, criar exposições virtuais e ações para a educação.

- I é o conceito compartilhado "obra de arte" que, concretamente, será representado pela "ficha catalográfica mínima" da "obra de arte", ou seja, os dados mínimos que a identificam adequada e unicamente, perante todas as instituições envolvidas;

- $R$ é um conjunto definido por:

- Sistema Baseado em Conhecimento:

Formado por Web Sites (do OpenMuseum Lite e dos membros da CoP) e Bancos de Dados. As Figuras 4.1, 4.2 e 4.3 ilustram este esquema.

- Semântica Compartilhada para Obra de Arte:

No domínio do OpenMuseum Lite, temos a Obra de Arte como o objeto central. Podemos definir informalmente sua semântica da seguinte forma:

* Cada Obra de Arte é de autoria de um Artista ou um Coletivo (conjunto de Artistas).

* Cada Obra de Arte pode ter vários Colaboradores (Fotógrafo, Colaborador, Editor).

* As Obras de Arte pertencem a uma Instituição (Museu, Galeria, Colecionador).

* As Obras de Arte podem estar expostas em uma Exposição, expostas numa Instituição à qual pertencem (Acervo), guardadas em Reserva Técnica da Instituição à qual pertencem(Guarda do acervo não exposto), mantidas em Restauro ou Comodato.

* Uma Obra de Arte pode ser Reproduzida ou publicada em uma Publicação (Catálogo de Exposição, Coleção, Guia, Calendário, Ensaios, Artigos, etc.).

\footnotetext{
${ }^{1}$ Existem iniciativas com alguns objetivos similares como, por exemplo, Artcyclopedia (http://www.artcyclopedia.com/). Entretanto, nossa proposta é mais ampla uma vez que abordamos as questões referentes à interoperabilidade semântica e organizacional entre as instituições de arte.
} 


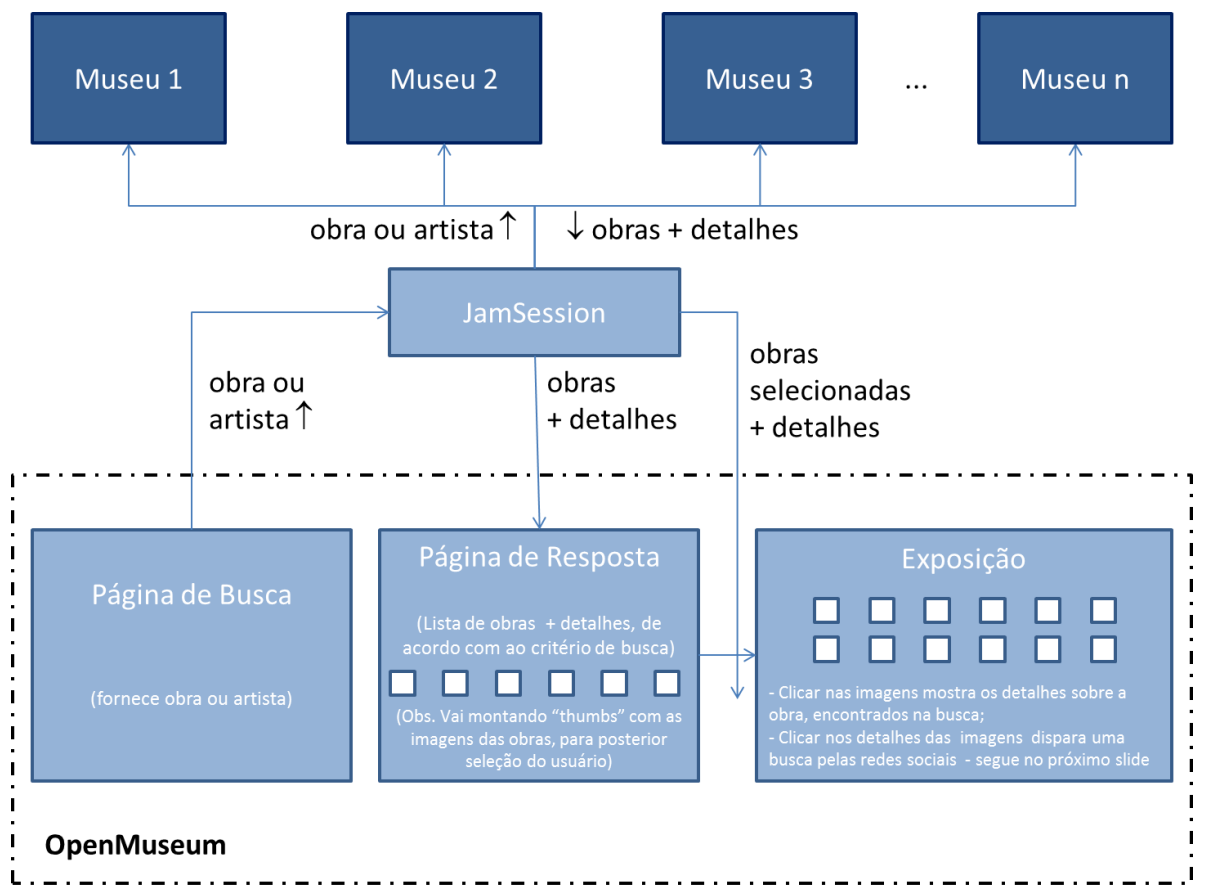

Figura 4.1: Esquema do OpenMuseum Lite - Busca e Criação de Exposição

Na Página de Busca, o usuário solicita uma busca por autor ou obra. A plataforma JamSession dispara os respectivos protocolos para efetivamente realizar as buscas automaticamente em toda a CoP. Se necessário, é realizado também o mapeamento de ontologias, de forma transparente para o usuário. Ao final de cada busca, a Página de Resposta é criada/atualizada, apresentando as imagens das obras encontradas. Quando o usuário finaliza sua pesquisa, ele pode selecionar, ainda nesta página, quais obras ele deseja ver "expostas". O usuário seleciona, então, a opção de criar Exposição e a respectiva página é gerada.

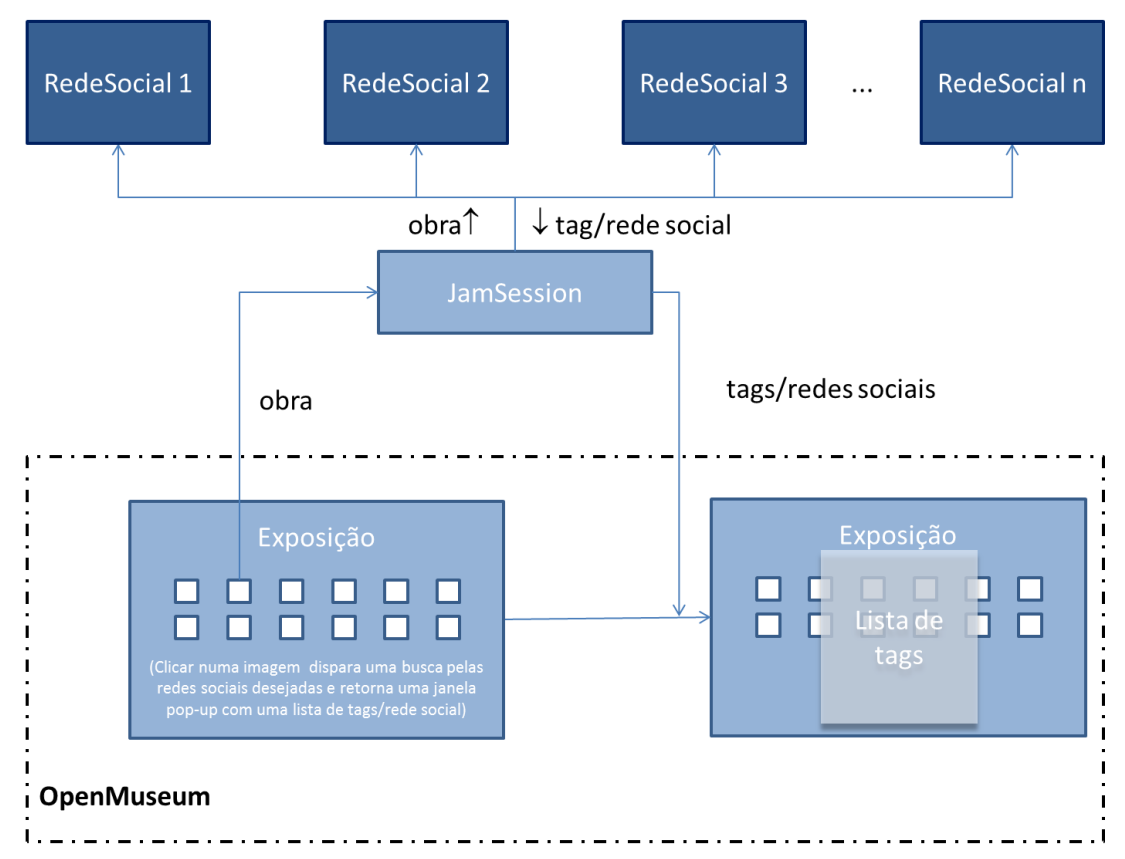

Figura 4.2: Esquema do OpenMuseum Lite - Detalhes de uma Obra e Interação com Redes Sociais Ao visualizar uma Exposição, o usuário pode selecionar uma obra e ter acesso às informações e detalhes sobre esta obra. $O$ usuário pode selecionar dentro destes detalhes, ver comentários em redes sociais. Neste caso, a plataforma JamSession dispara os protocolos para verificar estes comentários e retorná-los para o usuário. 


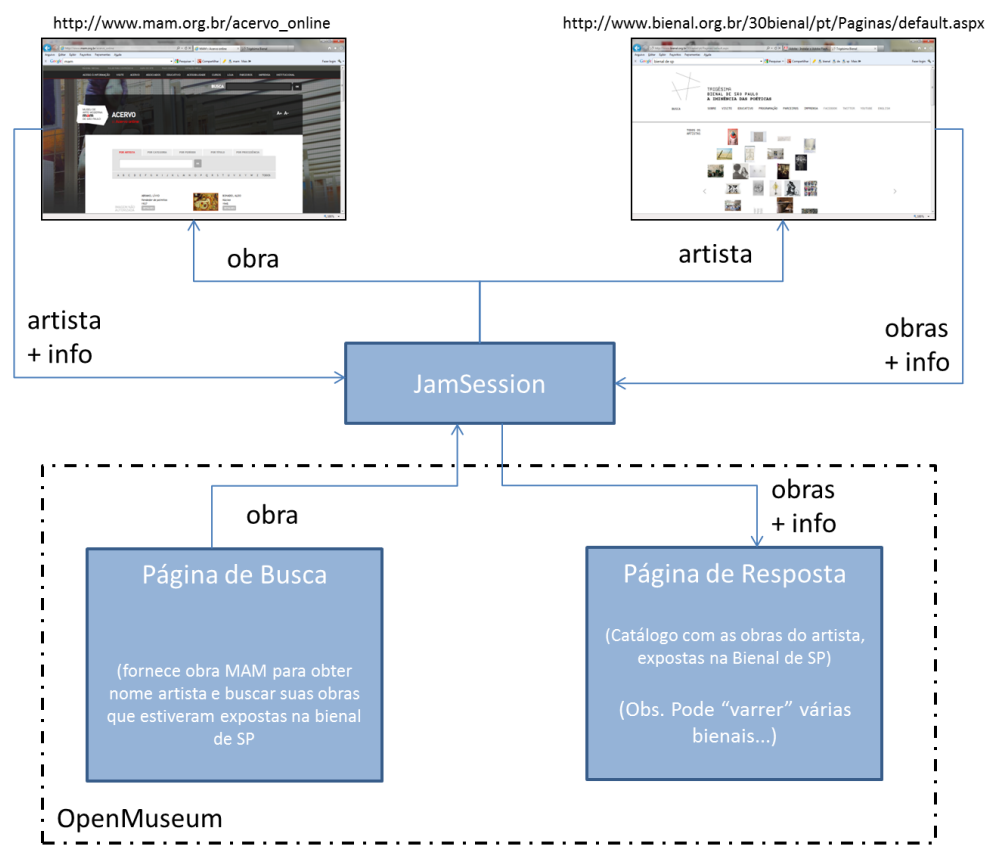

Figura 4.3: Esquema do OpenMuseum Lite - Cruzamento de Informações entre Web Sites Um exemplo de interoperabilidade de informações entre instituições da CoP, é utilizar os protocolos de interação para disparar uma busca por obra no site do Museu de Arte Moderna de São Paulo (MAM) e, retornado o nome do autor da obra, pesquisar no site da Bienal das Artes de SP quais obras deste autor estiveram presentes nesta mostra.

* Uma Obra de Arte possui uma Agenda de compromissos.

* Uma Obra de Arte pode ser composta por partes também designadas Obras de Arte.

* Artistas, Colaboradores e Coletivo são categorias de Pessoas. Cada Pessoa possui um Endereço.

- Ontologia Compartilhada para Obra de Arte:

A Figura 4.4 descreve a ontologia considerada neste exemplo.

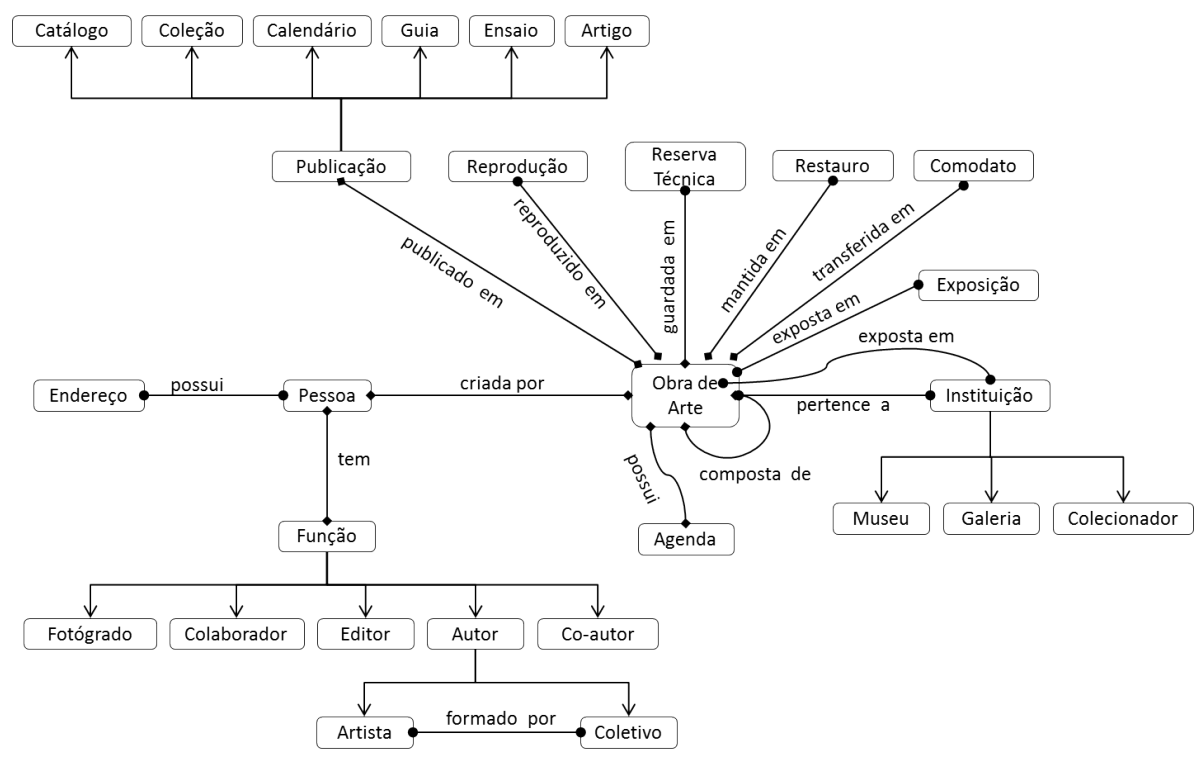

Figura 4.4: Ontologia Compartilhada do OpenMuseum Lite 
- Ontologias Particulares para Obra de Arte:

Não tratamos neste exemplo, pois queremos mostrar a interoperabilidade organizacional e podemos assumir que as instituições utilizam a mesma ontologia compartilhada.

- Workflows Particulares:

Não tratamos neste exemplo, pois queremos mostrar a interoperabilidade organizacional, nos concentrando no Workflow de Interoperabilidade.

- Workflow de Interoperabilidade:

A Figura 4.5 descreve o Workflow de Interoperabilidade desenvolvido para este exemplo.

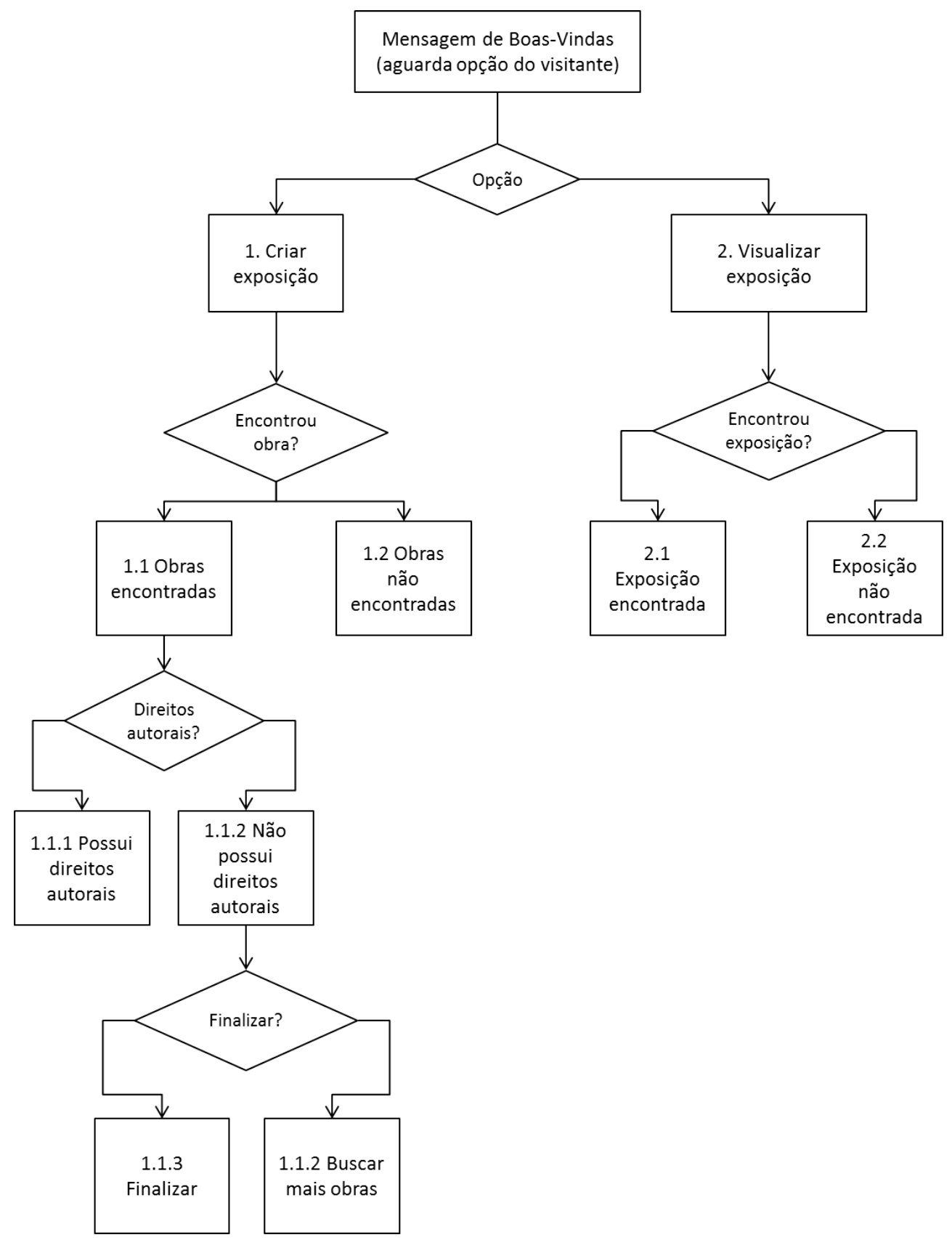

Figura 4.5: Workflow de Interoperabilidade do OpenMuseum Lite

onde as etapas são descritas da seguinte forma: 
1. Criar exposição

Exibe página de busca e aguarda parâmetros

Busca por obras em todos os museus ligados ao OpenMuseum Lite

(a) Obra(s) encontrada(s)

Exibe página com imagem das obras encontradas e aguarda seleção

Configura os dados da obra

Verifica se a obra selecionada possui direito autoral

i. Possui direito autoral

Solicita autorização

ii. Não possui direito autoral

O visitante deseja finalizar?

A. Sim

Configura os dados da exposição

Salva a exposição

Exibe mensagem de término do processo.

B. Não

Busca mais obras

Volta para 1

(b) Nenhuma obra foi encontrada

2. Visualizar exposição

Exibe página de busca e aguarda parâmetros

Busca exposições

(a) Exposição encontrada

Exibe exposições encontradas e aguarda seleção

Obter a exposição com dados das permissões para cada obra

Iniciar exposição

Aguarda comando para navegação pela exposição

(b) Nenhuma exposição encontrada

Exibe Mensagem

Volta para o passo 2

- Mediador para a interoperabilidade - JamSession:

A seguir, apresentamos os componentes da plataforma JamSession que foram desenvolvidos para o OpenMuseum Lite.

\section{* Grafo de Localizações e Agentes:}

Neste sistema temos 7 localizações e um agente para cada usuário. Conforme descrito anteriormente, na plataforma JamSession, a disponibilidade dos protocolos e predicados depende da localização dos agentes. Além destas 7 localizações citadas, cada museu participante do OpenMuseum Lite também possui uma localização.

Podemos considerar que o sistema reproduz as interações reais que um usuário poderia passar para criar uma exposição. Por exemplo, cada localização pode ser vista como uma simulação de uma atividade específica desenvolvida por um funcionário. Quando o agente se desloca para um local diferente, o usuário pode ter a sensação de ter se mudado para uma etapa diferente no processo de criação da exposição. 
A ideia é construir uma interface amigável cuja utilização permite quebrar os obstáculos que os usuários podem enfrentar para ter acesso a serviços complexos.

A Figura 4.6 descreve o grafo de localizações da plataforma JamSession desenvolvido para este exemplo,

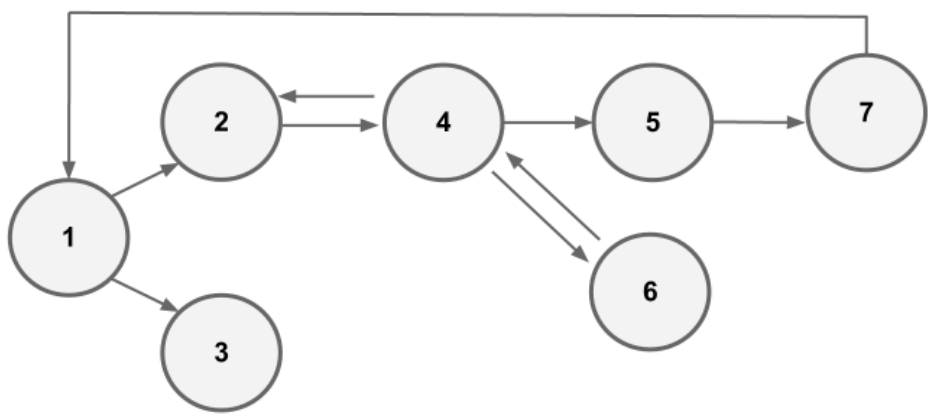

Figura 4.6: Grafo de Localizações do OpenMuseum Lite

onde:

- Localização 1: Início e Boas-Vindas

- Localização 2: Criando exposições

- Localização 3: Visualizando exposições

- Localização 4: Selecionando obras

- Localização 5: Finalizando a exposição

- Localização 6: Autorização de obra com direito autoral

- Localização 7: Exposição criada

A localização 1 é a porta de entrada da aplicação. Quando um usuário entra na aplicação, o agente que o representa é colocado em um local, que também abriga um predicado que pode desencadear um recurso que dá boas vindas ao usuário, fornece informações sobre o funcionamento da aplicação e capta alguma entrada inicial.

De acordo com a resposta do usuário, o agente é direcionado para a localização 2 ou localização 3. Uma vez em um dessas novas localizações, o agente que representa o usuário pode desencadear os predicados que estão hospedados nesses locais e que devem fornecer novas informações ao usuário, bem como solicitar outras respostas. Deste modo, à medida em que o agente é movido de localização para localização, diferentes estados da aplicação são caracterizados, diferentes recursos são liberados e diferentes comportamentos da aplicação podem ser percebidos pelo usuário.

A Figura 4.7 ilustra esta definição de Artefato do Conhecimento Interoperável, instanciado para o domínio do OpenMuseum Lite.

\section{Tecnologia Utilizada}

JamSession foi desenvolvida na plataforma .NET e seu kernel foi implementado utilizando a linguagem de programação funcional $F \sharp$. Esta ferramenta está disponível na plataforma de nuvem Windows Azure. O projeto utilizou o Microsoft SQL Server como servidor de banco de dados relacional. Alguns dos protocolos de interação foram escritos em $C \sharp$. A interface gráfica é um 


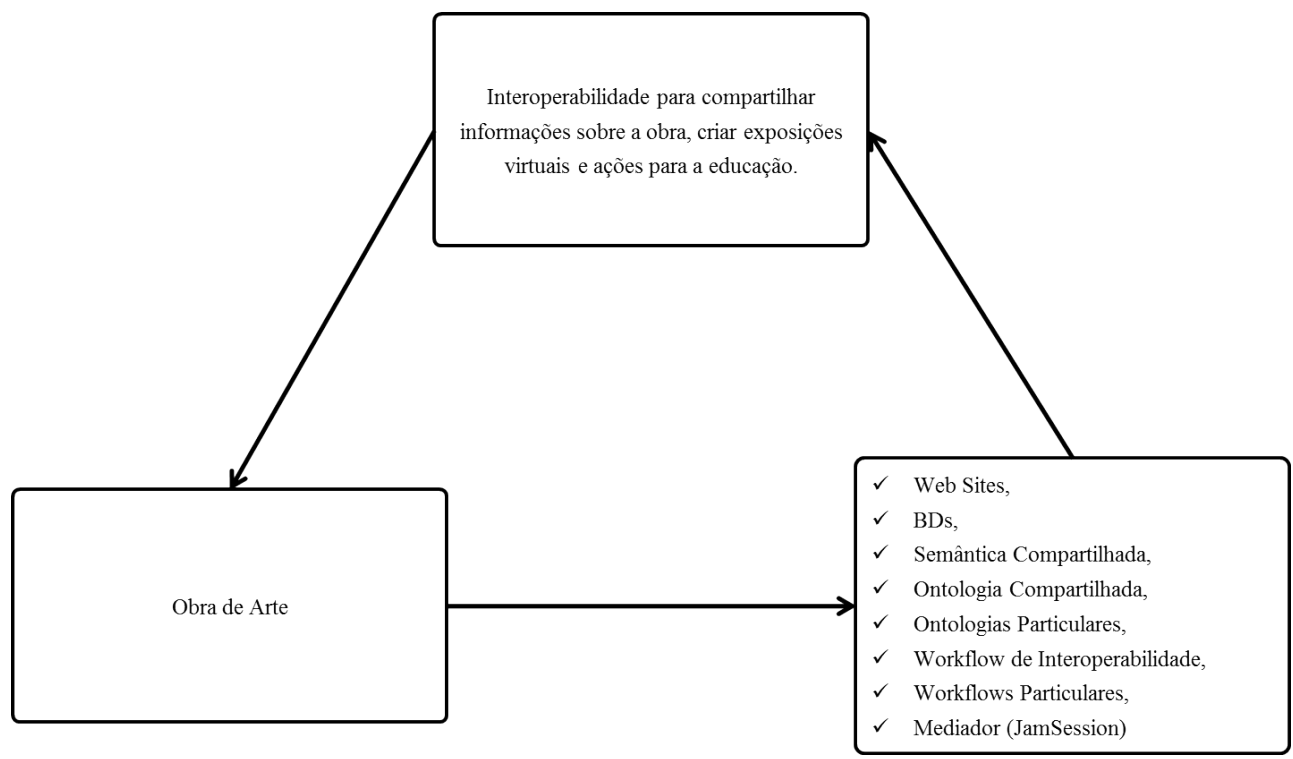

Figura 4.7: Esquema do Artefato do Conhecimento Interoperável

sítio, desenvolvidas ASP.NET MVC 3 usando a linguagem $C \sharp$, incluindo um cliente da plataforma JamSession integrado ao sítio. Para criar as interações nas páginas, foi utilizada a biblioteca jQuery. Também foram realizados testes com uma interface gráfica 3D desenvolvida utilizando a versão gratuita da ferramenta de desenvolvimento de jogos Unity 3D [uni]. Entretanto, para esta prova de conceito, percebemos não haver a necessidade de utilizarmos uma ferramenta 3D.

\section{Esquema da Solução}

A Figura 4.8 mostra um esquema do OpenMuseum, apontando suas funcionalidades e resumindo a descrição apresentada acima.

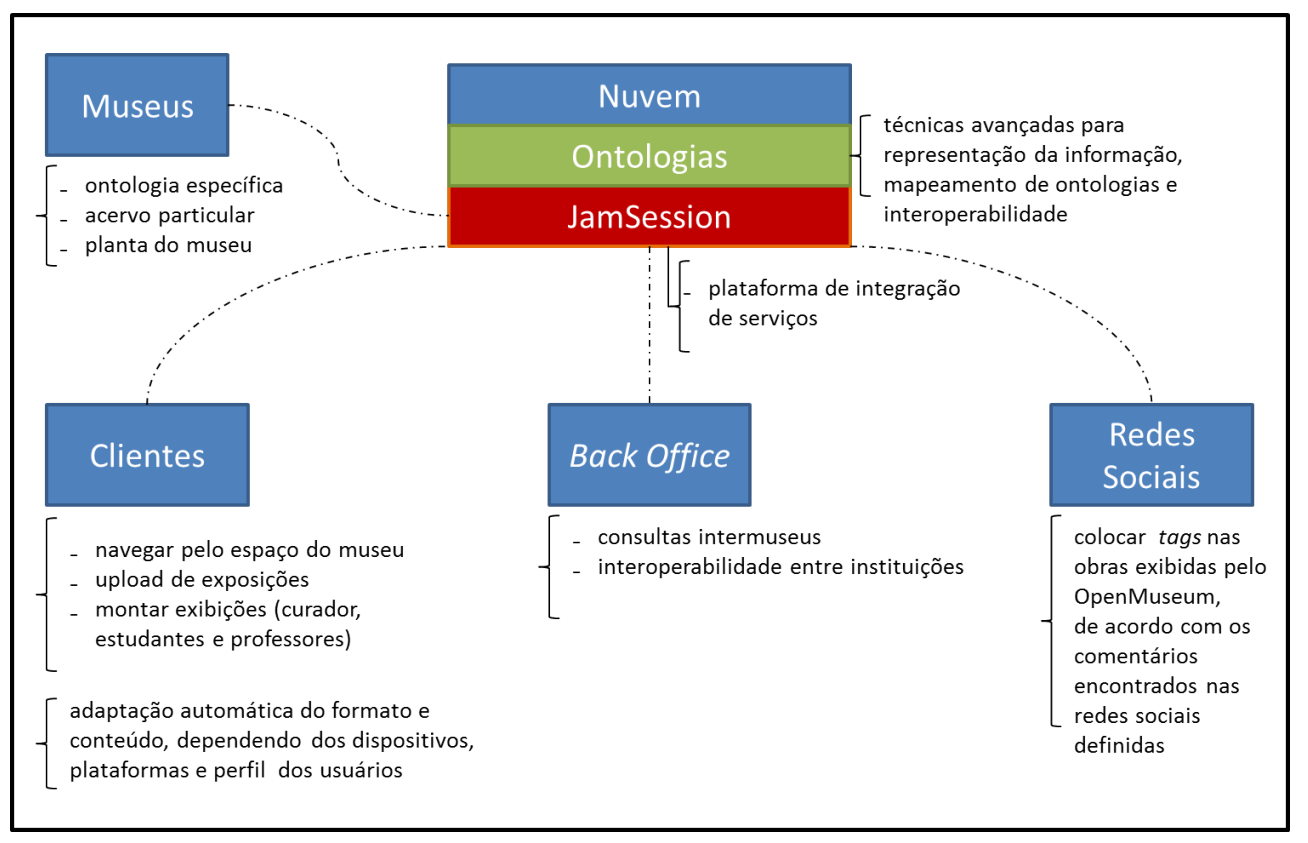

Figura 4.8: Esquema do OpenMuseum 


\section{Avaliação Heurística}

Propomos para este exemplo utilizar o método de avaliação heurística descrito na Seção 3.4. O roteiro utilizado pelos especialistas para avaliar a aplicação pode ser baseado no questionário utilizado no método g-Quality em [MNG]. Esta avaliação está em andamento e será apresentada em um trabalho futuro ${ }^{2}$. 


\section{$4.2 \quad$ PoupaVirtual}

\subsubsection{Definição do Sistema PoupaVirtual}

O sistema PoupaVirtual é um ambiente virtual para prestação de serviços públicos, que provê interoperabilidade entre as agências governamentais envolvidas e destas com os cidadãos. Seguimos a metodologia apresentada no MIIH para definirmos este sistema.

\section{Domínio do Sistema}

Ambiente de prestação de serviços governamentais.

\section{Community of Practice (CoP) do PoupaVirtual}

A CoP deste sistema compreende as instituições envolvidas na prestação de serviços governamentais e os cidadãos - agências governamentais e cidadãos.

\section{Jargão utilizado pela CoP}

O jargão utilizado pela CoP concentra-se em torno da expressão "Serviço Governamental".

\section{Artefato do Conhecimento Interoperável instanciado para o PoupaVirtual}

Instanciando o Modelo para Interoperabilidade entre Instituições Heterogêneas para o domínio das agências governamentais, definimos a tupla referente ao Artefato do Conhecimento Interoperável, da seguinte forma:

- $P$ é a interoperabilidade entre agências governamentais para prestação de serviço ao cidadão..

- I é o conceito compartilhado "Serviço Governamental";

- $R$ é um conjunto definido por:

- Sistema Baseado em Conhecimento, formado por Web Sites, Bancos de Dados e Sistemas Legados.

- Semântica Compartilhada para Serviço Governamental,

- Ontologia Compartilhada para Serviço Governamental,

- Ontologias Particulares para Serviço Governamental,

- Workflows Particulares,

- Workflow de Interoperabilidade,

- Mediador para a interoperabilidade - JamSession

- grafo de localizações e agentes

- predicados

- protocolos

A instanciação de cada um destes componentes de $R$ é dependente do Serviço Governamental em questão.

A Figura 4.9 ilustra esta definição de Artefato do Conhecimento Interoperável, instanciado para o domínio do PoupaVirtual. 


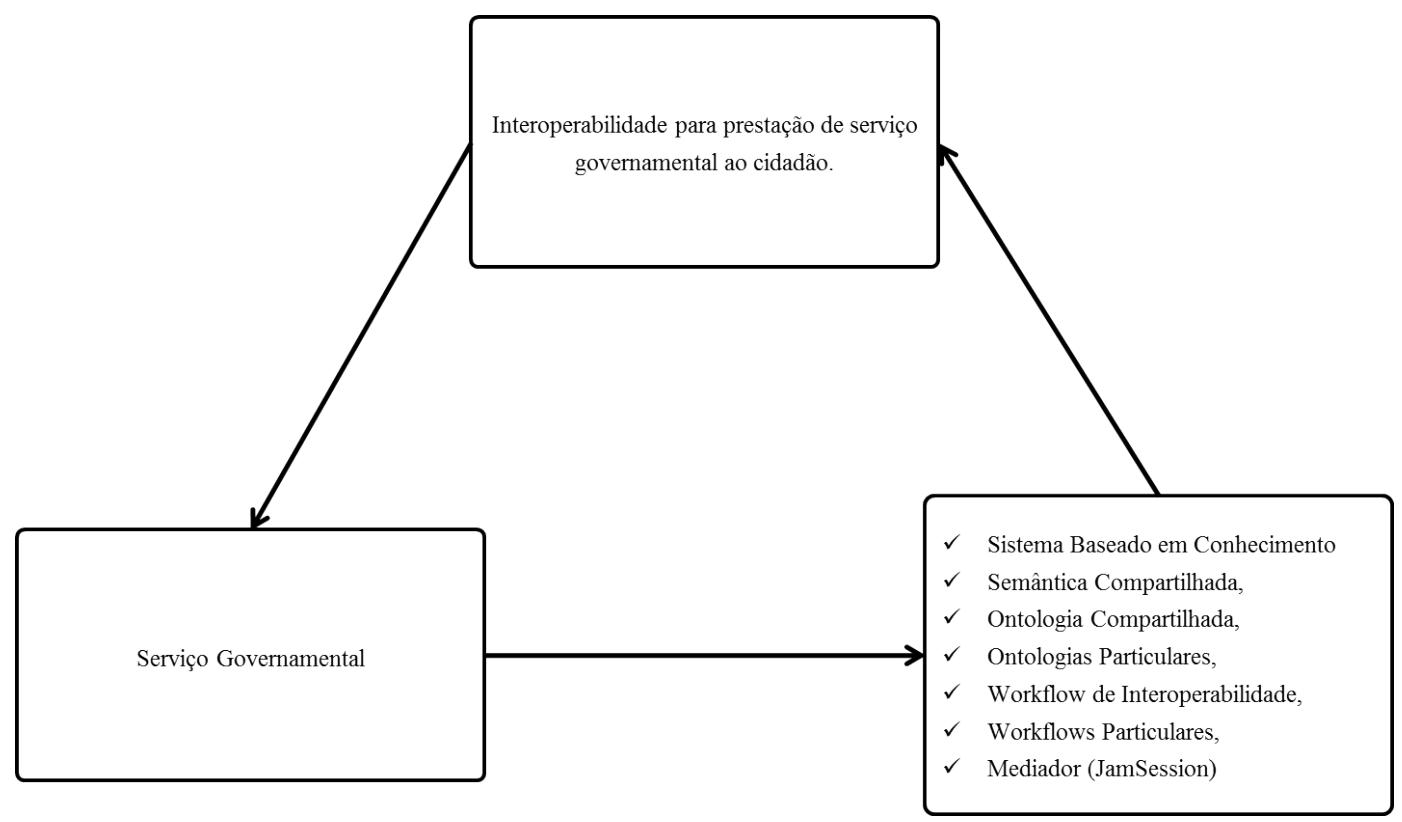

Figura 4.9: Esquema do Artefato do Conhecimento Interoperável

\subsection{Resumo}

Neste capítulo apresentamos dois Exemplos de Uso do MIIH:

- O OpenMuseum Lite, uma aplicação para museu virtual e um sistema de integração entre instituições, profissionais de arte e seus usuários, foi definido e implementado utilizando o modelo e a metodologia propostos neste trabalho.

- O Poupavirtual, um sistema que integra agências governamentais para oferecer serviços ao cidadão, foi modelado neste trabalho utilizando o MIIH e sua implementação foi proposta como trabalho futuro.

No próximo capítulo apresentamos as conclusões do nosso trabalho e propomos a realização de alguns trabalhos futuros. 


\section{Capítulo 5}

\section{Conclusões}

Neste capítulo, apresentamos as conclusões desta tese, sintetizamos os resultados obtidos e indicamos alguns trabalhos futuros.

\subsection{Considerações Finais}

Neste trabalho desenvolvemos um Modelo para Interoperabilidade entre Instituições Heterogêneas (MIIH), para atender a necessidade de interação entre instituições heterogêneas e distribuídas. Este modelo utiliza o conceito de Artefato do Conhecimento e define o conceito de Artefatos de Conhecimento Interoperáveis que funcionam como padrões de arquitetura pré-concebidos, para orientar e padronizar as interações entre organizações. Como mediador para a interoperabilidade, propusemos e utilizamos a plataforma JamSession, que é uma plataforma para a coordenação e integração de recursos computacionais heterogêneos, bem como uma ferramenta para a integração de cross-organizational workflows. Desenvolvemos como Exemplo de Uso uma aplicação para museu virtual, OpenMuseum Lite, conforme apresentado no Capítulo 4, que demonstra uma implementação do modelo MIIH em funcionamento.

\subsection{Resumo das Contribuições}

O resultado deste projeto é a definição de um Modelo para Interoperabilidade entre Instituições Heterogêneas (MIIH), gerando como contribuições:

1. Conceituação do Modelo para a Interoperabilidade entre Instituições Heterogêneas (MIIH), através do qual podemos especificar formalmente as atividades, interações e serviços oferecidos por instituições virtuais, garantindo a interoperabilidade e a autonomia das instituições envolvidas;

2. Modelo para representação do conhecimento, baseado em Artefatos do Conhecimento. Definição de Artefatos de Conhecimento Interoperáveis que funcionam como padrões de arquitetura pré-concebidos que orientam e padronizam as interações - e, portanto, a interoperabilidade organizacional e semântica - entre as organizações envolvidas;

3. Metodologia para a utilização do MIIH, que define etapas claras, objetivas, com um mecanismo simples de ser seguido e que garante o desenvolvimento de aplicações, de acordo com o MIIH;

4. Exemplo de Uso - OpenMuseum Lite: especificação e implementação de uma aplicação, utilizando o modelo conceitual definido neste trabalho. Como efeito colateral, esta aplicação é uma demonstração de que como a plataforma JamSession pode ser utilizada. 


\subsubsection{Publicações Realizadas}

As seguintes publicações foram geradas durante o desenvolvimento deste trabalho:

Cláudia J. Abrão de Araújo e Flávio S. Corrêa da Silva. Governmental Virtual Institutions. Em Proceedings of the 3rd International Conference on Theory and Practice of Electronic Governance, ICEGOV'09, páginas 404-406, New York, NY, USA, 2009. ACM.

Cláudia J. Abrão de Araújo e Flávio S. Corrêa da Silva. Governamental Virtual Institutions. RT-MAC-2009-03. Instituto de Matemática e Estatística, Universidade de São Paulo, São Paulo, SP, Brasil, junho 2009, 19pp.

Flávio S. Corrêa da Silva, Cláudia J. Abrão de Araújo, Lisney Alberti, Rosa Alarcon, Carla Vairetti, Jesus Bellido. TimeSaver - Virtual Worlds and Active Workflows to Deliver Friendly Public Services. RT-MAC-2010-03. Instituto de Matemática e Estatística, Universidade de São Paulo, São Paulo, SP, Brasil, fevereiro 2010, 17pp.

Cláudia J. Abrao de Araujo e Flávio S. Corrêa da Silva. A Software Platform for Governmental Virtual Institutions. Em Proceedings of the 2011 Fourth International Conference on Ubi-Media Computing, U-MEDIA'11, páginas 180-185, Washington, DC, USA, 2011. IEEE Computer Society.

Cláudia J. Abrão de Araújo e Flávio S. Corrêa da Silva . A System for Governmental Virtual Institutions based on Ontologies and Interaction Protocols. International Journal of Distance Education Technologies (IJDET), volume 10(4), páginas 82-95, 2012.

\subsection{Trabalhos Futuros}

Nesta seção apresentamos algumas possíveis extensões deste trabalho:

\section{Museu de Arte Contemporânea (MAC)}

A parceria estabelecida com o MAC resultou no Exemplo de Uso apresentado neste trabalho e estabeleceu novas etapas de pesquisa e desenvolvimento referente ao uso do nosso modelo na viabilização de outras atividades de interoperabilidade do museu.

\section{Federação de museus}

Utilizando nosso modelo para interoperabilidade e tendo como partida os sistemas desenvolvidos para o MAC, propomos criar uma Comunidade de Museus que possam interoperar e cooperar em suas atividades operacionais e de pesquisa.

\section{PoupaVirtual}

Desejamos estabelecer um projeto conjunto com agências governamentais, para desenvolver uma aplicação no mesmo modelo do Poupatempo. Esta aplicação, sendo amplamente baseada na oferta de serviços, conterá muitos workflows que precisarão ser integrados e coordenados para a correta execução destes serviços. Este é o cenário ideal para a utilização do MIIH e a plataforma JamSession.

\section{Métricas de Avaliação}

Propomos analisar a utilização do Método de Inspeção Semiótica (MIS) [dSLaP ${ }^{+}$10] [LdS09] como mecanismo de avaliação proposto pelo MIIH. 


\section{Referências Bibliográficas}

[AadAdS09] Cláudia J. Abrão de Araújo e Flávio S. Corrêa da Silva. Governmental virtual institutions. Em Proceedings of the 3rd international conference on Theory and practice of electronic governance, ICEGOV '09, páginas 404-406, New York, NY, USA, 2009. ACM. 41

$\left[\mathrm{AEN}^{+} 05\right]$ J. L. Arcos, M. Esteva, P. Noriega, J. A. Rodríguez-Aguilar e C. Sierra. Engineering open environments with electronic institutions. Em Journal on Engineering Applications of Artificial Intelligence, página 18(2):191204, 2005. 25

[AS97] L. O. Alvares e J. Sichman. Introdução aos sistemas multiagentes. Em Jornada de Atualização em Informática, páginas 1-38. SBC, 1997. 7

[AS11] Cláudia J. Abrao de Araujo e Flávio S. Corrêa da Silva. A software platform for governmental virtual institutions. Em Proceedings of the 2011 Fourth International Conference on Ubi-Media Computing, U-MEDIA '11, páginas 180-185, Washington, DC, USA, 2011. IEEE Computer Society. 13, 41

[BL04] Ronald Brachman e Hector Levesque. Knowledge Representation and Reasoning. Elsevier, 2004. 32

[Bog07] Anton Bogdanovych. Virtual Institution. Tese de Doutorado, University of Technology, Sydney, Australia, 2007. xi, 16, 24, 25, 26, 30

[Bor97] W. N. Borst. Construction of Engineering Ontologies for Knowledge Sharing and Reuse. Tese de Doutorado, University of Twente, Enschede, September 1997. 14, 32

[bri] B.c. government home - province of british columbia. http://www.gov.bc.ca/. último acesso em 06/02/2011. 21

[Bur04] Marut Buranarach. A framework for the organization and discovery of information resources in a www environment using association, classification and deduction. Tese de Doutorado, Pittsburgh, PA, USA, 2004. AAI3158613. 6

[CdS11] FlavioSoares Correa da Silva. Knowledge-based interaction protocols for intelligent interactive environments. Knowledge and Information Systems, páginas $1-24,2011.1,6$

[CH09] R. Cimander e H.Kubicek. Organisational interoperability and organizing for interoperability in e-government. Em Second European Summit on Interoperability in the iGovernment held in Rome, páginas 109-122, 2009. 6

[chia] Chileclic - guía de servicios del estado - chileclic. http://www.chileclic.gob.cl/ portal. último acesso em 05/02/2011. 21

[chib] Gobierno de chile. http://www.gobiernodechile.cl. último acesso em 05/02/2011. 21 
[cid] Cidadao.sp - portal do cidadão do estado de são paulo. http://www.cidadao.sp. gov.br/. último acesso em 05/02/2011. 21

[Com04a] European Communities. European interoperability framework for pan-european egovernment services (eif) - version 1.0, 2004. Luxemburgo. 6, 31

[Com04b] European Communities. European interoperability framework will be paneuropean egovernment services, 2004. IDABC. 6

$\left[\mathrm{dAOL}^{+} 10\right]$ Everson Lopes de Aguiar, João Batista Ferri Oliveira, Fernanda Hoffmann Lobato, Karine Castro, Thiago Augusto dos S. Silva e Sarita Gonzáles Fernandes. Padrões tecnológicos - o uso na prestação de serviços públicos e no relacionamento com o governo federal. Em Ministério do Planejamento Orçamento e Gestão Secretaria de Logística e Tecnologia da Informação, editor, Panorama da Interoperabilidade no Brasil, página 52. primeira edição, 2010. 17

[dEsaTdIedCC09] Centro de Estudos sobre as Tecnologias da Informação e da Comunicação CETIC.br. $5^{a}$ pesquisa sobre uso das tecnologias da informação e da comunicação no brasil - tic domicílios 2009. http://www.nic.br/imprensa/releases/2010/ rl-2010-06.htm, 2009. último acesso em 06/02/2011. 23

[dGE10] Governo Brasileiro Comitê Executivo de Governo Eletrônico. Documento de referência da e-ping versão 2010, 2010. 18, 19

[dInB] Comitê Gestor da Internet no Brasil. e-ping - programa de governo eletrônico brasileiro - sítio oficial. http://www.governoeletronico.gov.br/acoes-e-projetos/ e-ping-padroes-de-interoperabilidade. último acesso em 04/02/2011. 20

[dInB10] Comitê Gestor da Internet no Brasil. Pesquisa sobre o uso das tecnologias da informação e da comunicação no brasil : Tic governo eletrônico - 2010. http: //www.cetic.br, 2010. último acesso em 04/02/2011. 23

$\left[\mathrm{dSLaP}^{+} 10\right]$ Clarisse Sieckenius de Souza, Carla Faria Leitão, Raquel Oliveira Prates, Sílvia Amélia Bim e Elton José da Silva. Can inspection methods generate valid new knowledge in hci? the case of semiotic inspection. Int. J. Hum.-Comput. Stud., 68(1-2):22-40, Janeiro 2010. 56

[dSP] Folha de São Paulo. Google art project libera visita virtual à pinacoteca e ao mam. http://www1.folha.uol.com.br/ilustrada/ 1071082-google-art-project-libera-visita-virtual-a-pinacoteca-e-ao-mam.shtml. último acesso em 24/09/12. 27

[dSV10] F. S. Correa da Silva e W. Vasconcelos. Rule schemata for game artificial intelligence. Em International Joint Conference IBERAMIA/SBIA. Springer-Verlag Lecture Notes in Artificial Intelligence 4140, página 451461, 2010. 7

[dSVD $\left.{ }^{+} 12\right]$ Flávio Soares Corrêa da Silva, Mirtha Lina Fernández Venero, Diego Mira David, Mohammad Saleem e Paul W.H. Chung. Interaction protocols for crossorganisational workflows. Knowledge-Based Systems, (0), 2012. 1, 6, 34

[e-p] e-poupatempo. http://www.poupatempo.sp.gov.br/e-poupatempo/. último acesso em 05/02/2011. 20

[EB07] Governo Eletrônico-Br. Programa de governo eletrônico brasileiro — sítio oficial. http://www.governoeletronico.gov.br, 2007. Departamento de Governo Eletrônico, Secretaria de Logística e Tecnologia da Informação, Ministério do Planejamento, Orçamento e Gestão DGE/SLTI/MP, último acesso em 25/01/2011. 18, 19 
[Est03] M. Esteva. Electronic Institutions: From Specification to Development. Tese de Doutorado, UArtificial Intelligence Research Institute (IIIA-CSIC), Spain, 2003. 7,24

[goo] Google art project. http://www.googleartproject.com/. último acesso em 24/09/12. 27

[GPC02] Asunción Gómez-Pérez e Oscar Corcho. Ontology specification languages for the semantic web. IEEE Intelligent Systems, 17:54-60, 2002. 14, 33

[Gru93] Thomas R. Gruber. A translation approach to portable ontology specifications. KNOWLEDGE ACQUISITION, 5:199-220, 1993. 14

[Gua98] Nicola Guarino. Formal ontology and information systems. Em Proceedings of FOIS98, páginas 3-15. IOS Press, june 1998. 14, 33

[Hil11] Risto Hilpinen. Artifact. Em Edward N. Zalta, editor, The Stanford Encyclopedia of Philosophy. Winter 2011 edição, 2011. 12

[HJ01] C. W. Holsapple e K. D. Joshi. Organizational knowledge resources. Decis. Support Syst., 31(1):39-54, Maio 2001. 13

[Hol95] D. Hollingsworth. Workflow management coalition - the workflow reference model. Relatório técnico, Workflow Management Coalition, Janeiro 1995. 5, 33

[Hol03] Gerard Holzmann. Spin Model Checker, the: Primer and Reference Manual. Addison-Wesley Professional, first edição, 2003. 12

[HPSH03] Ian Horrocks, Peter F. Patel-Schneider e Frank Van Harmelen. From shiq and rdf to owl: The making of a web ontology language. Journal of Web Semantics, $1: 2003,2003.15,33$

[ins] Rankings de e-gov no mundo em 2010 e as iniciativas globais - parte 1 - ti:gov. http://igov.com.br/tigov/?p=392. último acesso em 05/02/2011. 22

[LdS09] Carla Faria Leito e Clarisse de Souza. Semiotic Engineering Methods for Scientific Research in HCI. Morgan and Claypool Publishers, 2009. 56

[Les95] V. Lesser. Multiagent systems: An emerging subdiscipline of ai. ACM Computing Surveys, 27:340-342, 1995. 7

[LS00] Irina A. Lomazova e Philippe Schnoebelen. Some decidability results for nested petri nets. Em Proc. of 3rd Perspectives of System Informatics, páginas 208-220. Springer Verlag, 2000. 12

[MdP08] Orçamento e Gestão e Secretaria de Gestão Ministério do Planejamento. Carta de serviços ao cidadão. https://www.governoeletronico.gov.br/anexos/ apresentacao-carta-de-servicos-ao-cidadao/download, 2008. último acesso em 04/02/2011. 20

[MdP10] Orçamento e Gestão com a consultoria da Agência Espanhola de Cooperação para o Desenvolvimento (AECID) e da Fundação Instituto para o Fortalecimento das Capacidades Institucionais (IFCI) Ministério do Planejamento * Guia de interoperabilidade - cartilha técnica. http://www.governoeletronico. gov.br/acoes-e-projetos/e-ping-padroes-de-interoperabilidade/

guia-de-interoperabilidade-de-servicos-de-governo, 2010. último acesso em 04/02/2011. 20 
[Mic98] G. Michaelis. Aperto, moteplice, continuo. Dunod, Milano, 1998. 12

[min] Chn redirect page - phac. http://www.canadian-health-network.ca. último acesso em 06/02/2011. 22

[MN88] P. Maes e D. Nardi. Meta-level architectures and reflection. Relatório técnico, Elsevier Science Inc., NY, USA, 1988. 25

[MNG] Cristiano Maciel, José Luiz T. Nogueira e Ana Cristina Bicharra Garcia. gquality: um método para avaliação da qualidade dos sítios de e-gov. Relatório técnico, Departamento de Ciências da Computação, IC Universidade Federal Fluminense (UFF). 39, 52

[Muc11] Marcos Luiz Mucheroni. A interoperabilidade dos sistemas de informação sob o enfoque da análise sintática e semântica de dados na web. PontodeAcesso, 5(1), 2011. 6

[Nie] Jakob Nielsen. useit.com: Jakob nielsen on usability and web design. http: //useit.com. último acesso em 19/02/2011. 38

[Nie94] Jakob Nielsen. Enhancing the explanatory power of usability heuristics. Em Conference companion on Human factors in computing systems, CHI '94, páginas 210-, New York, NY, USA, 1994. ACM. 38

[Nie95] Jakob Nielsen. Usability inspection methods. Em Conference companion on Human factors in computing systems, CHI '95, páginas 377-378, New York, NY, USA, 1995. ACM. 38

[NM90] Jakob Nielsen e Rolf Molich. Heuristic evaluation of user interfaces. Em Proceedings of the SIGCHI conference on Human factors in computing systems: Empowering people, CHI '90, páginas 249-256, New York, NY, USA, 1990. ACM. 38

[not] Cgu - imprensa. http://www.cgu.gov.br/Imprensa/Noticias/2005/noticia08305. asp. último acesso em 06/02/2011. 21

[oSC96] Ottawa: Minister of Supply e Services Canada. Building the information society: Moving canada into the 21st century, 1996. 22

[Pau03] Veronika Paulics. Poupatempo central de atendimento ao cidadão, 20 experiências de gestão pública e cidadania. http://www.eaesp.fgvsp.br/subportais/ ceapg/Acervo\%20Virtual/Cadernos/Experi\%C3\%AAncias/2002/18\%20-\% 20poupatempo.pdf, 2003. Versão Digital, último acesso em 02/02/2011. 2

[PB09] Theresa A. Pardo e G. Brian Burke. It governance capability: Laying the foundation for government interoperability, 2009. 18, 19

[PG04] Alexei Pavlichev e G. David Garson, editors. Digital government: principles and best practices. IGI Publishing, Hershey, PA, USA, 2004. 23

[PLGT08] V. Peristeras, N. Loutas, S. Goudos e K. Tarabanis. A conceptual analysis of semantic conflicts in pan-european e-government services. Em Journal of Information Science, página 34(6):877891, 2008. 6

$\left[\mathrm{PRH}^{+} 06\right]$ J. R. G. Pulido, M. A. G. Ruiz, R. Herrera, E. Cabello, S. Legrand e D. Elliman. Ontology languages for the semantic web: A never completely updated review. Know.-Based Syst., 19(7):489-497, 2006. 14, 33 
[pri] Prince edward island: Home page. http://www.gov.pe.ca. último acesso em 06/02/2011. 22

[Pro] OpenKnowledge Project. Openknowledge. http://www.openk.org. último acesso em 09/02/2011. 26

[Reu] Reuters. Google launches new online art gallery site. http://www.reuters. com/article/2011/02/01/arts-google-museums-idUKLDE7101JU20110201. último acesso em $24 / 09 / 12.27$

[Rez03] S.O. Rezende. Sistemas inteligentes: fundamentos e aplicaçôes. Manole, 2003. 32

[Rob04] David Robertson. A lightweight coordination calculus for agent systems. Em In Declarative Agent Languages and Technologies, páginas 183-197, 2004. 7, 26, 27

[SBF98] R. R. Studer, R. Benjamins e D. Fensel. Knowledge engineering: principles and methods. Data and knowledge engineering, 25:161-197, 1998. 14, 32

[SC02] William R. Sherman e Alan B. Craig. Understanding Virtual Reality: Interface, Application, and Design. Morgan Kaufmann Publishers Inc., San Francisco, CA, USA, 2002. 16

[Smi85] Reid G. Smith. Knowledge-based systems: Concepts, techniques, examples. Em Canadian High Technology Show, 1985. 32

[SRP07] Helen Sharp, Yvonne Rogers e Jenny Preece. Interaction Design: Beyond HumanComputer Interaction. Wiley, 2 edição, Março 2007. http://www.amazon. $\mathrm{com} /$ exec/obidos/redirect?tag $=$ citeulike07-20\&path=ASIN/0470018666, último acesso em 19/02/2011. 38, 40

[STCDS $\left.{ }^{+} 08\right]$ G. Salazar-Torres, E. Colombo, F.S. Correa Da Silva, C. A. Noriega e S. Bandini. Design issues for knowledge artifacts. Know.-Based Syst., 21(8):856-867, Dezembro 2008. 12

[UG96] Mike Uschold e Michael Gruninger. Ontologies: Principles, methods and applications. Knowledge Engineering Review, 11:93-136, 1996. 15, 33

[UND07] UNDP. e-government interoperability: A review of governmental interoperability frameworks in selected countries. http://www.apdip.net/projects/gif/ GIF-Review.pdf, 2007. disponível em:. 19

[une] Unesco. http://portal.unesco.org/culture/en/ev.php-URL_ID $=35032 \& U R L$ $\mathrm{DO}=\mathrm{DO} \_\mathrm{TOPIC} \& \mathrm{URL} \_\mathrm{SECTION}=201 . \mathrm{html}$. último acesso em 24/10/12. $\overline{41}$

[uni] Unity3d. http://www.unity3d.com/. último acesso em 27/10/12. 51

[vdA99] W.M.P. van der Aalst. Interorganizational workflows: An approach based on message sequence charts and petri nets, 1999. 12

[VdS12a] Mirtha Lina Fernández Venero e Flávio Soares Corrêa da Silva. A formal semantics for the jamsession coordination platform. Relatório técnico, University of São Paulo, Institute of Mathematics and Statistics, 05 2012. 12

[VdS12b] Mirtha Lina Fernández Venero e Flávio Soares Corrêa da Silva. Studying the behavior of jamsession interaction protocols using spin. Relatório técnico, University of São Paulo, Institute of Mathematics and Statistics, 04 2012. 12 
[Viz04] G. Vizzari. Dynamic interaction spaces and situated multi-agent systems: from a multi-layered model to a distributed architecture. Tese de Doutorado, University of Milano-Bicocca. Italy, 2004. 7

[VKN09] Wamberto W. Vasconcelos, Martin J. Kollingbaum e Timothy J. Norman. Normative conflict resolution in multi-agent systems. Autonomous Agents and MultiAgent Systems, 19:124-152, October 2009. 7

[WR02] Christopher Walton e David Robertson. Flexible multi-agent protocols. Em Procs. of UKMAS 2002. UKMAS, 2002. 27 